\title{
ANÁLISE DE UM EXPERIMENTO DE SELEÇÃO PARA \\ CRESCIMENTO EM BOVINOS NELORE: RESPOSTAS DIRETA NO \\ PESO AO SOBREANO E CORRELACIONADAS NO TAMANHO E REPRODUÇÃO DAS MATRIZES
}

MARIA EUGÊNIA ZERLOTTI MERCADANTE

Tese apresentada à Escola Superior de Agricultura "Luiz de Queiroz", Universidade de São Paulo, para obtenção do título de Doutor em Agronomia, Área de Concentração: Ciência Animal e Pastagens.

P I R A C I C A B A

Estado de São Paulo - Brasil

Outubro - 2001 


\section{ANÁLISE DE UM EXPERIMENTO DE SELEÇÃO PARA \\ CRESCIMENTO EM BOVINOS NELORE: RESPOSTAS DIRETA NO \\ PESO AO SOBREANO E CORRELACIONADAS NO TAMANHO E REPRODUÇÃO DAS MATRIZES}

MARIA EUGÊNIA ZERLOTTI MERCADANTE

Zootecnista

Orientador: Prof. Dr. IRINEU UMBERTO PACKER

Tese apresentada à Escola Superior de Agricultura "Luiz de Queiroz", Universidade de São Paulo, para obtenção do título de Doutor em Agronomia, Área de Concentração: Ciência Animal e Pastagens.

P I R A C I C A B A

Estado de São Paulo - Brasil

Outubro - 2001 


\title{
Dados Internacionais de Catalogação na Publicação (CIP)
} DIVISÃO DE BIBLIOTECA E DOCUMENTAÇÃO - ESALQ/USP

\author{
Mercadante, Maria Eugênia Zerlotti \\ Análise de um experimento de seleção para crescimento em bovinos \\ nelore: respostas direta no peso ao sobrea no e correlacionadas no tamanho e \\ reprodução das matrizes. - - Piracicaba, 2001. \\ $106 \mathrm{p}$. \\ Tese (doutora do) - Escola Superior de Agric ultura Luiz de Queiroz, 2001. \\ Bibliografia. \\ 1. Crescimento animal 2. Gado Nelore 3. Melhoramento genético animal 4. \\ Reprodução a nimal I. Título
}

CDD 636.291

\section{"Permitida a cópia total ou parcial deste documento, desde que citada a fonte - $\mathrm{O}$ autor"}




DEDICO este trabalho
ao meu filho Rodrigo, o
menino mais fofo do
mundo!!!

OFEREÇO a todos que toma ram possível o estabelecimento, a manutenção e a condução do Experimento de Seleção das Raças Zebuínas da Estação Experimental de Zootec nia de Sertãozinho. 


\section{AGRADECIMENTOS}

Ao Professor Irineu Umberto Packer, pela orientação, confiança e grande incentivo de novas idéias.

Ao Dr. Alexander George Razook, com certeza o co-orientador não oficial deste trabalho, pelas longas discussões que muito contribuíram na condução das análises e na interpretação dos resultados.

Aos amigos Joslaine Cyrillo, pesquisadora da Estação Experimental de Zootecnia de Sertãozinho e Cláudio de Mello, doutorando do Departamento de Produção Animal da ESALQ/USP, pela paciência de ler todo o texto e pelas valiosas sugestões.

Aos Professores e Funcionários do Departamento de Produção Animal da ESALQ/USP, que me acolheram com muito carinho e atenção, em especial às secretárias Cláudia Chuahy e Vera Graciano.

Aos amigos e colegas de curso, em especial à Ana Carolina Espasandin e

Juliana Giannotti pelo apoio incondicional nos momentos fáceis e difíceis, e ao Eduardo Beserra e Odinete Murari pela companhia nas longas peixadas e cervejadas na Rua do Porto.

À minha família, mãe e irmãs, pelos muitos feriados e finais de semana em que tomaram conta do Rodrigo. À Diretora e às Professoras do CCin, Centro de Convivência Infantil da ESALQ, pela seriedade e competência com que conduzem a educação dos filhos dos funcionários, professores e alunos, e à minha secretária Maria D’Ajuda pelo carinho e dedicação dispensados ao Rodrigo. 
Ao Instituto de Zootecnia, pelo afastamento concedido sem o qual não seria possível a obtenção desse título.

Ao colega e chefe da Estação Experimental de Zootecnia de Sertãozinho, Leopoldo Andrade de Figueiredo, que me apoiou no pedido e manutenção do afastamento.

Ao Conselho Nacional de Desenvolvimento Científico e Tecnológico (CNPq) pela bolsa concedida, um excelente estímulo para a obtenção do título de Doutor. 


\section{SUMÁRIO}

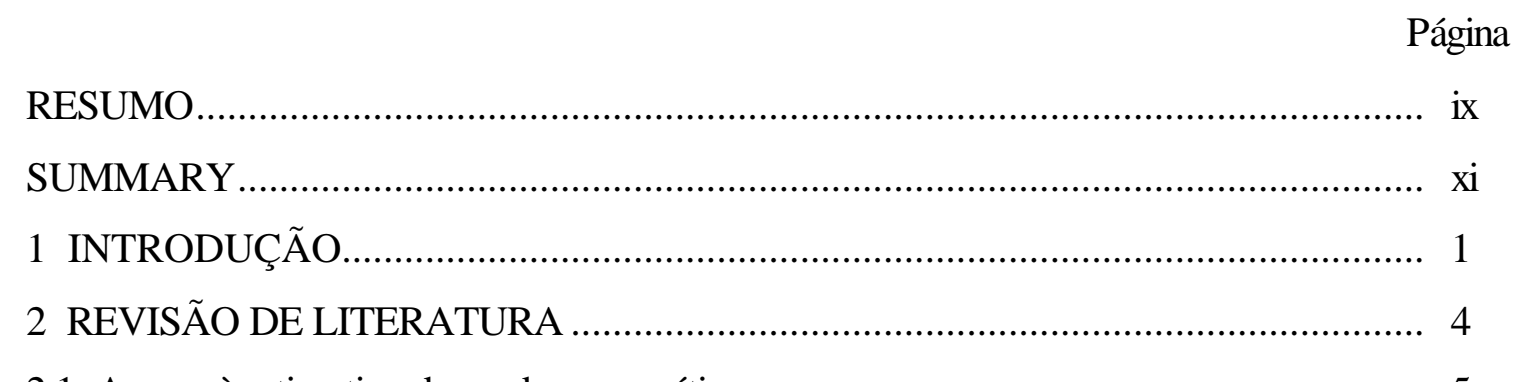

2.1 Acesso à estimativa da mudança genética................................................................ 5

2.2 Considerações sobre os procedimentos de quadrados mínimos e de modelo misto no acesso à estimativa da mudança genética....................................... 9

3 DIAS AO PARTO DE FÊMEAS NELORE DE UM EXPERIMENTO DE SELEÇÃO PARA CRESCIMENTO. I -

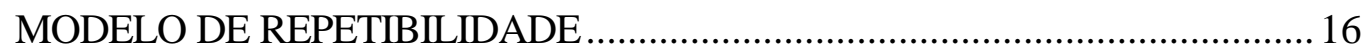

Resumo

Summary

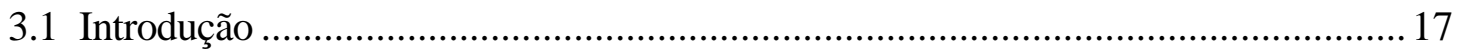

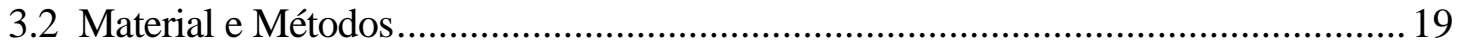

3.2.1 Animais e manejo ......................................................................................... 19

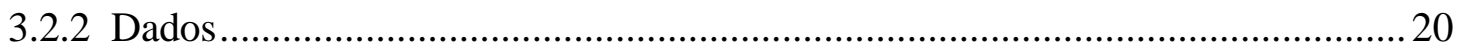

3.3 Resultados e Discussão ......................................................................................2

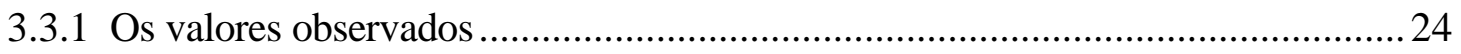

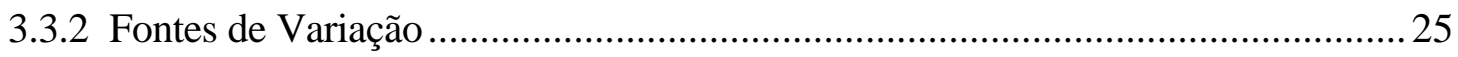

3.3.3 Componentes de variância e parâmetros genéticos ....................................................32

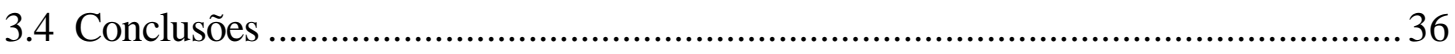


4 DIAS AO PARTO DE FÊMEAS NELORE DE UM EXPERIMENTO DE SELEÇÃO PARA CRESCIMENTO. II MODELO DE REGRESSÃO ALEATÓRIA ............................................................ 37

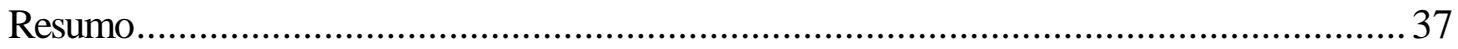

Summary

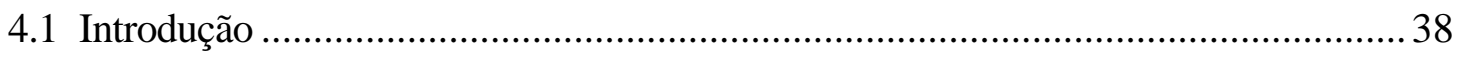

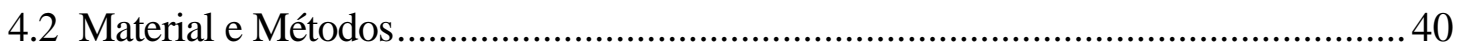

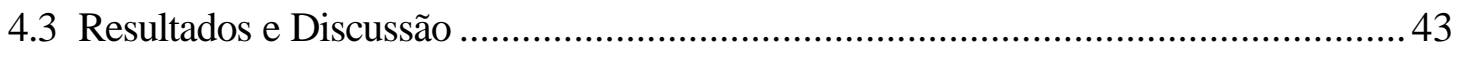

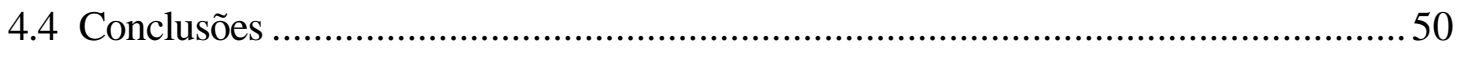

5 RESPOSTAS DIRETAS E CORRELACIONADAS À SELEÇÃO

PARA PESO AO SOBREANO NO DESEMPENHO DE FÊMEAS

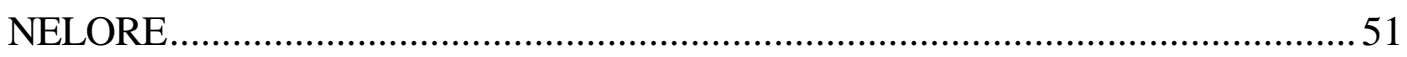

Resumo

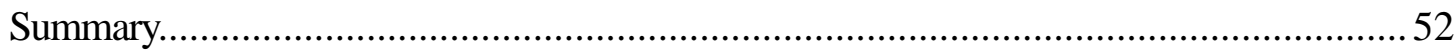

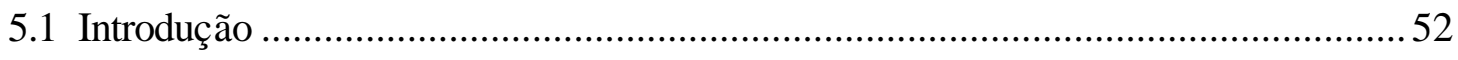

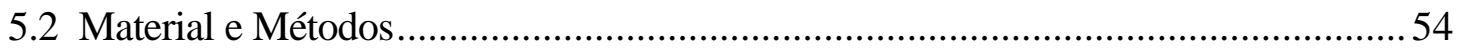

5.2.1 Formação dos rebanhos e seleção ......................................................................54

5.2.2 Formação dos lotes de monta e manejo das fêmeas ................................................55

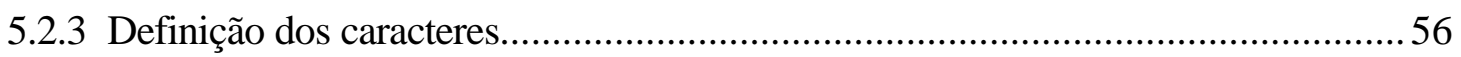

5.2.4 Análises estatísticas e genéticas..........................................................................59

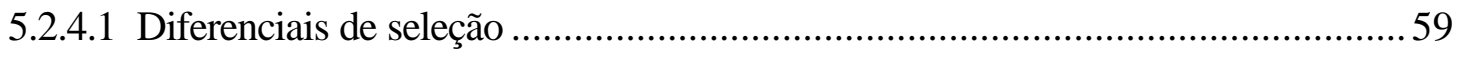

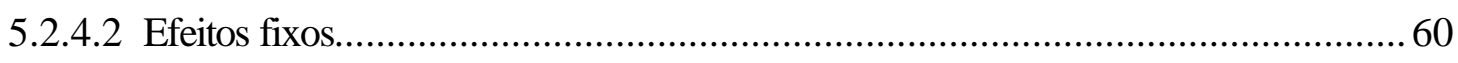

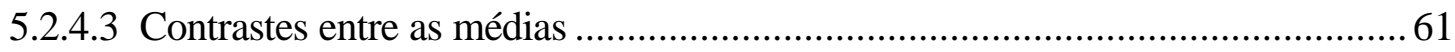

5.2.4.4 Componentes de variância e soluções para o efeito animal

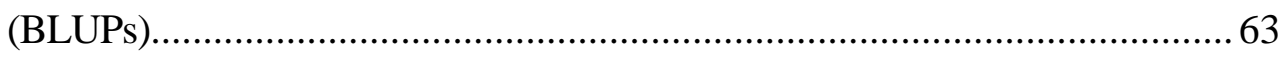

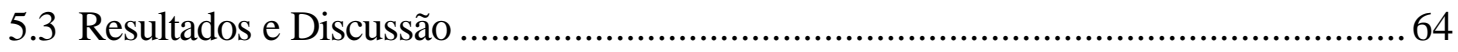

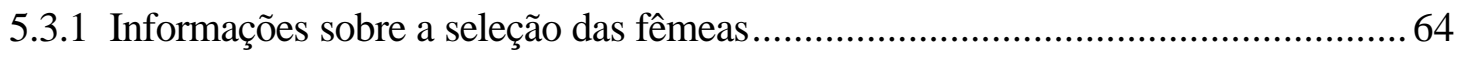

5.3.2 Análise dos BLUPs - resposta direta no peso à seleção e correlacionada na altura das fêmeas ao sobreano ...... .65 
5.3.3 Análise das médias e dos BLUPs - respostas correlacionadas no tamanho e reprodução das matrizes....................................................................... 71

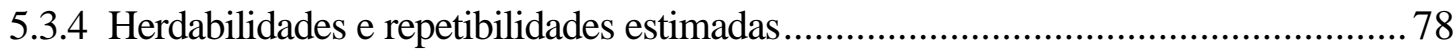

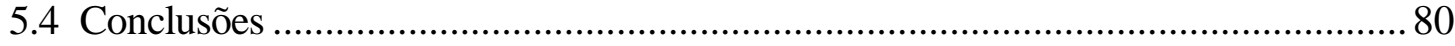

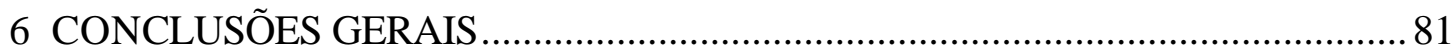

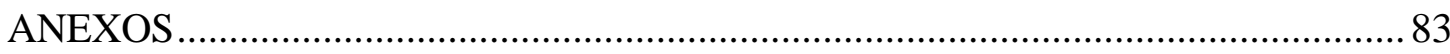

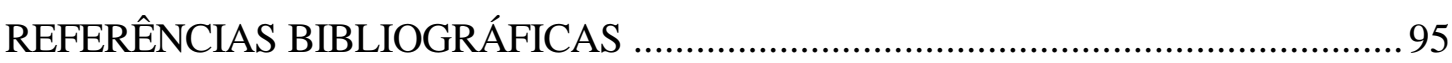




\title{
ANÁLISE DE UM EXPERIMENTO DE SELEÇÃO PARA CRESCIMENTO EM BOVINOS NELORE: RESPOSTAS DIRETA NO PESO AO SOBREANO E CORRELACIONADAS NO TAMANHO E REPRODUÇÃO DAS MATRIZES
}

\author{
Autora: MARIA EUGÊNIA ZERLOTTI MERCADANTE \\ Orientador: Prof. Dr. IRINEU UMBERTO PACKER
}

\section{RESUMO}

Foram estudados dados provenientes do experimento de seleção estabelecido na Estação Experimental de Zootecnia de Sertãozinho (IZ - SP), com o objetivo de avaliar a resposta direta no peso ao sobreano de machos e fêmeas e as respostas correlacionadas no tamanho e caracteres reprodutivos das matrizes. $\mathrm{O}$ experimento iniciou em 1978, com três rebanhos da raça Nelore, seleção (NeS), tradicional (NeT) e controle $(\mathrm{NeC})$, sendo os dois primeiros selecionados para maior peso ao sobreano e o terceiro para a média deste peso. O NeT diferencia-se de NeS por ter recebido, eventualmente, touros de outros rebanhos, inclusive comerciais. Registros de dias ao parto foram analisados separadamente nas novilhas, vacas e vacas e novilhas sem incluir e incluindo as fêmeas não paridas. Nenhuma diferença significativa $(\mathrm{P}<0,05)$ foi detectada entre os desempenhos das fêmeas dos rebanhos selecionados ( $\mathrm{NeS}$ e $\mathrm{NeT}$ ) e as do controle ( $\mathrm{NeC}$ ). As herdabilidades variaram de 0,02 a 0,16, sendo as mais altas obtidas em arquivos nos quais foram incluídos os registros das fêmeas não paridas. Os registros repetidos de dias ao parto de vacas e novilhas incluindo as fêmeas não paridas foram também analisados por modelo de regressão aleatória com polinômios ortogonais (Legendre) da idade na monta (em anos) como a covariável independente, para avaliar este caracter longitudinalmente durante a vida produtiva das fêmeas. As herdabilidades 
estimadas aumentaram de 0,08 a 0,28 da $1^{\mathrm{a}}$ à $6^{\mathrm{a}}$ monta. A seleção para peso não alterou o valor genético médio das vacas de $\mathrm{NeS}$ e NeT, entretanto os valores genéticos das vacas do $\mathrm{NeC}$ mostraram tendência de queda no decorrer dos anos, além de longitudinalmente, com o avanço da idade. Registros de peso ao sobreano dos animais nascidos de 1978 a 1998, e da altura na garupa ao sobreano das fêmeas nascidas a partir de 1985 foram analisados por modelo animal para obter a tendência genética de 1981 a 1996. Médias de peso, altura e escore de condição corporal na entrada da monta, dias ao parto e sucesso ao parto das matrizes nascidas nos últimos 4 anos foram contrastadas entre os selecionados e o $\mathrm{NeC}$, em análise de quadrados mínimos. As tendências genéticas médias obtidas em 16 anos foram $1,7 \pm 0,2 ; 2,3 \pm 0,2$ e $-0,1 \pm 0,1 \mathrm{~kg} /$ ano nos machos e $1,9 \pm 0,2 ; 2,4 \pm 0,2$ e $-0,1 \pm 0,1 \mathrm{~kg} / \mathrm{ano}$ nas fêmeas para peso, e $0,25 \pm 0,03$; $0,24 \pm 0,04$ e $-0,04 \pm 0,03 \mathrm{~cm}$ nas fêmeas para altura ao sobreano, respectivamente em $\mathrm{NeS}, \mathrm{NeT}$ e NeC. Novilhas e vacas de $\mathrm{NeS}$ e $\mathrm{NeT}$ foram $19 \%$ e $15 \%$ mais pesadas e $4 \%$ mais altas na entrada da monta, em relação às do $\mathrm{NeC}$. Não foram detectadas diferenças significativas $(\mathrm{P}<0,05)$ no desempenho reprodutivo das matrizes selecionadas em relação ao $\mathrm{NeC}$. Os resultados indicaram que a seleção para peso corporal promoveu respostas altas e consistentes nos pesos e alturas ao sobreano e em idades mais tardias, sem comprometer o desempenho reprodutivo das matrizes. 


\title{
ANALYSIS OF A SELECTION EXPERIMENT FOR GROWTH IN NELORE CATTLE: DIRECT RESPONSE OF YEARLING WEIGHT AND CORRELATED RESPONSES OF SIZE AND REPRODUCTION OF COWS
}

\author{
Author: MARIA EUGÊNIA ZERLOTTI MERCADANTE \\ Adviser: Prof. Dr. IRINEU UMBERTO PACKER
}

\section{SUMMARY}

Data from a selection experiment, carried out AT Experimental Station of Sertãozinho, State of São Paulo, Brazil, were analyzed in order to evaluate the direct response of yearling weight and the correlated responses of the size and reproduction traits of cows. The experiment started in 1978, with three lines of Nelore cattle, selection $(\mathrm{NeS})$, traditional $(\mathrm{NeT})$, both selected for greater yearling weight, and control $(\mathrm{NeC})$, selected for mean yearling weight. The NeT line is different from the NeS one because sires from another herds were eventually introduced into the NeT line. Records of days to calving were analyzed separately for heifers, cows and cows and heifers with and without non-calver females. There were no significant differences $(\mathrm{P}<0.05)$ between the performance of females from the selection lines (NeS and $\mathrm{NeT}$ ) and those from the control line $(\mathrm{NeC})$. The heritabilities were between 0.02 and 0.06 , and the higher estimates were from data sets including non-calver females. The repeated records of days to calving of cows and heifers with non-calvers, were too analyzed using a random regression model, with orthogonal polynomials (Legendre) of age in the breeding season (in years) as the independent covariable, to order to evaluate this trait longitudinally during the herd life of the females. The estimates of heritability increased from 0.08 to 0.28 , from first up to $6^{\text {th }}$ breeding season. The selection for weight did not alter the 
average breeding value of cows from $\mathrm{NeS}$ and $\mathrm{NeT}$, although the average genetic breeding values of cows declined throughout the years, and too longitudinally, with advancing age. Yearling weight of the animals born from 1978 to 1998, and the yearling hip height of females born from 1985 to 1998, were evaluated using an animal model, in order to obtain the genetic trends for the years 1981 to 1996. The averages for weight, height and body condition score at he start of the breeding season, days to calving and calving success of cows born in the last 4 years, were contrasted between the selected ( $\mathrm{NeS}$ and $\mathrm{NeT}$ ) and control lines. The genetic trends obtained after 16 years were $1.7 \pm 0.2 ; 2.3 \pm 0.2$ and $-0.1 \pm 0.1 \mathrm{~kg} /$ year for males and $1.9 \pm 0.2 ; 2.4 \pm 0.2$ e $-0.1 \pm 0.1$ $\mathrm{kg} /$ year for females with respect to weight, and $0.25 \pm 0.03 ; 0.24 \pm 0.04$ and $-0.04 \pm 0.03$ $\mathrm{cm}$ for females with respect to yearling height for the $\mathrm{NeS}$, $\mathrm{NeT}$ and $\mathrm{NeC}$ lines, respectively. Heifers and cows from $\mathrm{NeS}$ and $\mathrm{NeT}$ were $19 \%$ and $15 \%$ heavier and $4 \%$ taller at the start of the breeding season than those from NeC. Significant differences $(\mathrm{P}<0.05)$ were not detected with respect to the reproductive performance between selected (NeS and $\mathrm{NeT}$ ) and control females. The results indicated that the selection according to body weight gave high and consistent responses for weight and height both at the yearling and later ages, without compromised the reproductive performance of the cows. 


\section{INTRODUÇÃO}

Produtores de gado de corte e pesquisadores do mundo todo tem se preocupado com as consequências da seleção no longo prazo. Na busca de super vacas e super novilhos via seleção, os geneticistas estão obtendo também animais com maior propensão a problemas fisiológicos e imunológicos (Rauw et al., 1998). Com os conhecimentos atuais, a seleção ainda é uma técnica obscura, que opera como numa caixa preta, isto é, a seleção fenotípica no longo prazo pode alterar a frequência alélica de um grande número de loci, os quais afetam mais que um caracter e/ou estão ligados a outros loci, resultando além de resposta direta no caracter selecionado, também respostas correlacionadas (desejáveis e indesejáveis) em muitos outros caracteres.

Grande parte do conhecimento das consequências da seleção são provenientes de predições baseadas em parâmetros genéticos, obtidos a partir de análises de covariância entre parentes, em dados coletados de criações comerciais. Pequeno número de experimentos delineados para fornecer evidências empíricas de respostas à seleção em bovinos de corte foram conduzidos até hoje. Uma vez que a produção de carne é altamente dependente dos caracteres relacionados ao crescimento, muitos dos experimentos de seleção em bovinos de corte focalizaram caracteres de crescimento. Os trabalhos sobre respostas à seleção para aumento do peso corporal, realizados com bovinos de origem européia, têm evidenciado resultados positivos para os caracteres selecionados, reportados nas revisões de Mrode (1988b) e Razook (1988).

Até meados de 1980, trabalhos e revisões sobre os efeitos da seleção para crescimento indicavam respostas correlacionadas negativas na reprodução das matrizes (Barlow, 1978; Scholtz \& Roux, 1984; Luesakul-Reodecha et al., 1986). Em sua revisão, Barlow (1978) concluiu que o efeito detrimental poderia ser aproximadamente 1,1\% de 
decréscimo na porcentagem de desmame para cada desvio padrão de seleção para peso ao desmame, apesar de admitir que o impacto total não estava claro e que interações poderiam ocorrer com o nível nutricional. Baker \& Morris (1984), em um sumário crítico dos resultados das respostas correlacionadas à seleção para crescimento, obtidas em experimentos, apontaram para a falta de evidências de efeitos negativos na reprodução.

Trabalhos publicados mais recentemente, tanto com dados de experimentos de seleção como com dados de campo, têm negado qualquer antagonismo, indicando que a seleção para maior peso corporal em idades jovens não apresenta efeitos significativos sobre o desempenho reprodutivo das matrizes (Mrode et al., 1990; Wolfe et al., 1990; Meyer et al., 1991; Morris et al., 1992; Parnell, 1994; Archer et al., 1998a; Mercadante et al., 2000; Silva et al., 2000).

Apesar da limitação de um experimento de seleção em termos de número de animais, ele fornece excelente oportunidade de monitorar e estudar relações entre seleção direta e repostas correlacionadas. A Estação Experimental de Zootecnia de Sertãozinho (IZ - SP) iniciou, em 1978, um experimento de seleção pioneiro em raças zebuínas, com a manutenção de uma população controle, a fim de examinar a resposta à seleção para peso corporal em raças de interesse nos trópicos, já que os poucos experimentos de seleção no mundo eram com raças européias. Hoje, após cerca de 4 gerações de seleção dessas populações, baseada em peso corporal, torna-se necessário estudar os efeitos no desempenho reprodutivo das fêmeas. Razook et al. (1998) relataram as respostas diretas no peso ao sobreano e as correlacionadas nos pesos ao nascer e ao desmame, obtidas para machos e fêmeas separadamente por meio de análises de quadrados mínimos; e Cyrillo et al. (2000) as respostas correlacionadas nas medidas corporais dos machos, ambos nos rebanhos Nelore. Até o momento nada foi relatado quanto às respostas correlacionadas nos caracteres de reprodução das matrizes.

Os objetivos do presente trabalho foram avaliar a resposta direta no peso à seleção por meio da metodologia de modelos mistos, e as respostas correlacionadas decorrentes dessa seleção no tamanho e nos caracteres reprodutivos das matrizes, 
utilizando procedimentos de quadrados mínimos e de modelos mistos (regressão aleatória e modelo animal).

O trabalho como um todo é apresentado em três capítulos (Capítulos 3, 4 e 5) referentes a três artigos científicos distintos. Os dois primeiros foram enviados para o periódico Revista Brasileira de Zootecnia, e o terceiro será enviado para um periódico internacional. 


\section{REVISÃO DE LITERATURA}

Há muitas razões para se estabelecer um experimento de seleção para caracteres quantitativos. Hill (1980) enumera algumas delas, relativas à experimentos de curta duração, com cinco ou menos gerações de seleção: 1) checar predições teóricas feitas a partir de estimativas de parâmetros na população base; 2) estimar a variância genética e herdabilidade na população base e testar se os caracteres exibem variância genética; 3) estimar covariâncias genéticas, correlações e regressões entre os caracteres; 4) testar interações genótipo $x$ ambiente; 5) testar a não linearidade das respostas diretas e correlacionadas em diferentes intensidades de seleção e direções de seleção; e 6) comparar taxas de resposta em programas alternativos de seleção. Entretanto, alguns objetivos importantes, tais como: atingir e medir limites à seleção, testar teorias relativas ao tamanho populacional e intensidades de seleção à resposta no longo prazo, assim como estimar respostas correlacionadas no longo prazo, particularmente na adaptabilidade, só serão provavelmente obtidos em experimentos de seleção de longa duração.

Experimentos de seleção delineados para responder questões específicas sobre caracteres quantitativos em animais datam somente do início do século 20 e muitos deles foram montados a partir da década de 50 (Eisen, 1998). Comparados às espécies de laboratório, relativamente poucos experimentos de seleção em bovinos foram montados devido aos altos custos e ao longo intervalo de gerações. Mrode (1988a) cita que o primeiro experimento de seleção em bovinos de corte estabelecido com a manutenção de uma população controle fi o descrito por Newman et al. (1973), iniciado em 1960. Além das razões enumeradas por Hill (1980) para o estabelecimento de um experimento de seleção, Koch et al. (1994) ressalta que por volta de 1950 tornou- 
se necessário mostrar aos criadores de gado elite e produtores de carne como fazer seleção mostrando resultados empíricos de experimentos em bovinos e não por meio da teoria ou de experimentos realizados com animais de laboratório. Assim, a intenção primária em muitos experimentos de seleção com grandes animais poderia ser simplesmente testar e demonstrar que a seleção é praticável para um certo caracter.

Neste capítulo serão abordados aspectos gerais e problemas teóricos e conceituais encontrados no acesso à mudança genética realizada em populações fechadas e finitas. Evitou-se portanto repetir os resultados dos experimentos de seleção citados nos próximos capítulos sobre respostas direta e correlacionada à seleção para crescimento.

\subsection{Acesso à estimativa da mudança genética realizada}

$\mathrm{Na}$ análise de experimentos de seleção com grandes animais, onde normalmente é impossível o controle das flutuações ambientais, uma complicação na estimação da resposta à seleção é com certeza a distinção entre mudança genética e ambiental (Hill, 1980; Mrode, 1988a; Falconer \& Mackay, 1996; Walsh, 1999a). Newman et al. (1973), por exemplo, encontraram que $60 \%$ do aumento no peso a um ano de idade na linha selecionada de bovinos Shorthorn foi devido à mudança ambiental e não genética. Outro complicador é a variância considerável da resposta, muitas vezes já observada entre linhas selecionadas replicadas de animais de laboratório. Uma vez que a seleção artificial usualmente envolve a escolha de um pequeno número de pais para formar a próxima geração, grande parte desta variação entre linhas replicadas é devido à deriva genética (Walsh, 1999a).

A medida da resposta realmente obtida em uma ou mais gerações de seleção introduz vários problemas (Falconer \& Mackay, 1996). O primeiro surge da variabilidade das médias por geração, as quais não avançam de maneira simples e regular, mas flutuam erradicamente e mais ou menos violentamente, e a consequência disso é que a resposta raramente pode ser medida com uma certa acurácia até passar, 
pelo menos, as duas primeiras gerações de seleção. A melhor medida da resposta média por geração é então obtida da inclinação da linha de regressão ajustada às médias das gerações, assumindo que a verdadeira resposta é constante no decorrer do período analisado. As médias podem variar devido à deriva genética aleatória, a erros amostrais na sua estimação, às diferenças no diferencial de seleção e a fatores ambientais.

A variação devido à deriva aleatória e aos erros amostrais podem ser reduzidos respectivamente pelo aumento do número de indivíduos selecionados e medidos. A ação da seleção natural, principalmente através de diferenças de fertilidade, pode provocar diferenças entre as linhas quanto ao diferencial de seleção, mas o fato de ponderar os diferenciais de seleção já leva em conta boa parte dos efeitos da seleção natural. Diferenças ambientais entre gerações podem surgir de causas climáticas, nutricionais e de manejo em geral, e um meio óbvio de eliminar as flutuações ambientais na obtenção da resposta à seleção é o estabelecimento e manutenção de uma grande população controle contemporânea. Neste caso, sob a suposição de que as diferenças ambientais afetam a população selecionada e a controle do mesmo modo, a diferença entre elas estima o melhoramento genético obtido por seleção, e a variância da resposta é a soma das variâncias das duas linhas.

Entretanto, várias fontes de erro na estimação da mudança genética usando uma população controle tem sido identificadas, tais como, deriva genética aleatória na população controle, mudança direcional na população controle através de seleção natural ou de seleção não intencional, interação entre o ambiente e os genótipos das populações controle e selecionada, além de erro na estimação da média da população controle decorrente de medir poucos animais (Hill, 1980). Principalmente por razões econômicas, em animais domésticos geralmente a população controle possível de ser estabelecida e mantida é pequena, agravando o problema da deriva aleatória, resultando em sub (ou super) estimação da verdadeira resposta à seleção (Walsh, 1999a). Assegurando um diferencial de seleção de zero ou próximo de zero a variância devido à deriva, na população controle, pode ser minimizada (Hill, 1972a).

A quantidade de variância entre as médias de linhas replicadas pode também ser gerada por seleção (Hill, 1972a, Hill, 1980). Com seleção, os indivíduos não são 
escolhidos por acaso com respeito a seus fenótipos, o que diminui a variância devido à deriva pura, mas causa mudanças na frequência alélica e produz desequilíbrio de ligação, reduzindo a variância genética aditiva dentro de linha. Além disso, grandes mudanças podem ocorrer em poucas gerações nas variâncias genéticas dentro de linha se alelos de grande efeito estiverem segregando. Alelos de grande efeito, inicialmente em baixas frequências, podem gerar aumento substancial na variância entre as linhas, uma vez que podem ser perdidos em alguma linha e ter sua frequência aumentada em outra. O resultado é que diferentes linhas originadas de uma mesma população base podem ter iniciado com valores de variância genética muito diferentes, aumentando a variância da resposta (Hill, 1980; Walsh, 1999a). A seleção gera endogamia devido ao tamanho populacional finito e reduz a variância genética aditiva dentro de linha pela fixação de alelos. Walsh (1998) sumarizou os vários fatores que podem complicar a predição da resposta no curto prazo (Quadro 1), mesmo considerando somente uma geração de seleção a partir de uma população base não selecionada. É esperado que estes problemas aumentem juntamente com o número de gerações de seleção.

O primeiro passo na interpretação dos resultados de um experimento de seleção é a estimação dos parâmetros genéticos tais como as respostas diretas e correlacionadas à seleção. $\mathrm{O}$ método mais comumente usado na análise de experimentos delineados é o de quadrados mínimos, enquanto o método usual de escolha na análise de dados de campo é baseado na metodologia de modelos mistos devido às suas propriedades estatísticas bem definidas (Kennedy, 1990; Meyer \& Hill, 1991). Em populações com acasalamento ao acaso, as propriedades dos estimadores derivados por ambos métodos podem ser definidas sem ambiguidade, entretanto, as propriedades estatísticas dos estimadores dos parâmetros num modelo de seleção são menos claras (Sorensen \& Kennedy, 1984). A teoria genética de populações selecionadas é relativamente menos desenvolvida, mas a mudança na variância genética advinda da seleção já é bem reconhecida. A seleção direcional causa covariâncias negativas entre as frequências dos alelos nos diferentes loci (isto é, desequilíbrio gamético), entretanto, com muitos loci tem sido mostrado que a mudança na variância é quase que 
exclusivamente devido à geração de desequilíbrio gamético e não devido à mudanças na frequência gênica (Bulmer, 1971; Sorensen \& Kennedy, 1984).

\begin{tabular}{|c|c|}
\hline Fator & Consequências \\
\hline $\begin{array}{l}\text { Interação genótipo } \mathrm{x} \\
\text { ambiente }\end{array}$ & $\begin{array}{l}\text { a) Possibilidade de regressão não linear entre pai-progênie. } \\
\text { b) Possibilidade de resposta contrária. }\end{array}$ \\
\hline Estrutura de idade & $\begin{array}{l}\text { a) a não ser em equilíbrio, várias gerações são necessárias para } \\
\text { propagar a mudança genética uniformemente na população. }\end{array}$ \\
\hline Epistasia & $\begin{array}{l}\text { a) o componente de resposta devido à epistasia é passageiro. } \\
\text { b) a covariância pai-progênie superestima a resposta } \\
\text { permanente. }\end{array}$ \\
\hline Efeitos maternos & $\begin{array}{l}\text { a) complicada defasagem na resposta. } \\
\text { b) possibilidade de resposta contrária. }\end{array}$ \\
\hline Endogamia & $\begin{array}{l}\text { a) a resposta depende de componentes de variância adicionais } \\
\text { que são difíceis de estimar. } \\
\text { b) a resposta tem componentes permanentes e transitórios. }\end{array}$ \\
\hline Deriva & a) gera variância na resposta no curto prazo. \\
\hline $\begin{array}{l}\text { Desequilíbrio na fase } \\
\text { gamética }\end{array}$ & $\begin{array}{l}\text { a) mudança na variância genética aditiva. } \\
\text { b) a seleção direcional gera desequilíbrio negativo, reduzindo a } \\
\text { herdabilidade e diminuindo a velocidade da resposta. }\end{array}$ \\
\hline $\begin{array}{l}\text { Acasalamento } \\
\text { associativo }\end{array}$ & $\begin{array}{l}\text { a) gera desequilíbrio que tanto pode melhorar como retardar a } \\
\text { resposta. }\end{array}$ \\
\hline $\begin{array}{l}\text { Seleção sobre } \\
\text { caracteres } \\
\text { correlacionados }\end{array}$ & $\begin{array}{l}\text { a) resposta não predita, a menos que a seleção sobre os caracteres } \\
\text { correlacionados seja levada em conta. }\end{array}$ \\
\hline $\mathrm{Muc}$ & $\begin{array}{l}\text { a) uma mudança significativa no ambiente pode obscurecer a } \\
\text { verdadeira mudança genética. }\end{array}$ \\
\hline
\end{tabular}

Adaptado de Walsh (1998).

Quadro 1 - Sumário de vários fatores que complicam a predição da resposta à seleção no curto prazo a partir das médias fenotípicas, mesmo considerando somente uma geração de seleção a partir de uma população base não selecionada. 
Em uma série de trabalhos Sorensen \& Kennedy (1983, 1984, 1986), Kennedy et al. (1988) e Kennedy (1990) discutem o uso da análise de modelos mistos, mais precisamente modelo animal, na obtenção da estimativa da mudança genética em dados de campo e em experimentos de seleção, além das vantagens da incorporação das relações entre todos os animais, dentro e entre as gerações, para contornar os problemas que contribuem para a variância da resposta.

\subsection{Considerações sobre os procedimentos de quadrados mínimos e de modelo misto no acesso à estimativa da mudança genética}

Em um experimento com delineamento simples, sem sobreposição de gerações a resposta à seleção pode ser estimada usando procedimentos de quadrados mínimos, como a média das progênies dos pais selecionados, e neste caso, os efeitos ambientais são estimados pelo uso de uma população controle não selecionada. Dados de experimento de seleção podem também ser usados para obter estimativas de herdabilidade usando estimadores simples tipo regressão, como a resposta acumulada dividida pelo diferencial de seleção acumulado. Em contraste com estimador de modelo misto (considerando um modelo animal), o de quadrados mínimos usa somente os registros da geração i, digamos, para calcular a média da geração i, sem usar a informação das outras gerações. Entretanto, em alguns casos (como experimentos com animais) tem-se disponíveis muitas informações, tais como registros do desempenho de todos os indivíduos ao longo do experimento, assim como a genealogia completa de todos eles. Mesmo quando tais dados estão disponíveis, a análise de quadrados mínimos ignora a estrutura dos dados, usando somente os registros de uma geração em particular para computar a resposta e ponderar igualmente todos os indivíduos selecionados (Walsh, 1999b).

Alternativamente, procedimentos de modelos mistos podem ser usados para analisar os dados, produzindo estimativas da variância genética e da resposta à seleção numa única análise (Sorensen \& Kennedy, 1986). Modelo misto, considerando modelo 
animal, incorpora a matriz de relações genético-aditivas direta ou indiretamente. Assim, em uma análise de modelo misto, todas as covariâncias são consideradas (tanto aquelas entre indivíduos dentro de uma geração como aquelas entre indivíduos de diferentes gerações), além de incorporar o fato que algumas famílias fornecem mais informações sobre a resposta e de ponderar corretamente os indivíduos advindos destas famílias usando registros da geração corrente e de todas as gerações passadas para estimar a resposta. A omissão do relacionamento entre gerações tem implicações importantes na análise de dados que foram gerados por seleção (Sorensen \& Kennedy, 1984 e 1986), já que experimentos de seleção são processos estocásticos e o desempenho em uma dada geração é dependente da amostra genética retida na geração anterior (Hill, 1972b). Em virtude do uso destas informações adicionais, uma análise de modelo misto é potencialmente mais poderosa que uma análise de quadrados mínimos (Sorensen \& Kennedy, 1983, 1984, Blair \& Pollack, 1984; Meyer \& Hill, 1991).

Experimentos de seleção com grandes animais são geralmente longos e envolvem várias gerações sobrepostas e assim os registros podem ser afetados por efeitos de sexo, idade da mãe, tempo, entre outros, e uma abordagem de modelo misto, especificando o modelo corretamente, oferece vantagens consideráveis sobre os métodos tradicionais simples. Além disso, os estimadores tradicionais baseados em análise de variância assumem implicitamente acasalamento aleatório e grande tamanho populacional de modo que a endogamia e a deriva sejam desprezíveis (Kennedy, 1990). Como citado anteriormente, em muitos experimentos o tamanho populacional não é tão grande e a deriva deve ser considerada.

A variância dos estimadores deve levar em conta a correlação existente entre as observações, e se isso não é feito as variâncias podem ser viesadamente subestimadas. Sorensen \& Kennedy (1983) mostraram como a inclusão da matriz de parentesco fornece estimadores das médias genéticas com variâncias que levam em conta a variância devido à deriva genética. O uso da matriz de relações aditivas entre os animais, sendo essencialmente uma aproximação retrospectiva, leva em conta a redução no tamanho efetivo devido à seleção e o aumento associado na variância devido à deriva. 
Sob certas condições a análise de modelos mistos tem ainda a vantagem de particionar adequadamente a mudança fenotípica em seus componentes genético e ambiental sem a necessidade de uma população controle (Blair \& Pollack, 1984; Sorensen \& Kennedy, 1984). Estas condições são, primeiro, que a variância do caracter antes da seleção iniciar seja conhecida, segundo, que a seleção seja uma função linear dos registros. Uma terceira condição para particionar corretamente a mudança fenotípica com modelo misto é que a matriz de parentesco (A) seja completa. Isto significa que todos os animais envolvidos nas decisões de seleção, independentemente de ter ou não contribuído com progênies, devem estar no cálculo de A. Se esta condição não for satisfeita, os estimadores dos efeitos fixos e da resposta à seleção serão viesados. A quantidade de viés dependerá de quanto a variância do vetor de valores genéticos está incorreta em relação à variância real. Além disso a análise de modelo misto pode ser mais sensitiva, em particular à pressuposição de que os caracteres são determinados por infinitos loci agindo aditivamente, cada um com pequeno efeito (modelo infinitesimal) e que as frequências alélicas não mudam com a seleção. Consequentemente as variâncias genéticas permaneceriam constantes exceto como resultado da endogamia e pelo desequilíbrio gamético entre os loci não ligados causado pela seleção (Meyer \& Hill, 1991; Walsh, 1999b).

Na prática a herdabilidade inicial geralmente não é conhecida e isto pode ser resolvido de dois modos, usando informação da literatura ou estimá-la diretamente dos dados (Sorensen \& Kennedy, 1986). Como citado anteriormente, sob um modelo infinitesimal a variância genética aditiva não seria alterada por seleção, e considerando a inclusão das informações de parentesco até a geração inicial (base), além de todos os registros nos quais a seleção foi baseada, a variância estimada a partir dos dados, mesmo com seleção, seria uma boa estimativa da variância da população base (Meyer \& Hill, 1991), e a primeira condição seria satisfeita. Walsh (1999b) cita inúmeros trabalhos que provam que se a população base consiste de indivíduos não selecionados e não endogâmicos, e se os dados fenotípicos de todos os indivíduos selecionados e não selecionados estiveram disponíveis, o método da máxima verossimilhança sob um modelo infinitesimal produziria essencialmente estimativas da variância genética aditiva 
não viesadas da população base. Por outro lado, quando a população base consiste de indivíduos previamente selecionados, este método não garante estimativas não viesadas da população base antes da seleção, mesmo incorporando todas as informações.

Deste modo, como na análise de modelo misto a tendência genética é obtida através dos valores genéticos médios, e estes dependem da estimativa de herdabilidade na população base, a resposta será subestimada se a herdabilidade for menor que o verdadeiro valor, e será superestimada se a herdabilidade for maior. Parece lógico que o entendimento e a definição corretos da população base são críticos em uma análise considerando modelo animal. Com a matriz de parentesco, animais sem pais identificados são tratados como animais da população base com a suposição de que foram amostrados de uma única população com valor genético médio nulo e de mesma variância genética aditiva (Kennedy et al., 1988).

Se os registros antes da seleção são ajustados para os efeitos fixos usando estimadores não viesados de uma modelo sem seleção, então as equações dos modelos mistos ignorando seleção serão ótimas sob um modelo de seleção. As decisões de seleção tem que ser invariantes aos efeitos fixos, e a segunda condição também seria satisfeita (Sorensen \& Kennedy, 1984). A terceira condição, de que todos os animais envolvidos nas decisões de seleção devem estar no cálculo de A, é mais fácil de ser satisfeita, principalmente em um experimento de seleção. Outra fonte de viés são as forças da seleção natural que, teoricamente, podem se opor à seleção artificial e neste caso a estimativa da resposta por modelo misto pode ser viesada se a adaptabilidade for geneticamente correlacionada com o caracter sob seleção artificial. Estudos de simulação não detectaram viés significativo na estimativa da resposta mesmo quando o caracter reprodutivo tinha correlação genética negativa com o caracter sob seleção direta (Kennedy, 1990).

Como mencionado anteriormente, uma importante suposição no uso da abordagem de modelo misto é que o modelo descreva os dados corretamente, e esse modelo assume que o caracter métrico é determinado por um grande número de loci aditivos (não epistáticos) e não ligados. Com esse modelo genético, sob acasalamento ao acaso numa grande população, as contribuições dos diferentes loci para a variância 
genética são estatisticamente independentes, de modo que pelo teorema do limite central eles serão assintoticamente normais. A normalidade da distribuição fenotípica é verdadeira, uma vez que os valores fenotípicos são a soma dos efeitos genotípicos e dos efeitos ambientais normalmente distribuídos. Entretanto, uma consequência importante deste modelo é que com seleção direcional as mudanças nas frequências alélicas são infinitamente pequenas e a mudança na variância genética é devido à geração de desequilíbrio gamético entre os loci que afetam o caracter ("efeito de Bulmer"). Com número finito de loci, particularmente com alelos de grande efeito, a suposição de normalidade é menos sustentável e é, sem dúvida, o ponto mais crítico para o uso de modelo misto na análise de experimentos de seleção (Kennedy \& Sorensen, 1984, 1986; Kennedy, 1990; Meyer \& Hill, 1991).

Maki-Tanila \& Kennedy (1986), examinando as propriedades dos estimadores de modelo misto da mudança genética, em caracteres controlados por relativamente poucos loci, observaram que, com seleção não houve viés significativo, apesar de ter simulado somente três gerações de seleção. Meyer \& Hill (1991), ao analisarem 23 gerações de seleção para ingestão de alimentos em camundongos, verificaram que as estimativas da variância genética aditiva decresceram com o aumento do número de gerações. Os autores sugerem que o modelo infinitesimal não foi apropriado e que as variâncias mudaram como consequência da alteração nas frequências gênicas devido à seleção, uma vez que as alterações observadas foram maiores que as esperadas por desequilíbrio de ligação e endogamia. Assim, um modelo infinitesimal é provavelmente adequado para o acesso da resposta à seleção no curto e médio prazos, mas vem a ser menos válido conforme o número de gerações aumenta (Sorensen \& Kennedy, 1984; Meyer \& Hill, 1991; Wei et al., 1996).

$\mathrm{O}$ acesso à estimativa da mudança genética por modelo misto é feito a partir dos valores genéticos médios estimados, e sob a suposição de que a herdabilidade na população base é conhecida, a estimação da resposta à seleção é dependente dos dados. $\mathrm{O}$ uso da matriz A tem o efeito de comparar o registro do animal com um índice baseado nas informações de seus parentes, e os valores genéticos individuais são regredidos em direção aos valores preditos pelo índice, suavizando flutuações excessivas (Walsh, 
1999b). Devido a esta propriedade, a resposta estimada por modelo misto tende a ser mais suave que a resposta verdadeira (ou aquela estimada por quadrados mínimos), pois é menos afetada pelos verdadeiros desvios de amostragem (Kennedy \& Sorensen, 1986).

Uma terceira abordagem, a bayesiana, tem sido usada para acessar a estimativa da mudança genética em experimentos de seleção (Blasco et al., 1998; Walsh, 1999b). Opostamente aos estimadores pontuais (médias, variâncias), a estatística bayesiana trata de gerar uma distribuição posterior dos parâmetros desconhecidos condicionalmente aos dados e a alguma densidade previamente conhecida destes parâmetros, e as inferências são feitas baseando-se nesta distribuição marginal posterior após ter considerado todos os possíveis valores dos componentes de variância, ponderados por suas probabilidades (Blasco, 2001). Assim, a estatística bayesiana fornece um quadro muito mais completo da incerteza na estimação dos parâmetros desconhecidos. Tanto na análise de quadrados mínimos como em análises usando procedimentos de modelo misto é difícil obter uma estimativa precisa da variância do estimador da resposta à seleção. Na abordagem bayesiana, proposta por Sorensen et al. (1994), tanto o mecanismo de seleção que gera os dados como a incerteza acerca dos efeitos fixos e dos componentes de variância são considerados.

Quando a quantidade de dados é pequena, estimativas REML da dispersão dos parâmetros não são confiáveis. Isto pode ser um problema sério, uma vez que os valores genéticos dependem deles. A densidade marginal posterior pondera o estado de ignorância acerca dos componentes de variância quando os valores genéticos são estimados. Se algumas estimativas dos componentes de variância podem ser encontradas na literatura, o modo frequentista de estimação dos valores genéticos envolve o uso de um único valor baseado neles (a média, por exemplo). O modo bayesiano pondera os valores possíveis por sua probabilidade posterior (Blasco, 2001).

A questão agora é se um grupo controle é necessário. Em alguns casos a necessidade de um controle pode ser mínima. Entretanto, vários pontos merecem consideração, segundo Blair \& Pollack (1984), 1) na abordagem de modelo misto, para separar, com sucesso, mudanças genética e ambiental, são necessários fortes laços genéticos entre os anos e se estes laços não estão garantidos no início do experimento, 
um grupo controle poderia ser incluído, 2) um grupo controle é frequentemente incluído para permitir comparações fisiológicas entre os grupos selecionado e controle após várias gerações de seleção ter ocorrido, 3) os dados do grupo controle podem ser usados para calcular as herdabilidades estimadas necessárias para uma análise de modelos mistos e, 4) dados do grupo controle fornecerão estimativas dos efeitos fixos que podem ser comparadas com estimativas similares do grupo selecionado, permitindo um estudo interessante da interação genótipo e ambiente. Ainda, se a linha selecionada é geneticamente relacionada à controle, o uso de todos os dados numa única análise pode fornecer estimativas dos efeitos fixos e aleatórios com variância mínima (Sorensen \& Kennedy, 1984).

Finalmente, Kennedy (1990) comenta o pequeno, ou praticamente nenhum, uso dos valores genéticos estimados na condução de um experimento de seleção, ou seja, na escolha dos pais da próxima geração. A adequacidade do uso de métodos de modelo misto na seleção dos animais em um experimento de seleção depende totalmente da intenção do experimento. Como citado anteriormente, alguns experimentos são delineados para testar teorias genéticas e devido às propriedades dos modelos mistos apoiarem-se em um número de suposições teóricas, seu uso em tais situações, deve ser cuidadoso. A intenção primária em muitos experimentos de seleção com grandes animais é testar ou demonstrar que a seleção é praticável para um certo caracter, funcionando como um modelo para uma unidade comercial, e neste contexto faz pouco sentido o uso de métodos de seleção que são provavelmente menos eficientes que aqueles usados rotineiramente em rebanhos comerciais, e o uso de métodos de modelo misto na seleção das populações de animais domésticos tem aumentado muito. Se a intenção do experimento for criar rapidamente linhas geneticamente divergentes, para possibilitar estudos subsequentes das diferenças biológicas entre os animais de tipos genéticos diferentes, a eficiência destes experimentos provavelmente aumentará se a seleção for através do uso de métodos de modelos mistos. 


\section{DIAS AO PARTO DE FÊMEAS NELORE DE UM EXPERIMENTO DE SELEÇÃO PARA CRESCIMENTO. I - MODELO DE REPETIBILIDADE}

\section{RESUMO}

Registros de datas de entrada na monta e respectiva data do parto, referentes à 1.247 fêmeas Nelore dos rebanhos experimentais da Estação Experimental de Zootecnia de Sertãozinho (IZ - SP), selecionadas para altos (seleção e tradicional) e para médios (controle) pesos ao sobreano foram usados para obter a variável dias ao parto, com o objetivo de estudar o efeito da seleção para crescimento sobre o desempenho reprodutivo. Arquivos de novilhas e de vacas e novilhas foram analisados incluindo e não incluindo as não paridas. Nenhuma diferença significativa $(\mathrm{P}>0,05)$ foi detectada entre os registros provenientes das vacas dos rebanhos selecionados e do controle, apesar das vacas do rebanho seleção apresentarem as maiores médias de dias ao parto na maioria dos arquivos estudados. Concordando com os resultados obtidos para o efeito de rebanho, o peso à seleção foi significativo $(\mathrm{P}<0,05)$ somente para as vacas e novilhas considerando as não paridas, com tendência das mais pesadas à seleção apresentarem menores valores para dias ao parto. Modelos nos quais não foi considerado o peso à seleção forneceram os mesmos resultados para o efeito de rebanho. As herdabilidades variaram de 0,02 a 0,16, sendo as mais altas obtidas em arquivos nos quais foram incluídos os registros das não paridas, indicando que a observação de caracteres de reprodução somente das fêmeas férteis contribui para mascarar as diferenças genéticas entre os animais, e quando esta variabilidade é re-introduzida, designando-se penalidades às fêmeas que não pariram, as diferenças genéticas entre os animais aparecem. Existem evidências que a seleção para peso não comprometeu o desempenho reprodutivo das fêmeas, mesmo sendo criadas em condições ambientais similares. 


\section{SUMMARY}

Records at start of the breeding season and subsequent calving, from 1,247 Nelore females raised at Sertãozinho's Experiment Station (IZ - SP, Brazil), selected for high (selection and tradictional lines) and for average (control line) yearling weights were used to compute days to calving and to examine the effect of selection for yearling weight on reproductive performance. Data sets of heifers and cow and heifers were analysed with and without non-calvers females. There were no significant differences ( $>$ >0.05) among the performance of females from selection lines (selection and traditional) and those from control line $(\mathrm{NeC})$, although days to calving were higher in the selection line for all analyses. According to the results for selection line effects, the weight at selection was significant $(\mathrm{P}<0.05)$ only for cows and heifers including noncalvers females, and those with higher weight at selection showed smaller days to calving. Models without weight at selection showed equivalent results for line. The heritabilities were between 0.02 and 0.16 , and the higher estimates were from data sets including non-calvers females, suggesting that the observation of reproductive traits only on fertile females can make-up the genetic differences between the animals and when this variability is re-introduced, assigning penalty for non-calvers females, the genetic differences appear. The results show that the selection for high yearling weight did not compromise female reproductive performance, even being raised under the similar environmental conditions.

\subsection{INTRODUÇÃO}

O peso corporal ou a taxa de crescimento continua sendo o critério de seleção primário para a maioria dos criadores de bovinos de corte em todo o mundo, e de outras espécies exploradas para produção de carne. Em aves e suínos, que tem intervalos de gerações menores, os efeitos indesejáveis da seleção para peso corporal sobre o desempenho reprodutivo já são conhecidos (Rauw et al., 1998). Para bovinos de corte, até meados da década de 80 muito se discutiu sobre as conseqüências da seleção para 
peso corporal sobre a eficiência de produção, incluindo o desempenho reprodutivo das matrizes, principalmente pelo aumento no peso adulto advindo dessa seleção (Barlow, 1978; Scholtz \& Roux, 1984). Com o acúmulo dos dados dos experimentos de seleção por várias gerações, somado ao aumento quantitativo e qualitativo dos bancos de dados de criadores e associações de raças, e ao avanço dos métodos de predição, os estudos têm mostrado que a seleção para maior peso corporal não apresenta efeitos significativos sobre o desempenho reprodutivo das fêmeas (Wolfe et al., 1990; Meyer et al., 1991; Morris et al., 1992; Parnell, 1994; Archer et al., 1998a; Mercadante et al., 2000; Silva et al., 2000), embora na maioria deles os animais tenham sido criados em ambientes menos restritivos que o tropical.

A escolha do caracter reprodutivo a ser considerado tem variado entre autores. Dias ao parto (ou equivalentemente dia do parto ou data do parto) tem sido sugerido por alguns pesquisadores, enquanto outros têm argüido contra e defendido o uso da taxa de concepção ou parição (Ponzoni, 1992; Johnston \& Bunter, 1996). O caracter dias ao parto é realmente observado nas vacas paridas e reportado rotineiramente pelas associações de raça quando os bezerros são registrados. A expressão fenotípica de dias ao parto é composta combinando efeitos do bezerro controlando o início do parto, efeitos da mãe associados com o início do ciclo estral e fertilidade, e os efeitos do touro em serviço associado com a qualidade do sêmen e da libido (Macneil \& Newman, 1994).

Apesar da limitação de um experimento de seleção em termos de número de animais, ele fornece excelente oportunidade de monitorar e estudar relações entre seleção direta e repostas correlacionadas. A Estação Experimental de Zootecnia de Sertãozinho (IZ - SP) iniciou, em 1976, um experimento de seleção, pioneiro em raças zebuínas, estabelecendo os rebanhos Nelore seleção e Nelore controle, a fim de examinar a resposta à seleção para peso corporal em raças de interesse nos trópicos, já que os poucos experimentos de seleção no mundo eram com raças européias. Hoje, após cerca de 4 gerações de seleção dessas populações, baseada em peso corporal, torna-se necessário estudar os efeitos no desempenho reprodutivo das fêmeas. Razook et al. (1998) relataram as respostas diretas no peso ao sobreano e as correlacionadas nos pesos 
ao nascer e ao desmame e, Cyrillo et al. (2000) as respostas correlacionadas nas medidas corporais dos machos. O objetivo deste trabalho foi avaliar o efeito da seleção para peso ao sobreano no caracter dias ao parto, um dos indicadores do desempenho reprodutivo de fêmeas bovinas submetidas a estação de monta restrita.

\subsection{MATERIAL E MÉTODOS}

\subsubsection{Animais e manejo}

As informações utilizadas para este estudo foram provenientes dos rebanhos da raça Nelore que fazem parte do projeto de seleção das raças zebuínas, estabelecido na Estação Experimental de Zootecnia de Sertãozinho (EEZS), unidade de pesquisa do Instituto de Zootecnia, da Secretaria de Agricultura e Abastecimento do Estado de São Paulo. Todos os detalhes da implantação dos rebanhos e do processo seletivo foram descritos por Razook et al. $(1993,1998)$.

Em linhas gerais, o experimento de seleção, iniciado em 1976, com a reorganização dos rebanhos e introdução de novas linhagens, a partir do rebanho Nelore base existente na EEZS desde 1933, envolveu o estabelecimento de dois rebanhos, Nelore Controle $(\mathrm{NeC})$ e Nelore Seleção (NeS) em 1980. De 350 fêmeas aptas à reprodução, as 180 mais novas foram aleatoriamente designadas para os rebanhos Nelore Controle (NeC) e Nelore Seleção, com 60 e 120 fêmeas respectivamente, e as 170 restantes, posteriormente formaram o rebanho Nelore Tradicional (NeT). Foram usados anualmente 4, 6 e até 8 touros nos rebanhos $\mathrm{NeC}$, $\mathrm{NeS}$ e $\mathrm{NeT}$, sendo $50 \%$ deles com dois anos (primeira monta) e 50\% com três anos (segunda e última monta), selecionados de acordo com o diferencial de seleção, dentro de grupo contemporâneo rebanho x ano, para peso padronizado aos 378 dias (P378), obtido após prova de desempenho em confinamento de 168 dias de duração (Razook et al., 1997). As fêmeas

de reposição foram selecionadas de acordo com o diferencial de seleção do peso padronizado aos 550 dias (P550), em regime de pasto, mas em geral foram retidas 
anualmente $50 \%$ delas para uma taxa anual de descarte de $20 \%$ das matrizes. Nos rebanhos selecionados $\mathrm{NeS}$ e NeT foram retidos para reprodução machos e fêmeas de maior diferencial e para o $\mathrm{NeC}$ aqueles com diferencial de seleção nulo. $\mathrm{O} \mathrm{NeT}$, em um esquema de reposição de touros e matrizes mais flexível, recebeu no início touros de fora dos rebanhos da estação, assim como, eventualmente, touros e matrizes descartados dos $\mathrm{NeC}$ e NeS. Após 15 anos (progênies de 1981 a 1995), passadas 3,5 gerações de seleção, com intervalo de gerações médio de 5 anos, os machos e as fêmeas do NeS têm, em média, 17 e 16\% a mais no peso à seleção que os do NeC (Razook et al., 1998).

As novilhas de reposição foram colocadas em monta natural com dois anos de idade $(25,5 \pm 1$ meses), juntamente com o restante das fêmeas, em lotes médios de 25 matrizes para $\mathrm{NeS}$ e $\mathrm{NeT}$ e 15 matrizes para $\mathrm{NeC}$, para cada touro, durante 90 dias. Menores relações vaca/touro foram utilizadas para os tourinhos de 2 anos de idade, no primeiro ano de seu uso. Os bezerros foram desmamados nos meses de abril e maio, com 7 meses de idade. As fêmeas foram descartadas prioritariamente por falharem dois anos consecutivos, por problemas de saúde, por má habilidade materna (abandono de bezerro por dois anos consecutivos), ou por idade avançada, ao redor de 11 anos.

\subsubsection{Dados}

A variável dias ao parto (DIAP) foi obtida dos arquivos de estação de monta dos anos de 1978 a 1998, com 7.336 registros de 1.425 fêmeas filhas de 162 touros, para todas as fêmeas que pariram, a partir da diferença entre a data do parto e a data da entrada na estação de monta que deu origem a este parto. $\mathrm{Na}$ edição dos arquivos foram descartadas as informações provenientes de abortos, de partos fora da estação de nascimento (resultado de montas não controladas), e de inseminação artificial, totalizando 5.576 registros, pertencentes a 1.247 fêmeas. Durante os 20 anos as datas de entrada e saída da monta foram 15 de novembro e 15 de fevereiro, com pequenas variações no decorrer dos anos. Em 5\% dos registros de parto, as vacas pariram após o início da estação de monta, e nestes casos a data de entrada na monta foi ajustada somando-se 4 dias à data do parto. Um sub-arquivo foi montado considerando somente 
os registros das fêmeas nascidas entre 1981 e $1996(n=3.161)$, pois a partir de 1981 começaram a nascer as progênies dos rebanhos separados, e somente estas fêmeas têm registro do peso à seleção (P550). A partir deste arquivo, novilhas e vacas foram separadas, gerando dois arquivos distintos.

Após uma série de análises (MIXED; SAS, 2000) dos efeitos de rebanho de nascimento, ano do parto, ano de nascimento e touro em monta, o grupo contemporâneo para os registros repetidos de DIAP das vacas e vacas e novilhas foi definido como ano do parto $\mathrm{x}$ touro em monta, sem incluir o rebanho de nascimento pelo fato do NeT ter recebido, eventualmente, fêmeas descartadas dos rebanhos controle e seleção, ficando alguns grupos contemporâneos com reduzido número de observações. Para os registros de DIAP das novilhas o grupo contemporâneo foi definido como ano $\mathrm{x}$ rebanho de nascimento, embora em muitas análises os efeitos foram considerados separadamente para testar a significância de rebanho. Neste arquivo não foi possível considerar, como no caso das vacas e vacas e novilhas, o efeito do touro em monta pelo fato das novilhas entrarem em monta com as vacas, sendo em pequeno número nos lotes de monta.

Provavelmente, as vacas vazias após o término da estação de monta são as de mérito genético pior para habilidade de conceber durante uma estação de monta restrita, e, portanto, o fato de ignorar estes animais pode ocasionar a exclusão das informações potencialmente mais valiosas sobre a diferença genética entre eles (Notter, 1988; Meyer et al., 1990). Johnston \& Bunter (1996) recomendaram somar 21 dias ao mais alto registro de DIAP dentro do grupo contemporâneo, após testar e discutir três métodos para designar um valor predito para as vacas não paridas. Dois dos métodos baseavam-se na soma de um valor fixo ao maior registro de DIAP dentro do grupo contemporâneo ( 21 ou 42 dias) e o terceiro, já usado anteriormente por Meyer et al. (1990), baseava-se na teoria de limiar para encontrar um só valor a ser designado aos registros de monta sem sucesso, entretanto, o valor encontrado pode não ser mais alto que os valores mais altos dos registros válidos de DIAP pelo fato do método assumir distribuição normal, o que provavelmente não é o que ocorre, e assim, vacas paridas podem ser incorretamente comparadas às não paridas. Os autores ressaltam que pequena diferença foi observada entre os dois primeiros métodos (21 ou 42 dias), mas que 
considerando o método de 21 dias, os valores designados foram, em média, similares ao obtido a partir da teoria de limiar, com a vantagem de evitar o problema dos valores penalizados serem menores que os registros válidos.

Assim, a todo registro de monta sem DIAP foi designado um valor somandose 21 dias ao maior registro de DIAP do grupo contemporâneo em que a fêmea estava (Johnston \& Bunter, 1996), penalizando as fêmeas que entraram na monta e não pariram. Para as novilhas este procedimento foi feito com os registros de primeira monta e não com o de primeiro parto, que nem sempre é decorrente do primeiro ano de monta, e para as vacas e novilhas (nascidas de 1981 a 1996) separadamente das vacas e novilhas do arquivo completo (montas de 1978 a 1998 e fêmeas nascidas de 1961 a 1996). Este procedimento foi feito para todas as fêmeas que estavam em grupos contemporâneos com mais de 4 observações de DIAP. Pela ausência de diagnóstico de prenhez, neste processo foram penalizadas também aquelas fêmeas que emprenharam e que tiveram aborto precoce não percebido pelo pessoal de campo. Foram penalizadas cerca de $25 \%$ das observações válidas de DIAP nos três arquivos descritos anteriormente.

Os dados foram analisados usando o procedimento para modelos lineares mistos (MIXED; SAS, 2000) a fim de testar os efeitos fixos e covariáveis e obter as médias ajustadas. Neste procedimento as médias de quadrados mínimos são provenientes da mesma matriz L usada para obtê-las no GLM, mas os erros-padrão são ajustados para os efeitos aleatórios do modelo (Littel et al., 1996). Os modelos ajustados incluíram, para novilhas, os efeitos fixos de rebanho e ano de nascimento (grupo contemporâneo), interação rebanho x ano de nascimento, e as covariáveis exploratórias peso à seleção (P550) e idade na entrada da monta; e para as vacas e vacas e novilhas os efeitos de grupo contemporâneo (ano do parto + touro em monta), rebanho de nascimento, estado reprodutivo anterior, classe de idade da vaca na entrada da monta e as covariáveis P550 e peso na entrada da monta (PEM). Um modelo alternativo, considerando ano de nascimento e a interação rebanho x ano de nascimento (e não mais idade na entrada da monta), foi ajustado para novilhas e vacas a fim de obter as médias ajustadas de DIAP por rebanho $\mathrm{x}$ ano de nascimento e as soluções de ano de nascimento para estimar a tendência ambiental. Na análise do arquivo completo o P550 não foi 
considerado pois só houve registro deste peso a partir das progênies de 1981, e para as vacas nascidas antes de 1981, antes da separação dos rebanhos, o rebanho de nascimento foi igualado ao rebanho de monta.

$\mathrm{Na}$ análise de registros repetidos, a matriz de covariâncias residuais (R) ajustada para os registros de uma mesma vaca foi a auto-regressiva de primeira ordem, com homogeneidade de variâncias para os arquivos de vacas, vacas e novilhas sem as não paridas e para o arquivo completo, e com heterogeneidade de variâncias para o arquivo de vacas e novilhas incluindo as não paridas. Estas matrizes acomodam o padrão geral das covariâncias decrescendo com o aumento do intervalo entre as medidas, entretanto este decréscimo é uniforme, diminuindo o número de parâmetros a serem estimados. A estrutura de $\mathrm{R}$ foi escolhida, dentre outras, com base no menor valor do critério de informação de Akaike (Littel et al., 1996).

Em todos os modelos descritos acima foram testados também os efeitos do sexo do bezerro, do coeficiente de endogamia e do coeficiente de geração (estes últimos foram incluídos ou um ou outro, como covariável), além de todas as interações possíveis, sendo em geral não significativos $(\mathrm{P}>0,05)$. Com os mesmos efeitos fixos (com exceção das novilhas que foi considerado rebanho + ano de nascimento) os componentes de variância genético aditivo e permanente de ambiente foram estimados sob modelo animal no MTDFREML (Boldman et al., 1995). O arquivo de genealogia, com 5829 animais, foi estruturado considerando os pais das primeiras progênies (19791981) como fundadores. Para os arquivos das fêmeas nascidas a partir de 1981 e com registros penalizados, foram estimados os valores genéticos do DIAP da primeira monta (novilhas) e de todas as montas (vacas e novilhas). 


\subsection{RESULTADOS E DISCUSSÃO}

\subsubsection{Os valores observados}

A média de DIAP sem considerar as fêmeas não paridas foi 328 dias, com coeficiente de variação muito baixo $(7,6 \%)$, pela própria definição do caracter, já que ele contém a gestação com até mais noventa dias da estação de monta. Considerando período de gestação médio em Nelore de 295 dias e coeficiente de variação de 2\% (Pereira et al., 2000), o tempo médio pré-concepção na estação de monta (ou período de serviço) foi 34 dias, e as montas concentradas entre o primeiro e segundo terços da estação de monta, deslocando a curva de distribuição dos valores de DIAP para a esquerda (Figura 1). Com uma grande amostra de partos de fêmeas Nelore, Pereira et al. (2000) observaram média de 323 dias, com coeficiente de variação de 7,9\%. Nos arquivos incluindo as não paridas, a média e a variação (345 dias com coeficiente de variação de 11\%) foram logicamente maiores, pois foram somados 21 dias, introduzindo variabilidade e provocando um outro pico, menor que o dos registros observados, na curva de distribuição (Figura 1). Um problema que advém da própria definição do caracter dias ao parto é o valor mínimo considerado normal, que deve ser o menor valor aceitável para uma gestação normal. Ponzoni \& Gifford (1994) alertam que em um sistema de avaliação genética usando informações de vários parentes, gestações anormais curtas poderiam fornecer valores muito favoráveis para DIAP afetando não só a estimativa do valor genético do próprio indivíduo, mas também a de seus parentes, incorretamente.

Uma das propriedades desejáveis atribuídas aos dias ao parto, ou equivalentemente dia do parto, como variável reprodutiva é a sua variação contínua, que contrasta com a natureza discreta $\left(\begin{array}{lll}0 & \text { e } & 1\end{array}\right)$ da variável alternativa sucesso ao parto (Ponzoni \& Gifford, 1994), entretanto ela não apresenta distribuição normal (Figura 1). Meyer et al. (1990), Ponzoni \& Gifford (1994) e Gressler et al. (2000), utilizando transformações, falharam na tentativa de normalizar a variável, não obtendo efeito deste procedimento sobre os resultados obtidos. Em muitos outros estudos, entre eles os de 
Macneil \& Newman (1994), Johnston \& Bunter (1996), Archer et al. (1998), Bergmann et al. (1998) e Pereira et al. (2000), nenhuma transformação foi feita e os registros de dias ao parto foram analisados na escala original, procedimento também adotado no presente estudo.

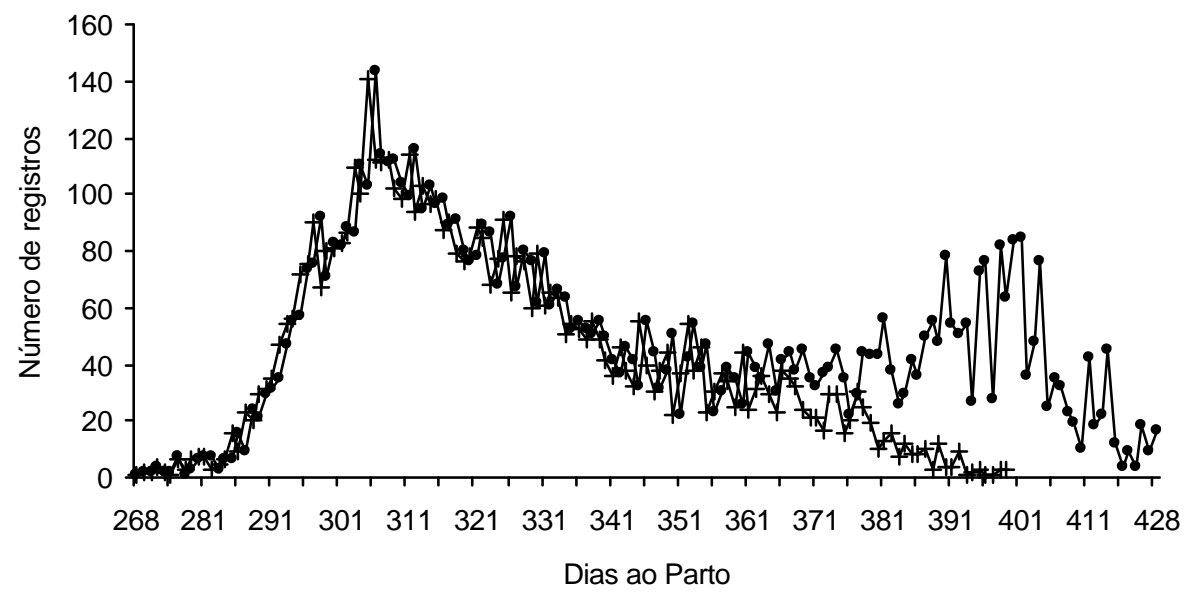

Figura 1 - Distribuição dos registros observados de dias ao parto, dos arquivos de novilhas e vacas sem considerar (+) e considerando as fêmeas não paridas $(\bullet)$.

\subsubsection{Fontes de variação}

O grupo contemporâneo foi altamente significativo $(\mathrm{P}<0,01)$ tanto para as novilhas, para as vacas, como para as duas categorias juntas. A média de registros de DIAP por grupo contemporâneo foi 16, 10 e 12 nos arquivos de novilhas, vacas e vacas e novilhas, sendo que $21 \%$, $45 \%$ e $28 \%$ dos registros ficaram em grupos com menos de 10 observações, respectivamente. As médias ajustadas de DIAP para os efeitos de rebanho de nascimento são apresentadas na Tabela 1 .

O rebanho de nascimento foi significativo $(\mathrm{P}<0,05)$ para as novilhas nos dois arquivos, sem considerar e considerando as fêmeas não paridas que tiveram o registro 
incluído por penalização, e, apesar do NeS apresentar sempre a maior média de DIAP, este não foi significativamente diferente do $\mathrm{NeC}$. Novamente, mesmo sendo não significativo, para as vacas e vacas e novilhas (com exceção do arquivo completo) as médias do $\mathrm{NeS}$ foram mais altas em relação ao $\mathrm{NeC}$ e $\mathrm{NeT}$, porém associadas a altos erros-padrão. Para o arquivo completo (incluindo todas as fêmeas participantes), NeT apresentou média maior e significativamente $(\mathrm{P}=0,05)$ diferente da média de $\mathrm{NeC}$, o que se explica pelo fato de ter sido o rebanho mais flexível na formação e na reposição das fêmeas, recebendo no início as vacas mais velhas do rebanho original e no decorrer dos anos eventualmente aquelas descartadas dos rebanhos $\mathrm{NeS}$ e $\mathrm{NeC}$ e, possivelmente, menos férteis.

Tabela 1. Número de animais e de registros e médias ajustadas para dias ao parto $(+$ erro-padrão) para o efeito de rebanho.

\begin{tabular}{lcccccc}
\hline & novilhas & $\begin{array}{c}\text { novilhas com as } \\
\text { não paridas }\end{array}$ & vacas & $\begin{array}{c}\text { novilhas e } \\
\text { vacas }\end{array}$ & $\begin{array}{c}\text { novilhas e } \\
\text { vacas com } \\
\text { não paridas }\end{array}$ & $\begin{array}{c}\text { novilhas e } \\
\text { vacas com as } \\
\text { não paridas }\end{array}$ \\
\hline Animais & 761 & 926 & 636 & 793 & 928 & 1406 \\
Regis tros & 761 & 926 & 2359 & 3159 & 4212 & 7228 \\
Rebanho & $\mathrm{P}=0,017$ & $\mathrm{P}=0,004$ & $\mathrm{NS}$ & $\mathrm{NS}$ & $\mathrm{NS}$ & $\mathrm{P}=0,026$ \\
$\mathrm{NeC}$ & $328 \pm 2^{\mathrm{ab}}$ & $347 \pm 3^{\mathrm{ab}}$ & $315 \pm 7$ & $319 \pm 6$ & $335 \pm 9$ & $333 \pm 3^{\mathrm{a}}$ \\
$\mathrm{NeS}$ & $333 \pm 1^{\mathrm{a}}$ & $354 \pm 2^{\mathrm{a}}$ & $332 \pm 5$ & $330 \pm 4$ & $340 \pm 6$ & $339 \pm 2^{\text {ab }}$ \\
$\mathrm{NeT}$ & $328 \pm 1^{\mathrm{b}}$ & $345 \pm 2^{\mathrm{b}}$ & $323 \pm 3$ & $327 \pm 3$ & $338 \pm 4$ & $343 \pm 1^{\mathrm{b}}$ \\
\hline
\end{tabular}

a , b, médias na mesma coluna com diferentes letras são significativamente $(\mathrm{P}<0,05)$ diferentes. ${ }^{1}$, todas as vacas das estações de monta de 1978-1998.

Os resultados com os arquivos incluindo as fêmeas não paridas podem ser considerados os mais importantes, funcionando como um tipo de análise da taxa de prenhêz (Ponzoni, 1992; Johnston \& Bunter, 1996), uma vez que as fêmeas que foram para monta e não pariram em determinado ano receberam os mais altos valores de DIAP. A correlação genética de $-0,97$ entre dia do parto (incluindo as fêmeas não paridas) e sucesso ao parto (0 e 1), estimada por Johnston \& Bunter (1996), indica que eles são geneticamente o mesmo caracter, embora os autores atentem que a natureza binária do 
caracter sucesso ao parto não foi levada em conta e ele foi analisado por técnicas para caracteres com distribuição normal. Os resultados encontrados aqui mostraram que o desempenho das fêmeas selecionadas para maior peso aos 18 meses de idade (P550) não diferiu significativamente do desempenho daquelas selecionadas para a média de P550, sugerindo, indiretamente, taxas de prenhêz semelhantes nos três rebanhos. Archer et al. (1998a) analisando o desempenho reprodutivo das fêmeas do experimento de seleção com bovinos Angus na Austrália não observaram diferenças significativas entre as selecionadas para maior ganho de peso diário e aquelas aleatoriamente selecionadas, tanto para dia do parto como para taxa de prenhêz, apesar dos animais do rebanho selecionado apresentarem, em média, peso $14 \%$ acima da média dos animais do rebanho controle aos 365 dias de idade (Parnell et al., 1997). Os autores observaram ainda períodos de gestação similares nas duas linhas seleção. $\mathrm{Na}$ análise dos caracteres de reprodução das fêmeas do experimento de seleção com bovinos Angus na Nova Zelândia, Morris et al. (1992) também não encontraram diferenças significativas para porcentagem de vacas parindo e taxa de desmama das fêmeas selecionadas para maior peso a um ano de idade e daquelas aleatoriamente selecionadas. Neste experimento os animais da linha selecionada são, em média, 19\% mais pesados a um ano de idade que aqueles do rebanho controle (Baker et al., 1991).

No presente trabalho, apesar dos rebanhos serem criados nas mesmas condições ambientais e de manejo, o tamanho dos lotes do $\mathrm{NeC}$ sempre foi menor que os dos rebanhos NeS e NeT mas a dimensão dos piquetes de monta foi sempre a mesma, fato este que poderia ter favorecido as fêmeas do rebanho controle devido à maior disponibilidade de forragem durante o período de monta. Este efeito é levado em conta quando o touro em monta (ou equivalentemente o lote) foi incluído no grupo contemporâneo, que não foi feito para as novilhas devido ao reduzido número de observações nas subclasses.

As médias ajustadas de DIAP para os efeitos de prenhêz anterior, classe de idade na entrada da monta, e os coeficientes de regressão para os efeitos de idade na entrada da monta, pesos à seleção e na entrada da monta são apresentadas na Tabela 2. 
Tabela 2. Médias ajustadas de dias ao parto ( \pm erro-padrão) para os efeitos de prenhez anterior e classe de idade na entrada da monta, coeficientes de regressão $(+$ erro-padrão) para os efeitos de idade na entrada da monta, pesos à seleção (P550) e na entrada da monta (PEM), e variâncias genética aditiva, permanente de ambiente e residual, herdabilidade e repetibilidade.

\begin{tabular}{|c|c|c|c|c|c|c|}
\hline & novilhas & $\begin{array}{l}\text { novilhas } \\
\text { com não } \\
\text { paridas }\end{array}$ & vacas & $\begin{array}{c}\text { novilhas e } \\
\text { vacas }\end{array}$ & $\begin{array}{c}\text { novilhas e } \\
\text { vacas com não } \\
\text { paridas }\end{array}$ & $\begin{array}{c}\text { novilhas e } \\
\text { vacas com } \\
\text { não } \\
\text { paridas }^{1}\end{array}$ \\
\hline \multicolumn{7}{|l|}{ Prenhêz } \\
\hline anterior & & & $\mathrm{P}<0,001$ & $\mathrm{P}<0,001$ & $\mathrm{P}<0,001$ & $\mathrm{P}<0,001$ \\
\hline Não & & & $316 \pm 2$ & $317 \pm 1$ & $321 \pm 2$ & $322 \pm 1$ \\
\hline Sim & & & $330 \pm 1$ & $334 \pm 1$ & $355 \pm 2$ & $354 \pm 1$ \\
\hline idade monta & & & $\mathrm{P}<0,001$ & $\mathrm{P}<0,001$ & $\mathrm{P}<0,001$ & $\mathrm{P}<0,001$ \\
\hline 2 anos & & & & $336 \pm 2^{a}$ & $354 \pm 3^{\mathrm{a}}$ & $354 \pm 2^{\mathrm{a}}$ \\
\hline 3 anos & & & $331 \pm 2^{\mathrm{a}}$ & $330 \pm 1^{\mathrm{b}}$ & $343 \pm 2^{b}$ & $343 \pm 1^{\mathrm{b}}$ \\
\hline 4 anos & & & $324 \pm 1^{\mathrm{b}}$ & $325 \pm 1^{\mathrm{c}}$ & $336 \pm 2^{c}$ & $335 \pm 1^{\mathrm{c}}$ \\
\hline 5 anos & & & $319 \pm 1^{\mathrm{c}}$ & $319 \pm 1^{\mathrm{d}}$ & $328 \pm 2^{d}$ & $329 \pm 1^{\mathrm{de}}$ \\
\hline$>5$ anos & & & $319 \pm 1^{\mathrm{c}}$ & $318 \pm 1^{\mathrm{d}}$ & $328 \pm 2^{\mathrm{d}}$ & $330 \pm 1^{\mathrm{e}}$ \\
\hline $\begin{array}{l}\text { idade monta } \\
\text { (dias) }\end{array}$ & $\mathrm{P}<0,001$ & $\mathrm{P}<0,001$ & & & & \\
\hline Linear & $-0,05 \pm 0,01$ & $-0,23 \pm 0,04$ & & & & \\
\hline P550 (kg) & NS & NS & NS & NS & $\mathrm{P}=0,041$ & \\
\hline Linear & $-0,09 \pm 0,05$ & $-0,05 \pm 0,07$ & $0,04 \pm 0,03$ & $-0,02 \pm 0,02$ & $-0,07 \pm 0,03$ & \\
\hline PEM (kg) & & & $\mathrm{P}=0,037$ & $\mathrm{P}<0,001$ & $\mathrm{P}<0,001$ & $\mathrm{P}<0,001$ \\
\hline Linear & & & $-0,03 \pm 0,01$ & $-0,05 \pm 0,01$ & $-0,10 \pm 0,02$ & $-0,09 \pm 0,01$ \\
\hline$\sigma_{a}^{2}{ }^{2}$ & 41,03 & 85,53 & 40,36 & 8,86 & 146,74 & 199,14 \\
\hline$\sigma_{c}^{2}{ }^{3}$ & & & 52,72 & 68,34 & 103,01 & 66,19 \\
\hline$\sigma^{2}{ }^{4}$ & 549,79 & 1063,84 & 403,27 & 442,70 & 953,21 & 991,92 \\
\hline$h^{2} \pm e p^{5}$ & $0,07 \pm 0,06$ & $0,07 \pm 0,06$ & $0,08 \pm 0,04$ & $0,02 \pm 0,02$ & $0,12 \pm 0,03$ & $0,16 \pm 0,02$ \\
\hline$r^{6}$ & & & 0,19 & 0,15 & 0,21 & 0,21 \\
\hline
\end{tabular}


$\mathrm{O}$ peso à seleção $(\mathrm{P} 550)$ só foi significativo $(\mathrm{P}<0,05)$ para os registros de vacas e novilhas considerando as fêmeas não paridas, concordando, de um modo geral, com os resultados obtidos para rebanho. O coeficiente de regressão de P550 em relação a DIAP foi igual a -0,07, mostrando tendência das mais pesadas à seleção apresentarem valores mais baixos de DIAP. Tendência semelhante foi observada para o peso na entrada da monta (PEM), incluído nos modelos para vacas e vacas e novilhas, que, como esperado, esteve associado a menores DIAP.

Como a diferença entre o rebanho $\mathrm{NeC}$ e os selecionados ( $\mathrm{NeS}$ e $\mathrm{NeT}$ ) está no P550, e, consequientemente nos pesos em idades posteriores, como os pesos na entrada da monta, uma série de análises foi realizada sem o P550 e o PEM. Para os registros das novilhas, modelos sem o efeito de rebanho forneceram os mesmos resultados para P550, o mesmo ocorreu no modelo sem P550, não alterando o resultado do efeito de rebanho, apesar das médias do DIAP de NeS serem sempre as mais altas. Para as vacas e vacas e novilhas, no ajuste de modelos sem P550 e com PEM, de modelos com PEM e sem P550, e de modelos omitindo os dois pesos, o efeito de rebanho permaneceu não significativo. Retirando o efeito do PEM no modelo de análise de vacas e novilhas com as não paridas, o efeito do P550 permaneceu significativo $(\mathrm{P}<0,01)$, com um coeficiente de regressão mais alto $(-0,11 \pm 0,03)$.

Estas análises reafirmam os resultados obtidos (Tabela 1), sugerindo que não há diferenças no desempenho de DIAP nos rebanhos experimentais. Os trabalhos com dados de experimentos de seleção em bovinos de corte não têm encontrado diferenças significativas entre o desempenho reprodutivo das fêmeas dos rebanhos selecionados para maior crescimento e dos rebanhos não selecionados, qualquer que seja o caracter estudado (Wolfe et al., 1990; Morris et al., 1992, Parnell, 1994; Archer et al., 1998a). Herd (1995), analisando duas linhas divergentes (alto peso-HW e baixo peso-LW) do experimento com Angus na Austrália, observou que as vacas da linha HW apresentaram requerimento energético diário de mantença semelhante às vacas da linha LW. Isto é, apesar da diferença no peso corporal das vacas provenientes das duas linhas seleção (24\%), as vacas HW necessitaram cerca de $79 \%$ da energia metabolizável por dia requerida pelas vacas LW para manter cada quilograma de peso corporal. Isto se deve ao 
fato das vacas HW apresentarem mais gordura e menos proteína por unidade de peso vivo que as vacas $\mathrm{LW}$, e o custo de manutenção de um quilograma de proteína é aproximadamente 1,05 megajoule de energia metabolizável, enquanto que o custo para manter um quilograma de gordura tende a ser negativo (-0,11 megajoule). Este fato pode ser uma explicação para o desempenho reprodutivo semelhante entre linhas seleção apesar da diferença nos caracteres de crescimento. Vale ressaltar que nenhum desses experimentos teve mais que 5 gerações de seleção avaliadas, o que pode não ter sido suficiente para que problemas reprodutivos se manifestem.

Vacas que falharam no ano anterior, incluindo as novilhas (nos três arquivos de novilhas e vacas), emprenharam mais cedo na estação de monta que as paridas no ano anterior $(\mathrm{P}<0,01)$, concordando com os resultados de Macneil \& Newman (1994), que analisaram os dias ao parto das fêmeas Hereford da "Linha 1 de Montana" e Meyer et al. (1990), com dados de fêmeas Angus, Hereford e cruzadas. Johnston \& Bunter (1996) não encontraram efeito do estado reprodutivo anterior no desempenho do caracter dia do parto trabalhando com grande número de registros de fêmeas Angus. Para os registros das vacas somente, a interação estado reprodutivo anterior e classe de idade à monta foi significativa $(\mathrm{P}=0,003)$, com as fêmeas de 3 anos paridas no ano anterior apresentando maiores médias de DIAP que as também paridas anteriormente nas classes de 4, 5 e 6 anos. Estas fêmeas ainda estão em crescimento e amamentando um bezerro e os aportes nutricionais podem não ter sido suficientes para crescimento e reprodução. Davis et al. (1993), trabalhando com o desempenho de fêmeas cruzadas de um experimento de seleção para taxa de prenhêz, observaram efeito significativo desta interação, com vacas lactentes de segundo e terceiro partos parindo mais tarde.

A idade de entrada na monta teve efeito significativo $(\mathrm{P}<0,01)$ nos registros de novilhas, apesar de todas as fêmeas terem sido expostas pela primeira vez ao redor de 24 meses de idade. Os registros originais, sem considerar as fêmeas não paridas, apresentam uma variação maior na idade de entrada na monta $(2,3 \pm 0,4$ anos $)$ pois são registros de primeiro parto com partos resultantes de monta aos 2 anos e partos das que falharam no primeiro ano, resultantes de monta aos 3 anos de idade. Para os registros de DIAP resultantes de primeira monta e considerando as fêmeas que não pariram a 
variação de idade é muito menor $(2,1 \pm 0,1$ anos $)$. Como observado também em outros estudos (Rege \& Famula, 1993, Johnston \& Bunter, 1996, Archer et al., 1998a, MacGregor \& Casey, 1999), para vacas e vacas e novilhas a idade de entrada na monta foi significativa, com as médias de DIAP das fêmeas de dois e três anos sendo mais altas que as demais. Nos arquivos de vacas e novilhas, incluindo as não paridas, novamente as maiores médias de DIAP são decorrentes de primeiro e segundo partos, podendo ser interpretadas como menores taxas de prenhêz. Com o descarte das fêmeas inférteis, principalmente após a segunda monta, a taxa de prenhêz aumenta, como mostram as médias mais baixas de DIAP nas classes 4, 5 e 6 (Tabela 2). Para o arquivo de vacas e novilhas incluindo as não paridas, as médias estimadas de DIAP por rebanho e idade de entrada na monta até dez anos são mostradas na Figura 2, ilustrando os desempenhos longitudinalmente semelhantes nos três rebanhos, ou seja, interação rebanho x idade na entrada da monta não significativa.

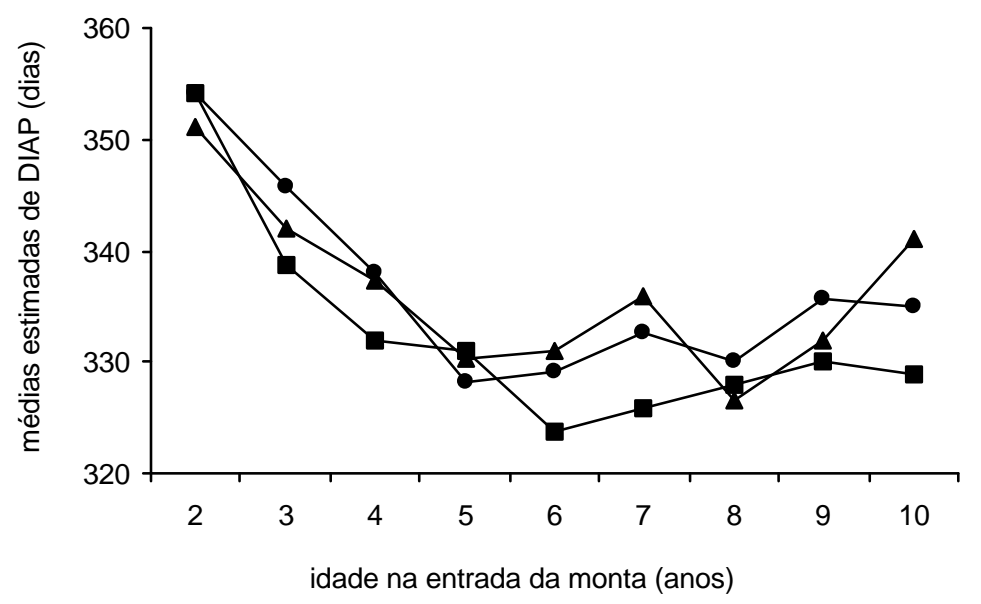

Figura 2 - Médias estimadas de dias ao parto de novilhas e vacas, incluindo as não paridas, nos três rebanhos (controle $\mathbf{\square}$, seleção •, tradicional • ).

A expressão fenotípica dos dias ao parto é composta da combinação dos efeitos do bezerro controlando o início do parto, efeitos da mãe associados com o início do ciclo estral e fertilidade, e os efeitos do touro em serviço associado com a qualidade do sêmen e da libido. O modelo biológico total é recursivo, já que a data do parto 
anterior, em conjunção com o anestro pós-parto determina completamente a data do ciclo estral no corrente ano (MacNeil \& Newman, 1994). Assim, alguns estudos sobre a modelagem do DIAP têm observado efeitos significativos da duração da gestação (MacGregor \& Casey, 1999), do peso ao nascer ou sexo do bezerro (MacNeil \& Newman, 1994, Bergmann et al., 1998) que influencia a duração da gestação, assim como de fatores relacionados ao ciclo reprodutivo anterior, como peso ao nascer ou ao desmame (MacGregor \& Casey, 1999) e dias ao parto (Rege \& Famula, 1993, Bergmann et al., 1998) anteriores. A inclusão, no modelo, de fatores que são dependentes do parto anterior reduz a amostra a registros das vacas que pariram no ano anterior, e a inclusão de fatores relacionados ao parto presente, como peso ao nascer do bezerro, impossibilita a inclusão das fêmeas não paridas na análise. Em uma análise que não considera estes fatores, como no presente estudo, supõem-se que eles estejam ocorrendo aleatoriamente nas subclasses estudadas, não influenciando as soluções dos fatores fixos de interesse.

\subsubsection{Componentes de variância e parâmetros genéticos}

As herdabilidades para o caracter DIAP (Tabela 2) foram baixas, além de associadas a erros-padrão muitas vezes da mesma magnitude do próprio parâmetro. Valores entre 0,02 a 0,09 foram relatados em grande parte dos trabalhos (Meyer et al., 1990, MacNeil \& Newman, 1994, Morris \& Cullen, 1994; Johnston \& Bunter, 1996; Gressler et al., 2000; Morris et al., 2000; Pereira et al., 2000). Quando os registros das fêmeas não paridas foram considerados nos arquivos conjuntos de vacas e novilhas, a herdabilidade do DIAP passou para 0,12 a 0,16, com erros-padrão menores pelo maior número de registros, o que se explica pelo fato dos arquivos sem as fêmeas não paridas serem amostras mais selecionadas que quando se inclui os registros de todas aquelas que foram escolhidas para reprodução (mesmo das inférteis), ou seja, a observação de caracteres de reprodução somente das fêmeas férteis, que parem pelo menos uma vez, contribui para mascarar a variabilidade das características e as diferenças genéticas entre os animais (Notter, 1988; Meyer et al., 1990). Quando esta variabilidade é re- 
introduzida, designando-se penalidades às fêmeas que não pariram, as diferenças genéticas entre os animais ficam evidentes. Este aumento na herdabilidade não foi observado no arquivo das novilhas, cujas estimativas de herdabilidade foram iguais, considerando ou não as fêmeas não paridas. Pereira et al. (2000) não observaram qualquer alteração na estimativa de herdabilidade quando os registros das fêmeas não paridas foram considerados na análise, através da penalização pelo método de 21 dias descrito anteriormente.

Os valores genéticos, obtidos em análises univariadas, para o DIAP de novilhas (Figura 3) e de vacas e novilhas (Figura 4), ambos incluindo os registros das fêmeas não paridas, mostram a diminuição do valor genético médio no decorrer dos anos, igual para os três rebanhos $(-0,09 \pm 0,02 \mathrm{dia} /$ ano nas novilhas e $-0,24 \pm 0,04 \mathrm{dia} / \mathrm{ano}$ nas vacas e novilhas), apesar da alta variação na resposta observada para este caracter. Deve ser ressaltado que a brusca diminuição do valor genético das fêmeas nascidas nos últimos anos do experimento pode ser simplesmente devido ao fato dessas fêmeas terem tido menor número de montas, e portanto menor número de falhas que aquelas mais velhas. As soluções do efeito de ano de nascimento obtidas simultaneamente às soluções dos efeitos de animal na análise dos registros de vacas e novilhas, expressas como desvios do ano 1982, fornecem uma estimativa da tendência ambiental para DIAP (Figura 5) igual a $-0,84 \pm 0,32$ dia/ano. Ponzoni (1992) comenta que a escolha da data em que a estação de monta iniciou a cada ano pode contribuir para a mudança ambiental, e a interpretação biológica para tal tendência pode ser inválida. Na tentativa de minimizar este vício, ajustou-se um modelo considerando o efeito do dia da entrada na monta como covariável, e como este foi não significativo, as soluções para ano de nascimento confirmaram a tendência mostrada na Figura 5.

Houve coerência da tendência genética com os resultados obtidos para o efeito de rebanho, e aqueles da interação rebanho $\mathrm{x}$ ano de nascimento, significativa $(\mathrm{P}<0,01)$ para as novilhas e não significativa $(\mathrm{P}=0,06)$ para vacas e novilhas (resultados não mostrados). MacNeil \& Newman (1994) relataram ganho genético praticamente nulo para dias ao parto das matrizes Hereford da Linha 1 de Montana, de 1940 a 1990, após 13 gerações de seleção, enquanto que os valores genéticos estimados para peso a 
desmama e peso a um ano de idade aumentaram, em média, 14,5 kg e 62,4 kg, respectivamente (MacNeil et al., 1992).

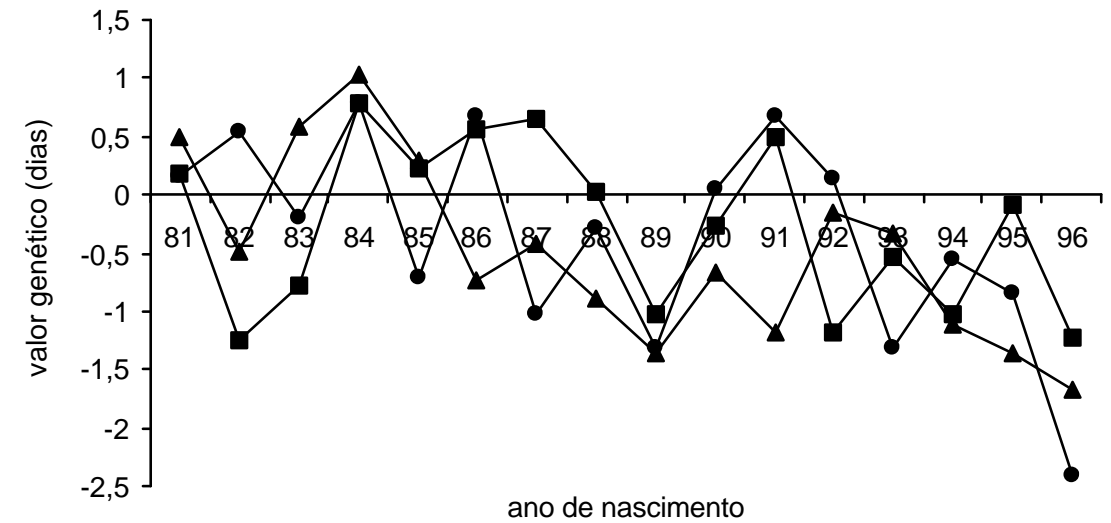

Figura 3 - Valores genéticos médios para dias ao parto da primeira monta, nos três rebanhos (controle घ, seleção •, tradicional • ).

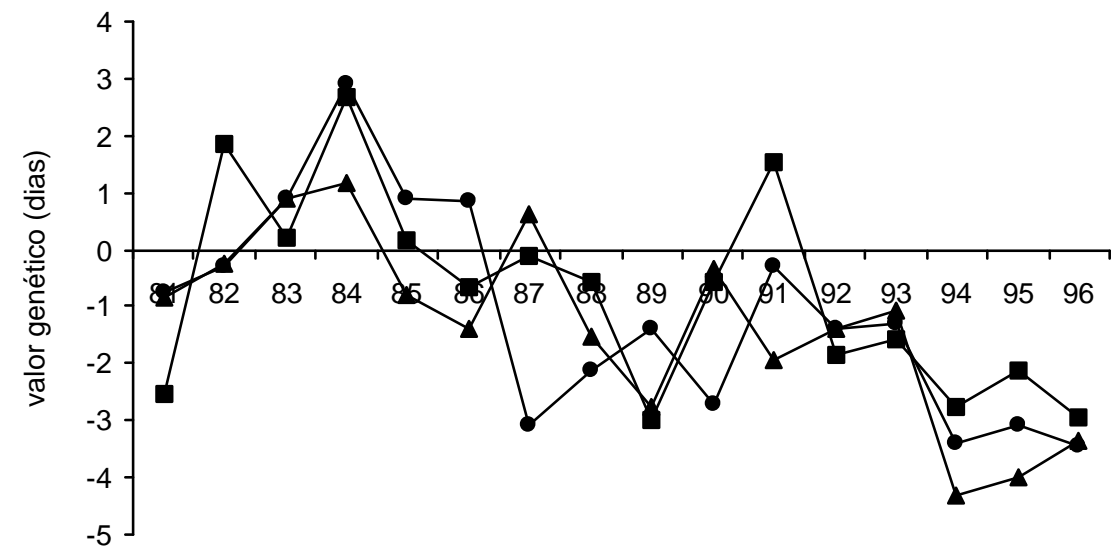

ano de nascimento

Figura 4 - Valores genéticos médios para dias ao parto de novilhas e vacas, nos três rebanhos (controle $\boldsymbol{\bullet}$, seleção $\bullet$, tradicional $\bullet$ ). 
As estimativas de repetibilidade do DIAP (Tabela 2), ficaram entre os valores encontrados em outras publicações (Meyer et al., 1990; Rege e Famula, 1993; Johnston \& Bunter, 1996; Morris et al., 2000; Pereira et al., 2000) e a inclusão das fêmeas não paridas teve efeito sobre estas estimativas.

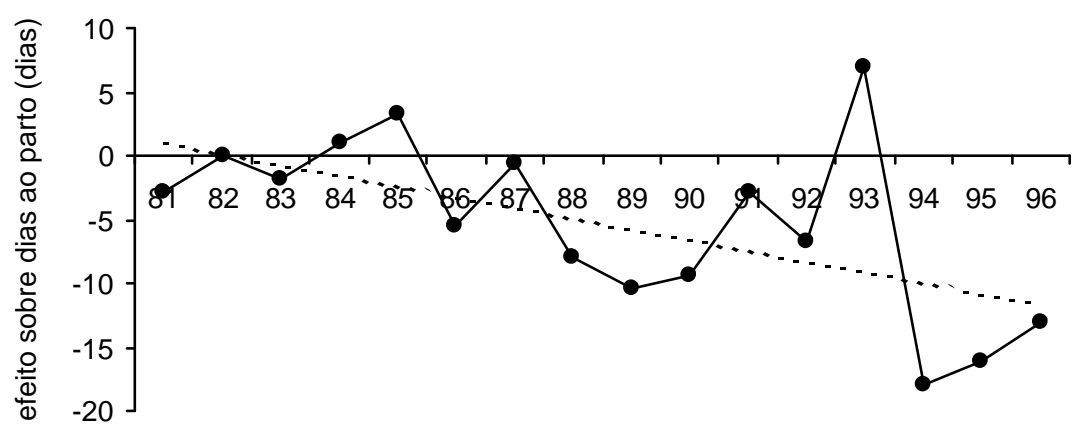

ano de nascimento

Figura 5 - Estimativa da tendência ambiental por ano de nascimento de novilhas e vacas para dias ao parto, expressas como desvio de 1982.

Apesar do caracter DIAP, ou equivalentemente o dia do parto no calendário juliano, ser um dos caracteres mais simples de ser obtido (Ponzoni, 1992) considerando a complexidade da reprodução em fêmeas, os bancos de dados da maioria das associações de raças ou empresas privadas foi organizado de modo a ter registrado somente os nascimentos, isto é, registros provenientes das montas férteis, e não o registro de todas as montas, observações úteis para a inclusão das fêmeas não paridas nas análises. A solução para isso seria considerar a falta de registro em um ano, seguido de registro de parto em ano subseqüente, como uma monta sem sucesso, e assim incluir esta "falta de informação" nas avaliações genéticas. Ponzoni (1992) e Johnston \& Bunter (1996) defendem o uso do DIAP, incluindo as fêmeas não paridas, como o caracter que deve ser considerado nas avaliações genéticas nacionais, pelo fato de medir a taxa de prenhêz, além de identificar as fêmeas com capacidade de emprenhar mais cedo na 
estação de monta. No Brasil, a avaliação genética de uma grande empresa privada de melhoramento genético já inclui o valor genético para dias ao parto das filhas nas avaliações genéticas de reprodutores Nelore (CFM, 1999).

Os resultados encontrados comparando o desempenho reprodutivo de fêmeas selecionadas para peso ao sobreano por 3,5 gerações de seleção (Razook et al., 1998) com fêmeas selecionadas para média deste peso concordam com os trabalhos publicados na última década, tanto com dados experimentais (Wolfe et al., 1990, Morris et al., 1992; MacNeil \& Newman, 1994; Parnell et al., 1994; Archer et al., 1998a) como com dados de campo (Meyer et al., 1991; Johnston \& Bunter, 1996; Mercadante et al., 2000; Silva et al., 2000), indicando que a seleção para peso corporal não comprometeu o desempenho reprodutivo das fêmeas, mesmo estando os três rebanhos sob níveis nutricionais similares.

\subsection{CONCLUSÕES}

A seleção para peso corporal não acarretou diferenças no desempenho reprodutivo das fêmeas, mesmo sendo criadas em condições ambientais similares. Dias ao parto (considerando as fêmeas não paridas) pode ser incluído como um caracter de desempenho reprodutivo em avaliações genéticas pois além de medir a taxa de prenhêz, identifica as fêmeas com capacidade de emprenhar mais cedo na estação de monta. 


\section{DIAS AO PARTO DE FÊMEAS NELORE DE UM EXPERIMENTO DE SELEÇÃO PARA CRESCIMENTO. II - MODELO DE REGRESSÃO ALEATÓRIA}

\section{RESUMO}

Parâmetros genéticos para dias ao parto foram estimados usando um modelo de regressão aleatória, com polinômios ortogonais da idade na monta (em anos) como a covariável independente. Os registros de dias ao parto (4.118) foram provenientes de 926 vacas de 3 rebanhos Nelore experimentais, seleção e tradicional selecionadas para maior peso ao sobreano, e controle selecionadas para a média do peso ao sobreano. As variâncias genéticas aditivas e permanentes de ambiente foram descritas por uma função polinomial de ordem 4, com 9 medidas de erro, resultando em variâncias fenotípicas e genética aditivas altas nas idades mais avançadas, principalmente após a $6^{\mathrm{a}}$ monta. As herdabilidades estimadas aumentaram de 0,08 a 0,28 da $1^{\mathrm{a}}$ à $6^{\mathrm{a}}$ monta. As correlações genéticas foram médias entre o primeiro desempenho e os demais, altas entre os desempenhos adjacentes, e um pouco menores entre os não adjacentes. A seleção para peso não alterou o valor genético médio das vacas dos rebanhos selecionados, entretanto os valores genéticos médios das vacas do rebanho controle mostraram tendência de queda no decorrer dos anos.

\section{SUMMARY}

Genetic parameters for days to calving were estimated using a random regression model, with orthogonal polynomials of age at breeding season (in years) as the independent covariable. The records of days to calving $(4,118)$ came from 926 cows from three experimental Nelore lines, been selection and traditional selected for higher 
yearling weight and control selected for the mean of yearling weight. Genetic and permanent environmental variances were described by a fourth order polynomial function, with 9 measures of error. The phenotypic and additive genetic variances were high in late records, especially after the $6^{\text {th }}$ breeding season. The estimates of heritability increased from 0.08 to 0.28 , from first up to $6^{\text {th }}$ breeding season. The genetic correlations were moderate between the first and the later records, high between the adjacent records, and a little smaller between the no adjacent records. The selection for weight did not alter the average breeding value of cows of selection lines, however the average genetic breeding values of control cows declined through the years.

\subsection{INTRODUÇÃO}

A Estação Experimental de Zootecnia de Sertãozinho (São Paulo, Brasil) iniciou em 1976 um experimento de seleção com animais Nelore a fim de examinar a resposta à seleção para peso corporal em genótipos de interesse nos trópicos, já que os poucos experimentos de seleção no mundo eram com raças européias. Após 15 anos (progênies de 1981 a 1995), passadas 3,5 gerações de seleção, os machos e as fêmeas do rebanho selecionado são, em média, 17 e 16\% mais pesados à seleção que aqueles do rebanho controle (Razook et al., 1998). Até meados da década de 80 muito se discutiu sobre as consequiências da seleção para peso corporal sobre a eficiência de produção, incluindo o desempenho reprodutivo das matrizes, principalmente pelo aumento no peso adulto advindo dessa seleção. Estudos mais recentes têm mostrado que a seleção para maior peso corporal não apresenta efeitos significativos sobre o desempenho reprodutivo das fêmeas (Meyer et al., 1991; Archer et al., 1998a), embora na maioria deles os animais tenham sido criados em ambientes menos restritivos que o tropical.

Dias ao parto tem sido incluído nas avaliações genéticas como um caracter de desempenho reprodutivo das matrizes (Johnston \& Bunter, 1996; CFM, 1999). Registros de dias ao parto durante a vida reprodutiva da matriz são caracterizados como dados longitudinais, ou medidas repetidas no tempo, e geralmente estudados com modelo de 
repetibilidade que considera todas as medidas como o mesmo caracter (como em Johnston \& Bunter, 1996; Pereira et al., 2000), ou com modelo uni ou multicaracter, que considera cada medida como um caracter diferente, geralmente os primeiros dois ou três desempenhos (como em Johnston \& Bunter, 1996; Gressler et al., 2000). O modelo de repetibilidade pode não acomodar heterogeneidade de variâncias e o padrão geral das correlações decrescentes conforme aumenta o intervalo entre as medidas e, portanto, não ser adequado para descrever as (co)variâncias genéticas dos desempenhos de dias ao parto durante a vida produtiva da matriz. Por outro lado, o modelo multicaracter, com o número de caracteres igual ao número de medidas nas diferentes idades $(n)$, resultaria em análises altamente parametrizadas, com $n(n+1) / 2$ componentes de (co)variâncias para descrever a variação genética (Meyer \& Hill, 1997).

Recentemente tem sido reconhecido que modelos de regressão aleatória e suas funções de covariância resultantes são os mais apropriados para análise de dados longitudinais na área de melhoramento genético. Tais modelos acomodam registros repetidos para caracteres que mudam gradualmente através do tempo, não requerendo pressuposições quanto à constância das variâncias e correlações (Meyer, 2000). No melhoramento animal tem sido usados para modelar registros diários de produção de leite durante a lactação em bovinos leiteiros (Jamrozik et al., 1997a, b; Olori, et al., 1999; Rekaya et al., 1999), assim como crescimento corporal em bovinos de corte (Meyer, 1999 e 2000; Albuquerque \& Meyer $^{1}$ ), embora a metodologia seja apropriada a outros caracteres em que o fenótipo de um indivíduo é uma função contínua, tal como normas de reação e formas morfológicas, entre outros (Kirkpatrick et al, 1990; Meyer \& Hill, 1997). Modelos de regressão aleatória permitem ajustar uma trajetória aleatória para cada indivíduo como desvios de uma trajetória média da população. A trajetória para uma vaca individual pode ser vista como dois conjuntos de regressões sobre a idade: as regressões fixas para todos os indivíduos pertencentes à mesma subclasse (como ano x rebanho, por exemplo) descrevem a forma geral, enquanto as regressões aleatórias descrevem os desvios genéticos a partir das regressões fixas, permitindo que

\footnotetext{
1 ALBUQUERQUE, L.G.; MEYER, K. Estimates of covariance functions for growth from birth to 630
} days of age in Nelore cattle. Journal of Animal Science. 2001. (Trabalho não publicado). 
cada vaca tenha uma forma diferente da trajetória de seus desempenhos em termos genéticos (Jamrozik et al., 1997b).

Análises prévias dos registros de dias ao parto com modelo de repetibilidade não detectaram diferenças significativas entre os desempenhos das vacas provenientes dos rebanhos selecionados e daquelas do rebanho controle (Mercadante et al. ${ }^{2}$ ). No presente trabalho serão analisados todos os desempenhos de dias ao parto simultaneamente. Será feita a modelagem da variação genética aditiva e ambiental usando a técnica de regressão aleatória e o estudo do comportamento genético dos dias ao parto durante a vida produtiva das vacas dos rebanhos selecionados e do controle.

\subsection{MATERIAL E MÉTODOS}

Foram utilizadas informações das vacas pertencentes aos rebanhos experimentais, Nelore Controle $(\mathrm{NeC})$, Nelore Seleção (NeS), e Nelore Tradicional (NeT), da Estação Experimental de Zootecnia de Sertãozinho (EEZS), nascidas entre 1981 e 1996, e participantes das estações de monta de 1983 a 1998. O experimento de seleção iniciou em 1976, com a reorganização e introdução de novas linhagens no rebanho Nelore existente na EEZS, estabelecendo-se os rebanhos $\mathrm{NeC}$, NeS e NeT com 60, 120 e 170 vacas. Foram usados anualmente 4, 6 e até 8 touros selecionados de acordo com o diferencial para peso aos 378 dias obtido após prova de desempenho em confinamento, e as fêmeas selecionadas de acordo com o diferencial para peso aos 550 dias, em regime de pasto. Em $\mathrm{NeS}$ e $\mathrm{NeT}$ foram retidos para reprodução animais com maior diferencial de seleção e para $\mathrm{NeC}$ aqueles de diferencial de seleção nulo. Todos os detalhes do processo seletivo foram descritos por Razook et al. (1998).

2 MERCADANTE, M.E.Z.; PACKER, I.U.; RAZOOK, A.G.; CYRILLO, J.N.S.G.; FIGUEIREDO, L.A. Dias ao parto de fêmeas Nelore de um experimento de seleção para crescimento. I. Modelo de repetibilidade. Revista Brasileira de Zootecnia. 2001. (Trabalho não publicado). 
A variável dias ao parto (DIAP) foi obtida da diferença entre a data do parto e a data da entrada na monta correspondente. Para as vacas que falharam em determinados anos, desde que houvesse o registro de entrada na monta, um registro penalizado foi designado como sendo o maior valor observado de DIAP do grupo contemporâneo (ano do parto + touro em monta) em que ela estava, somado a 21 dias (Johnston \& Bunter, 1996), somente se este grupo contemporâneo tivesse mais de 4 observações. As novilhas de reposição foram colocadas em monta natural aos dois anos de idade, junto com o restante das matrizes, por 90 dias, em lotes médios de 25 vacas nos $\mathrm{NeS}$ e $\mathrm{NeT}$ e 15 vacas no $\mathrm{NeC}$ para cada touro. As vacas foram descartadas voluntariamente por falharem dois anos consecutivos, por má habilidade materna, ou por idade avançada, ao redor de 11 anos. Registros provenientes de montas acima de 10 anos foram desconsiderados pelo pequeno número de animais. Um resumo dos dados é apresentado na Tabela 1. A maioria das vacas (56\%) tem mais que 3 registros de DIAP, com apenas $26 \%$ delas com mais de 6 registros.

Tabela 1. Estrutura dos dados, média e desvio-padrão de dias ao parto (DIAP).

\begin{tabular}{lr}
\hline Registros & 4.118 \\
Animais na análise & 5.754 \\
Touros & 125 \\
Mães & 548 \\
Animais com registros & 926 \\
com 1 registro & 155 \\
com 2 registros & 117 \\
com 3 registros & 135 \\
com 4 registros & 105 \\
com 5 registros & 94 \\
com 6 registros & 80 \\
com 7 registros & 59 \\
com 8 registros & 88 \\
com 9 registros & 93 \\
Média (dias) & 344 \\
Desvio-padrão (dias) & 36 \\
\hline
\end{tabular}


Os registros de DIAP foram analisados simultaneamente ajustando um modelo de regressão aleatória com idade na monta (em anos) como a covariável independente através de polinômios ortogonais de ordem quatro $(\mathrm{k}=4)$, usando o programa DxMRR (Meyer, 1998), que estima as covariâncias entre os coeficientes de regressão aleatória por máxima verossimilhança restrita. As idades na monta foram transformadas em escala logarítmica como sugerido por Meyer (1999) com a finalidade de diminuir a distância entre os registros tomados cedo e tarde na vida do animal, reduzindo o grande efeito que os valores mais afastados da média tem em uma análise de regressão.

O modelo geral pode ser representado por:

$$
\mathrm{y}_{\mathrm{ij}}=\mathrm{F}_{\mathrm{ij}}+\sum_{\mathrm{r}=0}^{\mathrm{k}-1} \beta_{\mathrm{r}} \phi_{\mathrm{r}}\left(\mathrm{a}_{\mathrm{ij}}^{*}\right)+\sum_{\mathrm{r}=0}^{\mathrm{k}-1} \alpha_{\mathrm{ir}} \phi_{\mathrm{r}}\left(\mathrm{a}_{\mathrm{ij}}^{*}\right)+\sum_{\mathrm{r}=0}^{\mathrm{k}-1} \rho_{\mathrm{ir}} \phi_{\mathrm{r}}\left(\mathrm{a}_{\mathrm{ij}}^{*}\right)+\varepsilon_{\mathrm{ij}},
$$

onde $\mathrm{y}_{\mathrm{ij}}$ é o j-ésimo registro do i-ésimo animal, $\mathrm{a}_{\mathrm{ij}}^{*}$ é a idade ao registro padronizada $(-1 \mathrm{a}+1), \phi_{\mathrm{r}}\left(\mathrm{a}_{\mathrm{ij}}^{*}\right)$ é o r-ésimo polinômio de Legendre da idade, $\mathrm{F}_{\mathrm{ij}}$ é o conjunto de efeitos fixos, $\mathrm{k}$ é a ordem do polinômio, $\beta_{\mathrm{r}}$ são coeficientes de regressão fixa para modelar a média da população, $\alpha_{\text {ir }}$ e $\rho_{\text {ir }}$ são coeficientes de regressão aleatória para modelar os efeitos genético direto e permanente de ambiente, e $\varepsilon_{\mathrm{ij}}$ é o erro aleatório associado ao i-ésimo registro do j-ésimo animal.

Os primeiros quatro polinômios normalizados são $\sqrt{1} / 2, \sqrt{3} / 2 a_{j}^{*}$, $-\sqrt{5 / 8}+\sqrt{45 / 8}\left(a_{j}^{*}\right)^{2}$ e $-\sqrt{63 / 8} a_{j}^{*}+\sqrt{175 / 8\left(a_{j}^{*}\right)^{3}}$, e assim um polinômio de ordem 4 envolve potências de idade até 3, já que o primeiro termo é um escalar (Meyer, 2000). O conjunto de efeitos fixos incluiu o grupo contemporâneo (ano do parto + touro em monta), rebanho de nascimento, estado reprodutivo anterior, e as covariáveis pesos à seleção e na entrada da monta. É pressuposto que $\alpha, \rho$ e $\varepsilon$ apresentam distribuição normal com $\mathrm{E}(\alpha)=0, \quad \mathrm{E}(\rho)=0$ e $\mathrm{E}(\varepsilon)=0, \quad \operatorname{var}(\alpha)=\mathrm{k}_{\mathrm{A}}, \quad \operatorname{var}(\rho)=\mathrm{k}_{\mathrm{P}}, \quad \operatorname{var}(\varepsilon)=\operatorname{diag}\left\{\sigma_{\mathrm{e}_{\mathrm{j}}}^{2}\right\} \mathrm{e}$ covariâncias nulas entre eles. $\mathrm{k}_{\mathrm{A}}$ e $\mathrm{k}_{\mathrm{P}}$ são matrizes de covariâncias entre os coeficientes 
de regressão aleatória e $\sigma_{\mathrm{e}_{\mathrm{j}}}^{2}$ as variâncias de medidas de erro, sendo $\sigma_{\mathrm{e}_{\mathrm{j}}}^{2}$ dependente do DIAP $\mathrm{j}=\{1, \ldots, 9\}$.

Análises prévias foram feitas ajustando modelos com polinômios ortogonais com $\mathrm{k}=1, \ldots, 5$, iguais para as três curvas (média e efeitos aleatórios genético aditivo e permanente de ambiente). O modelo com polinômio ortogonal de ordem $4(\mathrm{k}=4)$ foi selecionado com base no menor valor do critério de informação de Akaike, que considera a qualidade do ajuste por meio do valor da função de verossimilhança e penaliza para o número de parâmetros do modelo, favorecendo modelos parcimoniosos (Verbeke \& Molenberghs, 2000). O valores genéticos foram preditos somente para os 6 primeiros desempenhos de DIAP.

\subsection{RESULTADOS E DISCUSSÃO}

Estimativas de covariâncias e correlações entre os coeficientes de regressão aleatória, e seus autovalores associados são apresentados na Tabela 2. A variação devido aos efeitos genético aditivo e permanente de ambiente foi explicada por uma função polinomial de ordem 4, apesar de dois dos coeficientes terem tido contribuição muito pequena para ambos efeitos. Altas correlações entre os coeficientes de regressão fazem com que alguns autovalores sejam negligenciáveis (Albuquerque \& Meyer $^{1}$ ).

Geralmente a qualidade do ajuste aumenta com o número de parâmetros da função que descreve a curva. $O$ valor do $\log$ da função de verossimilhança (logL) para o modelo com $\mathrm{k}=5$ foi menor que aquele do modelo $\mathrm{k}=4$, mas como o valor do critério de informação de Akaike (CIA) penaliza para o número de parâmetros a serem estimados $(\mathrm{CIA}=-2 \log \mathrm{L}+2 \mathrm{q}$, sendo q o número de parâmetros do modelo), o modelo com $\mathrm{k}=4$ teve o menor valor de CIA. Para medidas altamente correlacionadas, há vários autovalores próximos de zero e a informação genética fornecida por $\mathrm{n}$ medidas está totalmente contida por $\mathrm{k}$ combinações lineares correspondentes aos maiores autovalores (Meyer \& Hill, 1997). 
Tabela 2. Estimativas de variâncias (diagonal), covariâncias (abaixo da diagonal) e correlações (acima da diagonal) entre os coeficientes de regressão aleatória da matriz dos coeficientes, e seus autovalores $(\lambda)$, para os efeitos genético aditivo e permanente de ambiente.

\begin{tabular}{crrrr}
\hline 0 & 1 & 2 & 3 & \multicolumn{1}{c}{$\lambda$} \\
\hline Efeito genético aditivo & & & & \\
483,863 & 0,838 & 0,579 & 0,543 & 630,14100 \\
232,329 & 162,784 & 0,905 & 0,814 & 63,35780 \\
84,443 & 76,6030 & 43,980 & 0,650 & 0,0000 \\
34,714 & 30,1674 & 12,519 & 8,43918 & 5,56739 \\
Efeito permanente de ambiente & & & & \\
303,941 & $-0,257$ & $-0,486$ & $-0,373$ & 343,7980 \\
$-33,977$ & 57,469 & $-0,581$ & $-0,786$ & 0,0000 \\
$-73,568$ & $-38,245$ & 75,454 & 0,768 & 148,4360 \\
$-55,431$ & $-50,870$ & 56,919 & 72,791 & 17,4214 \\
\hline
\end{tabular}

Com exceção do modelo $\mathrm{k}=1$, as funções de covariâncias estimadas pelos modelos ajustando polinômios com $\mathrm{k}=2$ a $\mathrm{k}=5$ geraram herdabilidades semelhantes até a $6^{\text {a }}$ medida de DIAP (monta aos 7 anos de idade). Os modelos ajustando polinômios de maiores graus tiveram tendência de aumento excessivo da variância fenotípica e da genética aditiva para as medidas finais (7으, $8^{\underline{0}}$ e $9^{\underline{0}}$ desempenhos). Meyer (1999), analisando pesos de vacas dos 2 aos 10 anos de idade, com até 9 registros por vaca, ajustando polinômios de Legendre de vários graus, observou que a partir de $\mathrm{k}=3$ as funções de covariâncias, tanto fenotípicas como genéticas, tiveram comportamentos semelhantes, demonstrando que a modelagem é robusta a partir de certa ordem mínima de ajuste.

Os desvios-padrão fenotípico, genético aditivo, permanente de ambiente e residual para todas as idades, gerados a partir da função de covariância estimada, são mostrados na Figura 1. O desvio padrão fenotípico aumentou de 33 dias no início da vida reprodutiva até 51 dias na última medida (10 anos de idade), o desvio-padrão genético aditivo de 9 a 43 dias, enquanto que aquele devido ao efeito permanente de 
ambiente decresceu de 17 a 6 dias do $1^{-}$ao $8^{\underline{0}}$ registro, voltando a subir para 16 dias no 9ำ registro. Os desvios-padrão residuais mantiveram-se mais ou menos constantes, variando de 22 dias aos 10 anos a 29 dias aos 7 anos, sugerindo que um modelo considerando menos medidas de erro poderia ser usado, o que diminuiria o número de parâmetros a serem estimados. Os valores indicam que até o $6^{\underline{o}}$ registro de DIAP a variância fenotípica parece ter sido consistentemente separada nos seus componentes causais, mas após o $\mathfrak{\sigma}^{0}$ registro a variância fenotípica cresceu muito provocando aumento excessivo da variância genética e diminuição da permanente de ambiente. Valores implausíveis dos componentes de variância nas idades mais avançadas podem ser, provavelmente, devido ao pequeno número de vacas com mais de 6 registros de DIAP (Tabela 1). Entretanto, Meyer (1999) salienta que o fato de usar polinômios ortogonais, que são simétricos, implica que pesos iguais são dados às observações tomadas cedo e tarde na vida, apesar dos últimos registros serem menos representativos do animal pois são sujeitos a efeitos acumulados de seleção e do ambiente. A transformação logarítmica das idades diminui o espaçamento dos últimos registros, reduzindo a ênfase dada a eles na análise de regressão, e pode contornar o problema, mas não elimina-lo.

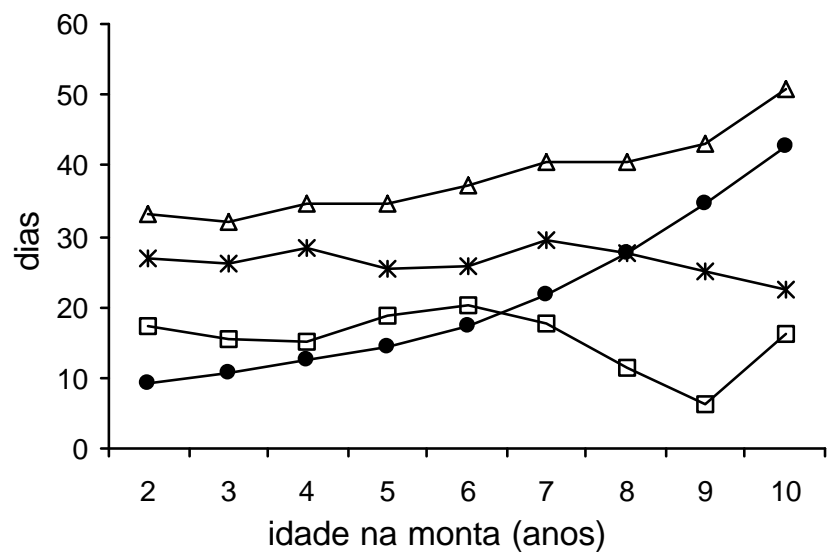

Figura 1 - Desvios-padrão fenotípico $(\Delta)$, residual ( ), genético aditivo $(\bullet)$ e permanente de ambiente ( $\square$ ) estimados para os desempenhos de DIAP até a 10 monta. 
Na Figura 2 são apresentadas as herdabilidades $\left(h^{2}\right)$ e as frações da variância total devido ao efeito permanente de ambiente $\left(\mathrm{c}^{2}\right)$. As $\mathrm{h}^{2}$ estimadas aumentaram de 0,08 a 0,28 do $1^{\circ}$ ao $6^{\circ}$ desempenho de DIAP, enquanto que o $c^{2}$ estimado diminuiu de 0,27 a 0,19 neste mesmo período. Mercadante et al. $^{2}$, com os mesmos dados, obtiveram $\mathrm{h}^{2}$ igual a 0,07 para o primeiro desempenho, e 0,12 para todos os desempenhos com modelo de repetibilidade, com $\mathrm{c}^{2}$ igual a 0,09, e Johnston \& Bunter (1996) observaram aumento da $\mathrm{h}^{2}$ do primeiro para o segundo desempenho, de 0,11 para 0,14 , também incluindo registros de vacas que não pariram. Há razões para justificar $h^{2}$ mais altas já que a raça Nelore, ou mais precisamente o rebanho em questão, não tem sido selecionado para reprodução, de modo geral a taxa reprodutiva é baixa e as diferenças entre os reprodutores podem ser mais nítidas nestas populações. Além disso pode-se supor que em uma estação experimental as condições ambientais sejam mais controladas que em rebanhos comerciais.

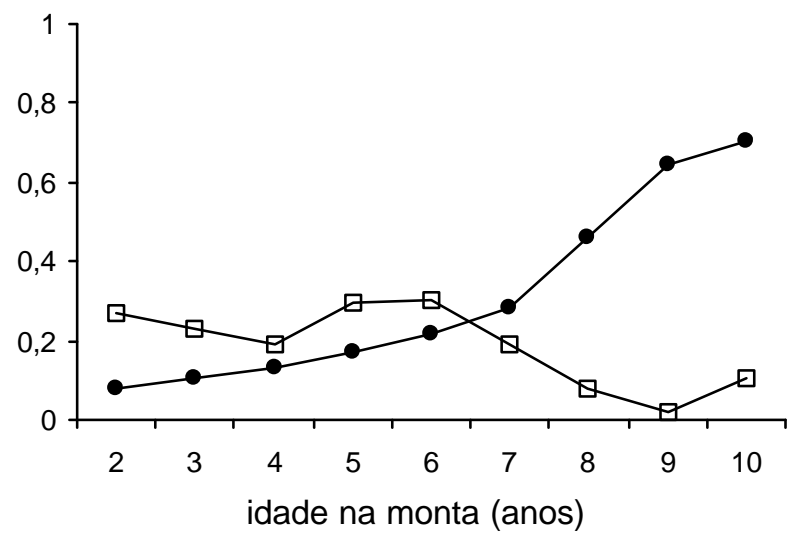

Figura 2 - Herdabilidade $(\bullet)$ e fração da variância total devido ao efeito permanente de ambiente ( ) estimadas para os desempenhos de DIAP até a $10^{\circ}$ monta.

As correlações genéticas e fenotípicas entre os desempenhos de DIAP são apresentadas na Tabela 3. Em geral, as correlações tendem a diminuir com o aumento do espaçamento entre os registros. As correlações fenotípicas foram baixas entre os primeiros desempenhos, mesmo entre registros adjacentes, e levemente mais altas após o 
$3^{\underline{0}}$ desempenho. Estes resultados são consistentes com o fato da fêmea estar em crescimento até 5 anos de idade, sendo neste período mais vulneráveis ao estresse ambiental, e assim os desempenhos de DIAP mais variáveis. Quando adultas os desempenhos tendem a ser mais uniformes. As correlações genéticas entre o primeiro desempenho de DIAP e os demais foram as mais baixas, estando de acordo com o fato das fêmeas estarem em crescimento, e portanto, impossibilitadas de expressarem totalmente o potencial genético reprodutivo. Apesar da consistência dos valores de correlação fenotípica e genética aditiva com as fases de crescimento e reprodução das matrizes, Albuquerque \& Meyer ${ }^{1}$ salientam que muitos autores têm reportado problemas para modelar covariâncias entre os registros obtidos cedo e tarde na vida do animal, e novamente o pequeno número de observações nas idades extremas, distantes da média, além do ajuste de modelos superparametrizados são colocados como as principais causas.

Tabela 3. Correlações fenotípicas (abaixo da diagonal) e genéticas (acima da diagonal) estimadas para os desempenhos de dias ao parto (DIAP) até 10 anos de idade.

\begin{tabular}{crrrrrrrrr}
\hline Anos & 2 & 3 & 4 & 5 & 6 & 7 & 8 & 9 & 10 \\
\hline 2 & & 0,63 & 0,62 & 0,66 & 0,64 & 0,57 & 0,48 & 0,39 & 0,32 \\
3 & 0,23 & & 0,99 & 0,98 & 0,93 & 0,84 & 0,76 & 0,69 & 0,63 \\
4 & 0,21 & 0,28 & & 0,99 & 0,93 & 0,85 & 0,77 & 0,70 & 0,65 \\
5 & 0,22 & 0,23 & 0,36 & & 0,98 & 0,92 & 0,86 & 0,80 & 0,75 \\
6 & 0,21 & 0,20 & 0,35 & 0,48 & & 0,98 & 0,94 & 0,90 & 0,86 \\
7 & 0,19 & 0,19 & 0,31 & 0,43 & 0,48 & & 0,99 & 0,97 & 0,94 \\
8 & 0,19 & 0,21 & 0,28 & 0,38 & 0,45 & 0,48 & & 0,99 & 0,98 \\
9 & 0,16 & 0,23 & 0,23 & 0,28 & 0,35 & 0,42 & 0,55 & & 0,99 \\
10 & 0,12 & 0,24 & 0,16 & 0,15 & 0,21 & 0,32 & 0,50 & 0,70 & \\
\hline
\end{tabular}

Nas Figuras 3, 4 e 5 estão plotados os valores genéticos médios das vacas dos três rebanhos experimentais $(\mathrm{NeC}, \mathrm{NeS}$ e $\mathrm{NeT})$ para os seis primeiros desempenhos de DIAP (2 a 7 anos de idade). Os valores genéticos médios das vacas no decorrer dos anos mostraram tendência de diminuição no rebanho controle, sem alteração nos rebanhos 
selecionados, concordando com Mercadante et al. (2001) que encontraram menores DIAP para $\mathrm{NeC}$, apesar de não serem significativamente diferentes de $\mathrm{NeS}$ e NeT. Analisando os desempenhos longitudinalmente observa-se menores valores genéticos de DIAP para as vacas do $\mathrm{NeC}$ no decorrer de sua vida produtiva, especialmente após 1986. Vale ressaltar que as vacas nascidas nos últimos anos do experimento não têm desempenho próprio das últimas medidas de DIAP plotadas nos gráficos, ou seja, as vacas nascidas após 1991 tiveram, no máximo, 5 oportunidades.

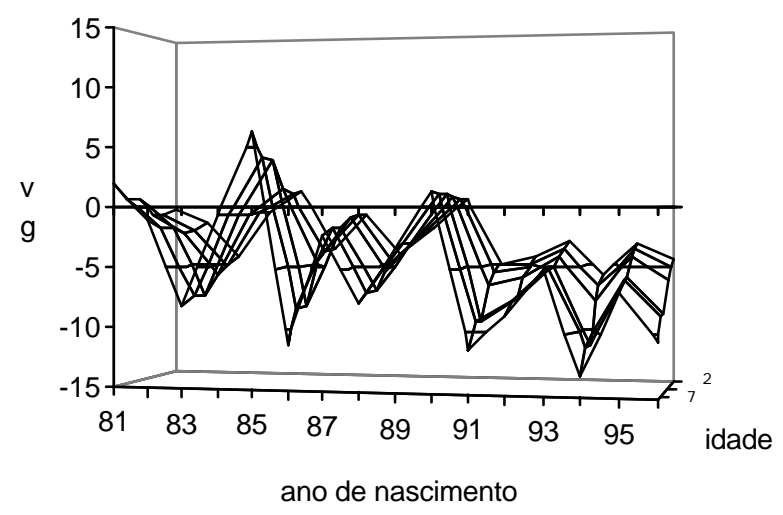

Figura 3 - Valores genéticos médios (dias) para os desempenhos de dias ao parto (DIAP) das vacas do $\mathrm{NeC}$ até a $6^{\mathrm{a}}$ monta, por ano de nascimento.

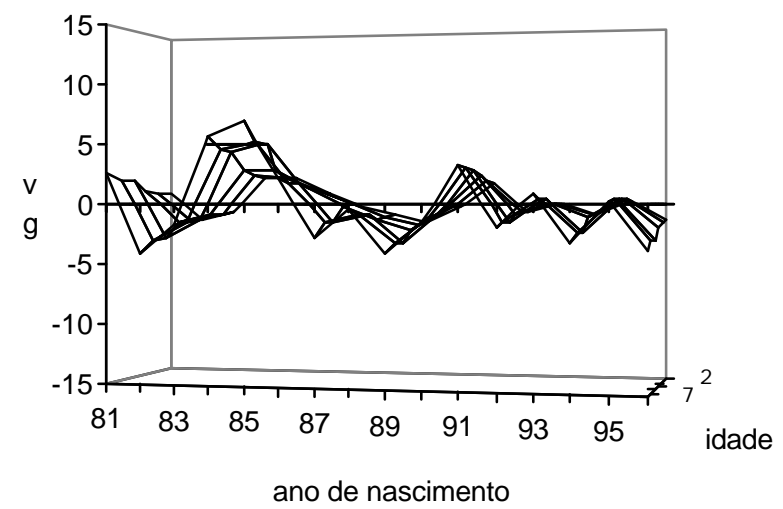

Figura 4 - Valores genéticos médios (dias) para os desempenhos de dias ao parto (DIAP) das vacas do NeS até a $6^{\underline{a}}$ monta, por ano de nascimento. 


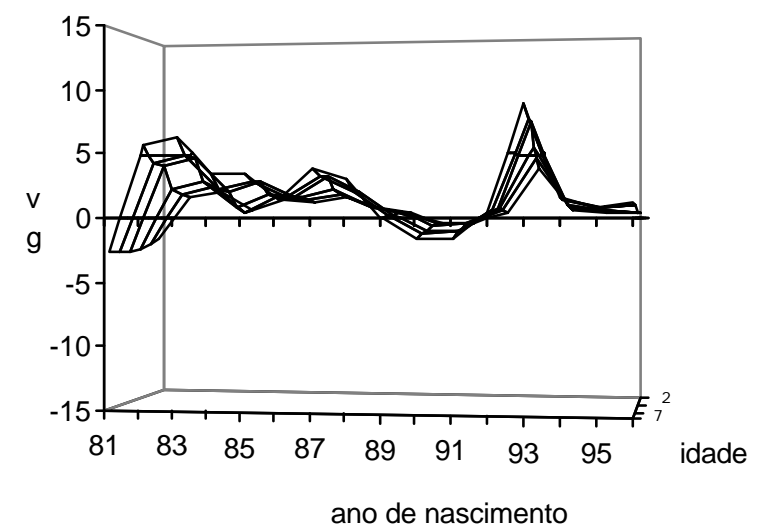

Figura 5 - Valores genéticos médios (dias) para os desempenhos de dias ao parto (DIAP) das vacas do NeT até a $6^{\text {a }}$ monta, por ano de nascimento.

Se considerarmos que as vacas são descartadas pelos mesmos critérios no $\mathrm{NeC}$ e $\mathrm{NeS}$, (o NeT é mais flexível e no início recebeu vacas descartadas por idade dos outros rebanhos), além do fato daquelas que falharam em determinado ano terem recebido um valor de DIAP maior que suas contemporâneas, os resultados sugerem que as vacas do rebanho controle tem sido mais eficientes no decorrer de sua vida reprodutiva. Entretanto, as vacas do $\mathrm{NeC}$ podem ter sido favorecidas pelo fato dos lotes de monta do rebanho $\mathrm{NeC}$ serem sempre menores que os dos rebanhos $\mathrm{NeS}$ e $\mathrm{NeT}$, em piquetes de mesma dimensão, apesar deste favorecimento já ter sido levado em conta com inclusão do efeito do touro em monta na definição do grupo contemporâneo.

Lembrando do processo seletivo dos rês rebanhos ao longo dos 15 anos, ou seja, $\mathrm{NeS}$ e NeT selecionados para maiores pesos ao sobreano e $\mathrm{NeC}$ selecionado para a média do peso ao sobreano, torna-se difícil explicar que em um rebanho fechado e não selecionado tenha ocorrido mudança na média genética de DIAP ao longo dos anos, como mostra a Figura 3. Uma explicação para isso poderia ser que devido à limitação de um experimento de seleção quanto ao número de animais o método não foi totalmente eficiente para separar a mudança genética da ambiental. Ao longo dos 15 anos a mudança ambiental para DIAP, obtida em modelo de repetibilidade, foi igual a $0,84 \pm 0,32$ dia/ano (Mercadante et al. $^{2}$ ), o que sugere que as vacas do rebanho controle 
responderam às mudanças ambientais e os valores genéticos médios mostrados na Figura 3 estão confundidos com efeitos de ambiente. As vacas dos rebanhos selecionados não responderam à mudança ambiental, ou melhor, se não houvesse melhoria nas condições ambientais poderia ter havido aumento do valor fenotípico, e provavelmente genético, do DIAP das vacas NeS e NeT.

Apesar disso, a aplicação de modelo de regressão aleatória aos registros de DIAP proporcionou uma análise detalhada do comportamento das covariâncias genéticas e do valor genético do desempenho reprodutivo das fêmeas no decorrer de sua vida, o que pode ser oportuno em muitos estudos. Análises adicionais devem ser realizadas em populações maiores, uma vez que os dados foram obtidos em experimento de seleção que por si só tem limitação de número de animais, além de que a metodologia é de certa forma recente, um grande número de modelos e polinômios podem ser testados, e sua aplicação é inédita a dados de reprodução.

\subsection{CONCLUSÕES}

O estudo do comportamento dos dias ao parto ao longo da vida reprodutiva da vaca por meio da técnica de regressão aleatória foi eficiente até o $6^{\underline{0}}$ desempenho, porém a mudança genética não foi totalmente separada da mudança ambiental.

A seleção para peso não alterou o valor genético para dias ao parto das vacas dos rebanhos selecionados, mas os valores genéticos das vacas do rebanho controle mostraram tendência de queda. 


\section{RESPOSTAS DIRETAS E CORRELACIONADAS À SELEÇÃO PARA PESO AO SOBREANO NO DESEMPENHO DE FÊMEAS NELORE}

\section{RESUMO}

Foram analisadas a resposta direta no peso ao sobreano de machos e fêmeas e as repostas correlacionadas no tamanho e caracteres reprodutivos das matrizes do experimento de seleção da Estação Experimental de Zootecnia de Sertãozinho-SP. O experimento iniciou em 1978, com três rebanhos da raça Nelore, seleção (NeS), tradicional $(\mathrm{NeT})$ e controle $(\mathrm{NeC})$, sendo os dois primeiros selecionados para maior peso ao sobreano e o terceiro para a média deste peso. O NeT diferencia-se de NeS por ter recebido, eventualmente, touros de outros rebanhos, inclusive comerciais. Registros de peso ao sobreano dos animais nascidos de 1978 a 1998, e da altura na garupa ao sobreano das fêmeas nascidas a partir de 1985 foram avaliados por modelo animal a fim de obter a tendência genética de 1981 a 1996. Médias de peso, altura e escore de condição corporal na entrada da monta, dias ao parto e sucesso ao parto das matrizes nascidas nos últimos 4 anos foram contrastadas entre os selecionados e o NeC. As tendências genéticas médias obtidas em 16 anos foram $1,7 \pm 0,2 ; 2,3 \pm 0,2$ e $-0,1 \pm 0,1$

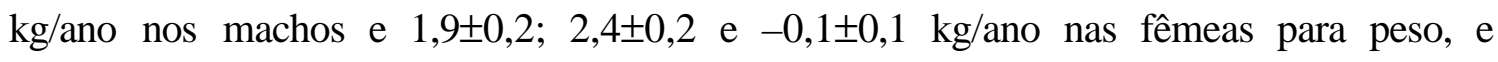
$0,25 \pm 0,03 ; 0,24 \pm 0,04$ e $-0,04 \pm 0,03 \mathrm{~cm}$ nas fêmeas para altura ao sobreano, respectivamente em $\mathrm{NeS}, \mathrm{NeT}$ e NeC. Novilhas e vacas de $\mathrm{NeS}$ e $\mathrm{NeT}$ foram $19 \%$ e $15 \%$ mais pesadas e $4 \%$ mais altas na entrada da monta, em relação às do $\mathrm{NeC}$. Não foram detectadas diferenças significativas $(\mathrm{P}<0,05)$ no desempenho reprodutivo das matrizes selecionadas em relação ao $\mathrm{NeC}$. Os resultados indicaram que a seleção para peso corporal promoveu respostas altas e consistentes nos pesos e alturas ao sobreano e em idades mais tardias, sem comprometer o desempenho reprodutivo das matrizes. 


\section{SUMMARY}

Data from a selection experiment for growth, carried out in Brazil, were analyzed in order to evaluate the direct response on yearling weight and the correlated responses in the size and reproduction traits of cows. The experiment started in 1978, with three lines of Nelore cattle, selection $(\mathrm{NeS})$, traditional $(\mathrm{NeT})$, both selected for higher yearling weight, and control $(\mathrm{NeC})$, selected for mean yearling weight. The NeT line is different from the $\mathrm{NeS}$ one, because sires from another herds were eventually introduced into the NeT line. Records of yearling weight for animals born from 1978 to 1998, and yearling hip height of females born from 1985 to 1998, were evaluated using an animal model, in order to obtain the genetic trends for the years 1981-1996. The averages for weight, height and body condition score at the start of the breeding season, days to calving and calving success of cows born in the last 4 years, were contrasted between the selected ( $\mathrm{NeS}$ and $\mathrm{NeT}$ ) and control lines. The genetic trends obtained after 16 years were $1.7 \pm 0.2 ; 2.3 \pm 0.2$ and $-0.1 \pm 0.1 \mathrm{~kg} /$ year for males and $1.9 \pm 0.2 ; 2.4 \pm 0.2 \mathrm{e}-$ $0.1 \pm 0.1 \mathrm{~kg} /$ year for females with respect to weight, and $0.25 \pm 0.03 ; 0.24 \pm 0.04$ and $0.04 \pm 0.03 \mathrm{~cm}$ for females with respect to yearling height for the $\mathrm{NeS}, \mathrm{NeT}$ and $\mathrm{NeC}$ lines, respectively. Heifers and cows from NeS and NeT were 19\% and 15\% heavier and $4 \%$ taller at the start of the breeding season than those from NeC. Significant differences

$(\mathrm{P}<0.05)$ were not detected with respect to the reproductive performance between selected (NeS and NeT) and control females. The results indicated that the selection for body weight gave high and consistent responses for weight and height both at the yearling and later ages, without compromised the reproductive performance of the cows.

\subsection{INTRODUÇÃO}

Até meados de 1980, trabalhos e revisões sobre os efeitos da seleção para crescimento indicavam respostas correlacionadas negativas na reprodução das matrizes (Barlow, 1978; Scholtz \& Roux, 1984; Luesakul-Reodecha et al., 1986). Se a seleção 
para peso em idades jovens leva, inevitavelmente, a maiores pesos adultos (Smith et al., 1976), e considerando situações em que os recursos alimentares são inadequados e os indivíduos menores têm vantagem produtiva sobre os demais (Fitzhugh, 1978), respostas correlacionadas negativas na reprodução das fêmeas, provocadas por maiores pesos adultos advindos de seleção para crescimento em idades jovens, poderiam mesmo ser esperadas. Entretanto, trabalhos publicados mais recentemente, tanto com dados de experimentos de seleção como com dados de campo, têm negado este antagonismo, indicando que a seleção para maior peso corporal em idades jovens não apresenta efeitos significativos sobre o desempenho reprodutivo das matrizes (Mrode et al., 1990b; Wolfe et al., 1990; Meyer et al., 1991; Morris et al., 1992; Parnell, 1994; Archer et al., 1998a; Mercadante et al., 2000; Silva et al., 2000).

Correlações entre crescimento e reprodução e resultados experimentais sobre os efeitos da seleção para maior peso em idades jovens no desempenho das matrizes não foram ainda bem documentadas em populações de bovinos de origem indiana, Bos indicus, (Mrode et al., 1988b; Koots et al., 1994b; Lôbo et al., 2000). Com o objetivo de obter respostas à seleção para peso em populações de origem indiana, além de mostrar aos criadores de gado de corte a eficiência de um processo simples de seleção dentro de rebanhos, foi montado no Brasil, no final da década de 70, um experimento de seleção para crescimento. As respostas diretas e correlacionadas no peso até o sobreano foram descritas ao longo dos anos por Packer et al. (1986); Razook et al. (1993) e Razook et al. (1998), porém nada foi relatado quanto aos valores genéticos do caracter sob seleção direta, e as respostas correlacionadas no tamanho e caracteres de reprodução das fêmeas. Este trabalho avalia as respostas diretas no peso à seleção por meio da metodologia de modelos mistos, além dos efeitos da seleção para peso ao sobreano sobre o tamanho e o desempenho reprodutivo das matrizes. 


\subsection{MATERIAL E MÉTODOS}

\subsubsection{Formação dos rebanhos e seleção}

O experimento de seleção foi conduzido na Estação Experimental de Zootecnia de Sertãozinho (EEZS), unidade de pesquisa do Instituto de Zootecnia, localizada ao norte do Estado de São Paulo (21 $10^{\circ}$ ' latitude norte e $48^{\circ} 5^{\prime}$ longitude oeste), Brasil. A região apresenta clima tropical úmido, com temperatura e precipitação médias anuais de $24^{\circ} \mathrm{C}$ e $1312 \mathrm{~mm}$ respectivamente. As pastagens são constituídas de capim colonião (Panicum maximum) e braquiária (Brachiaria brizantha).

Os animais utilizados foram provenientes do rebanho Nelore registrado da EEZS deste a década de 1930. A reorganização do rebanho como um todo para posterior estabelecimento dos rebanhos separados iniciou com o uso de alguns reprodutores comerciais, via inseminação artificial, além dos provenientes do próprio rebanho, na estação de monta de 1976, com a finalidade de ampliar a base genética do rebanho experimental. Em 1980 houve o estabelecimento dos rebanhos separados, utilizando reprodutores nascidos em 1977 e 1978, 3 deles com diferencial de seleção positivo para peso ao sobreano e 2 com diferencial nulo. De 350 fêmeas aptas à reprodução, as 180 mais novas foram aleatoriamente designadas para os rebanhos Nelore Controle $(\mathrm{NeC})$ e Nelore Seleção (NeS), com 60 e 120 fêmeas respectivamente, e as 170 restantes formaram posteriormente o rebanho Nelore Tradicional (NeT). Os animais considerados como base genética (pais desconhecidos) na genealogia são portanto aqueles nascidos até 1977.

Foram usados anualmente 4, 6 e até 8 touros nos rebanhos $\mathrm{NeC}, \mathrm{NeS}$ e $\mathrm{NeT}$, sendo 50\% deles com dois anos (primeira monta) e 50\% com três anos (segunda e última monta), selecionados segundo o diferencial de seleção, dentro de grupo contemporâneo rebanho x ano, para peso padronizado aos 378 dias (P378), obtido após prova de desempenho em confinamento de 168 dias de duração (Razook et al., 1997). As fêmeas de reposição foram selecionadas segundo o diferencial de seleção do peso padronizado aos 550 dias (P550), em regime de pasto, mas em geral foram retidas anualmente $50 \%$ 
delas para uma taxa anual de descarte de $20 \%$ das matrizes. Nenhum ajuste adicional foi feito nos pesos à seleção. Nos rebanhos selecionados NeS e NeT foram retidos para reprodução machos e fêmeas de maior diferencial e para o $\mathrm{NeC}$ aqueles com diferencial de seleção nulo. O NeT, em um esquema de reposição de touros e matrizes mais flexível, recebeu no início touros de fora dos rebanhos da estação, assim como, eventualmente, touros e matrizes descartados dos $\mathrm{NeC}$ e NeS. Sempre houve o cuidado de não selecionar, em um mesmo ano, mais que dois filhos de um reprodutor. Todos os detalhes da implantação dos rebanhos e do processo seletivo já foram descritos por Packer et al. (1986) e Razook et al. (1993, 1998).

\subsubsection{Formação dos lotes de monta e manejo das fêmeas}

Após a seleção aos 18 meses, que ocorre no mês de abril, as novilhas foram mantidas em pasto até a entrada na primeira monta, no mês de novembro, ao redor dos dois anos de idade $(25,5 \pm 1$ meses). Os lotes de monta foram formados por meio da inspeção visual das genealogias, a fim de evitar acasalamentos consanguíneos, e a partir de 1994 passou-se a utilizar um programa computacional para o mesmo fim, com maior eficiência. As fêmeas foram colocadas em monta natural a pasto, em lotes médios de 25 matrizes para $\mathrm{NeS}$ e $\mathrm{NeT}$ e 15 matrizes para $\mathrm{NeC}$, para cada touro, durante 90 dias, recebendo somente suplementação mineral. Menores relações vaca/touro foram utilizadas para os tourinhos de 2 anos de idade (15:1).

Durante os 15 anos relatados neste estudo para os caracteres de reprodução, as datas de entrada e saída da monta foram 15 de novembro e 15 de fevereiro, com pequenas variações no decorrer dos anos. Setenta e sete por cento dos partos ocorreram nos meses de setembro e outubro, $16 \%$ em novembro, e 5 e $2 \%$ em agosto e dezembro, respectivamente. Os bezerros foram desmamados nos meses de abril e maio, com 7 meses de idade. As fêmeas foram descartadas prioritariamente por falharem dois anos consecutivos, por problemas de saúde, por má habilidade materna (abandono de bezerro por dois anos consecutivos), ou por idade avançada, ao redor de 11 anos. 


\subsubsection{Definição dos caracteres}

Com o objetivo de caracterizar a população quanto à seleção praticada em peso e ter, para análises posteriores, toda a amostra no momento da seleção, o peso dos machos foi incluído no estudo, porém os caracteres obtidos posteriormente à seleção são relativos somente às fêmeas.

Os pesos à seleção dos machos (P378) e das fêmeas (P550) foram calculados como descrito por Razook et al. (1993), somando ao peso de desmame, padronizado para 210 dias, o ganho de peso pós-desmame em confinamento até um ano para os machos, e o ganho de peso pós-desmame em regime de pasto até um ano e meio para as fêmeas (Anexos A e B). A altura das fêmeas aos 550 dias (A550) foi tomada por uma vertical baixada da porção anterior do sacro ao solo, no momento da pesagem, usando uma fita métrica colada à balança, e foi ajustada para a idade de 550 dias por meio de coeficientes de regressão da idade obtidos dentro de rebanho (Anexo C).

Peso (PEM), altura (AEM) e condição corporal (CEM) na entrada da monta foram tomados anualmente, no mês de novembro, para todas as fêmeas participantes da monta, independentemente de seu estado lactacional, exceto aquelas que ainda não haviam parido da estação de monta anterior (cerca de 5\%). Para tais vacas, a pesagem ocorria por volta de 4 dias após o parto, quando ingressavam no lote de monta. A AEM foi tomada do mesmo modo que A550. As avaliações da CEM, por serem subjetivas, foram feitas pelos mesmos dois técnicos, durante todos os anos, designando valores em uma escala de 1 a 9 para vacas extremamente magras até extremamente gordas. No entanto, como praticamente não havia registros nas classes mais extremas (1, 2 e 9), aqueles referentes às classes 1 e 2 foram designados para a 3, e os da classe 9 para a 8 , ficando a escala de 3 a 8 .

Os registros de dias ao parto (DIAP) foram obtidos para todas as fêmeas que pariram, a partir da diferença entre a data do parto e a data da entrada na monta que deu origem a este parto, sendo descartadas as informações provenientes de abortos, de partos fora da estação de nascimento, e de inseminação artificial. Foram considerados válidos os valores observados de DIAP entre 268 e 407 dias. Vacas que pariram após o início da 
estação de monta (cerca de 5\%) tiveram a data de entrada na monta ajustada somando-se 4 dias à data do parto. Pelo fato das vacas vazias após o término da estação de monta serem, provavelmente, as de pior mérito genético para habilidade de conceber durante uma estação de monta restrita, ocasionando a exclusão das informações potencialmente mais valiosas sobre a diferença genética entre elas (Notter, 1988; Meyer et al., 1990), registros de vacas não paridas foram incluídos. A todo registro de monta sem DIAP foi designado um valor somando-se 21 dias ao maior registro de DIAP do grupo contemporâneo em que a fêmea estava (Johnston \& Bunter, 1996), penalizando as fêmeas que entraram na monta e não pariram. Este procedimento foi feito para todas as fêmeas que estavam em grupos contemporâneos com mais de 4 observações de DIAP. Entretanto, pela ausência de diagnóstico de prenhez, neste processo foram penalizadas também aquelas fêmeas que emprenharam e que tiveram aborto precoce não percebido pelo pessoal de campo.

Sucesso ao parto (SP) foi considerado como um caracter binomial (0 ou 1), sendo 1 para a vaca parida, independentemente do estado do bezerro e 0 para a não parida, desde que houvesse registro de monta. Tanto para DIAP como para SP houve a preocupação de invalidar registros de monta quando houve evidências de problemas de fertilidade com o touro; além dos registros de vacas com mais de 12 anos de idade. Para minimizar os efeitos do descarte das vacas nas estimativas das médias e dos parâmetros genéticos, o primeiro desempenho de todos os caracteres obtidos após a seleção foi também estudado como caracter único, além do sucesso ao parto na segunda monta, dado que a vaca pariu na primeira.

Apesar do experimento ter iniciado com um rebanho de vacas nascidas desde a década de 60, optou-se neste estudo por trabalhar somente com registros daquelas nascidas de 1981 em diante em cada um dos três rebanhos (isto é, após o início do experimento). Isto fez com que o número de registros fosse reduzido nos primeiros anos, estabilizando somente na monta de 1990, época em que praticamente todas as matrizes nascidas antes do início da experimento já tinham sido descartadas (Anexo D). Como ressaltado por Archer et al. (1998a), em experimentos deste tipo, os registros repetidos de reprodução são incompletos dentro de classes de idade da vaca e ano, ocorrendo nos 
primeiros anos somente registros das fêmeas mais novas. Assim, as vacas nascidas no início da experimento tiveram muitas oportunidades, e se não foram descartadas por produção, foram por idade, enquanto aquelas nascidas em 1996 só tiveram uma oportunidade. Este problema atinge também os registros repetidos referentes ao tamanho da vaca (PEM, AEM e CEM). Na Tabela 1 estão as médias observadas e desviospadrões fenotípicos de todos os caracteres analisados, com o número de animais e de registros envolvidos e o período em que estes registros foram obtidos.

Registros do peso à seleção dos animais nascidos de 1978 a 1980, antes da separação dos rebanhos, foram também incorporados na análise e identificados como um quarto rebanho. Para os registros repetidos houve uma média de 4,5 observações por vaca, e considerando o descarte das vacas conforme sua produção, as classes de idade da vaca estiveram representadas com um número razoável de registros (Anexo E). Como observado em outro estudo (Northcutt et al., 1992), os registros de CEM foram mal distribuídos nas classes de escore consideradas, ficando $86 \%$ das observações entre as classes 5 e 7, 9\% delas na classe de escore 9, e 5\% dividido entre as classes 3 e 4 . Pelo fato das médias dos registros repetidos conter número maior (55\%) de vacas até 4 anos de idade (Anexo E), os valores, principalmente de PEM e AEM são mais baixos que os relatados na literatura para vacas Nelore adultas (Rosa et al., 2001), além de refletir medidas tomadas após o período seco, que para PEM e CEM tende a ser menores que as tomadas após o período das águas. As taxas de prenhez médias observadas estão muito abaixo daquelas relatadas para raças de corte Bos taurus puras, tanto em novilhas em monta com um ano de idade (83\%, Doyle et al., 2000; Morris et al., 2000), para prenhez subsequente (92\%, Doyle et al., 2000), como para vacas (87\%, Buddenberg et al, 1989; Meyer et al., 1990; Archer et al., 1998a; Morris et al., 2000). Vargas et al. (1999), em um rebanho não muito grande de fêmeas Brahman obtiveram 93\%, 59\% e $84 \%$ de taxa de prenhez respectivamente na primeira monta aos dois anos de idade, prenhez subsequente, e demais montas; e surpreendentemente o valor para prenhez subsequente foi o mesmo observado neste trabalho, embora o ambiente nutricional relatado pelos autores tenha sido, aparentemente, melhor. 
Tabela 1. Número de animais avaliados, número de registros e número de touros (pais dos animais com registros), média observada e desvio-padrão fenotípico dos caracteres estudados.

\begin{tabular}{|c|c|c|c|c|c|c|}
\hline Caracter $^{1}$ & $\begin{array}{c}\text { anos de } \\
\text { nascimento }\end{array}$ & $\begin{array}{c}\mathrm{n}^{\mathbf{0}} \\
\text { animais }\end{array}$ & $\begin{array}{c}\mathrm{n}^{\mathbf{0}} \\
\text { registros }\end{array}$ & $\begin{array}{c}\mathrm{n}^{\mathrm{o}} \\
\text { touros }\end{array}$ & média & $\begin{array}{l}\text { desvio } \\
\text { padrão }\end{array}$ \\
\hline Peso à seleção (kg) & $1978-98$ & 4677 & & 166 & 282 & 42 \\
\hline Peso aos 550 dias (kg) & $1978-98$ & 2353 & & 161 & 263 & 39 \\
\hline Altura aos 550 dias $(\mathrm{cm})$ & $1985-98$ & 1599 & & 124 & 129,6 & 4,5 \\
\hline \multicolumn{7}{|l|}{ Peso entrada da monta $(\mathrm{kg})$} \\
\hline $1^{\mathrm{a}}$ monta & $1981-96$ & 900 & & 125 & 303 & 34 \\
\hline todas montas & $1983-98^{3}$ & 928 & 4247 & 127 & 392 & 70 \\
\hline \multicolumn{7}{|l|}{ Altura entrada da monta $(\mathrm{cm})$} \\
\hline $1^{\mathrm{a}}$ monta & 1984-96 & 765 & & 105 & 137 & 4,4 \\
\hline todas montas & $1986-98^{3}$ & 914 & 3999 & 125 & 141,9 & 5,0 \\
\hline \multicolumn{7}{|l|}{$\begin{array}{l}\text { Condição corporal entrada da } \\
\text { monta }(\text { escore })^{2}\end{array}$} \\
\hline $1^{\mathrm{a}}$ monta & $1985-96$ & 727 & & 101 & 6,2 & 0,7 \\
\hline todas montas & $1987-98^{3}$ & 901 & 3843 & 125 & 6,2 & 1,0 \\
\hline \multicolumn{7}{|l|}{ Dias ao parto (dias) } \\
\hline $1^{\mathrm{a}}$ monta & $1981-96$ & 926 & & 125 & 350 & 37 \\
\hline todas montas & $1984-98^{3}$ & 945 & 4236 & 126 & 344 & 36 \\
\hline \multicolumn{7}{|l|}{ Sucesso ao parto $(\%)$} \\
\hline $1^{\mathrm{a}}$ monta & $1981-96$ & 926 & & 126 & 0,73 & 0,44 \\
\hline $2^{\mathrm{a}}$ monta/pariu na $1^{\mathrm{a}}$ & $1981-95$ & 601 & & 112 & 0,59 & 0,49 \\
\hline todas montas & $1983-98^{3}$ & 947 & 4307 & 127 & 0,75 & 0,43 \\
\hline
\end{tabular}

, peso à seleção obtido em machos e fêmeas, os outros caracteres obtidos nas fêmeas;

2 , escala de 6 pontos: 3 -emaciada, 8 - extremamente gorda; ${ }^{3}$, anos da entrada na monta.

\subsubsection{Análises estatísticas e genéticas}

\subsubsection{Diferenciais de seleção}

Os diferenciais de seleção ponderados e não ponderados das matrizes podem fornecer uma idéia dos efeitos conjuntos da seleção natural e artificial (Koch et al., 
1994; Falconer \& Mackay, 1996). Para este fim foram calculados os diferenciais de seleção para os machos (P378) e fêmeas (P550) como o desvio do desempenho do indivíduo, em relação à média dos contemporâneos (ano x rebanho), além dos diferenciais de seleção efetivos das matrizes, nascidas até 1993, como a média ponderada destes desvios pelo número de filhos avaliados à seleção até 1998. Pelo fato do NeT ter recebido animais provenientes de outros rebanhos que não da EEZS nos primeiros anos, além de vacas e touros remanescentes dos rebanhos controle e seleção, estes cálculos se restringiram somente aos rebanhos $\mathrm{NeC}$ e $\mathrm{NeS}$.

\subsubsection{Efeitos fixos}

Para definição dos modelos quanto aos efeitos fixos, os caracteres foram analisados usando procedimento para modelos lineares mistos (PROC MIXED) do SAS (2000), com exceção do caracter binomial sucesso ao parto. O PROC MIXED permite a inclusão de estruturas de covariâncias residuais apropriadas na análise de registros repetidos, ajustando para a covariância existente entre os registros de uma mesma vaca, além da possível heterogeneidade das variâncias residuais em cada idade. Os registros repetidos de PEM, AEM, CEM e DIAP foram analisados considerando estruturas de covariâncias (R) apropriadas, escolhidas pelo critério de informação de Akaike (Littel et al., 1996). Os efeitos fixos de interesse e suas interações foram considerados em todas as análises preliminares e quando não significativos $(\mathrm{P}>0,05)$ foram retirados do modelo.

Os pesos à seleção de machos e fêmeas, apesar de terem sido obtidos em idades diferentes e com manejos distintos no pós-desmame, foram estudados como um só (PSEL) ajustando para os efeitos fixos de rebanho, ano de nascimento, mês de nascimento $(8,9,10$ e 11), sexo, classe de idade da mãe (3 a 10 anos) e as interações rebanho $\mathrm{x}$ ano, rebanho $\mathrm{x}$ sexo e ano $\mathrm{x}$ sexo. A altura à seleção (A550) foi analisada ajustando os efeitos de rebanho, ano de nascimento e a interação rebanho x ano.

Os primeiros desempenhos de peso (PEM1), altura (AEM1) e condição corporal (CEM1) na entrada da monta, dias ao parto (DIAP1), sucesso ao parto (SP1) e o segundo sucesso ao parto, dado sucesso no primeiro (SP2/1) foram analisados ajustando os efeitos fixos de rebanho, ano de nascimento e idade na entrada da monta (em dias), 
além da interação rebanho $\mathrm{x}$ ano de nascimento para PEM1, AEM1 e DIAP1. Na impossibilidade de incluir no grupo contemporâneo das novilhas o touro em monta devido ao reduzido número de observações, os valores penalizados de DIAP1 para as vacas que não pariram foram obtidos nas subclasses de rebanho $\mathrm{x}$ ano de nascimento da primeira monta.

Para os caracteres repetidos PEM e CEM foram ajustados os efeitos fixos de rebanho, ano de entrada na monta, classe de idade (2 a 9 anos) e estado reprodutivo anterior; e para AEM os efeitos de rebanho, ano de nascimento e classe de idade (2 a 9 anos). Foram consideradas as interações rebanho $\mathrm{x}$ ano de entrada na monta para peso e condição corporal, rebanho x ano de nascimento para altura, rebanho x classe de idade da vaca para condição corporal, e rebanho x estado reprodutivo anterior para o peso.

O modelo para DIAP como medida repetida ajustou os efeitos fixos de rebanho, grupo contemporâneo (ano de entrada na monta + touro em serviço), classe de idade (2 a 9 anos) e estado reprodutivo anterior, e para registros repetidos de SP os efeitos fixos de rebanho, ano de entrada na monta, classe de idade ( 2 a 6 anos) e estado reprodutivo anterior. O touro em monta, fator importante a ser considerado em análises de DIAP ou de SP (Buddenberg et al., 1989; MacNeil \& Newman, 1994; Johnston \& Bunter, 1996), só foi incluído no modelo de análise de DIAP repetido e por esta razão os registros das montas de 1983, além de alguns grupos da monta de 1984 foram descartados nesta análise por terem menos que 4 observações. Para os registros repetidos de SP não foi incluído o efeito de grupo contemporâneo definido anteriormente, além da interação entre os efeitos principais, para evitar a ocorrência de subclasses não informativas (ocorrência só de 0 ou só de 1), como sugerido por Evans et al. (1999) e Varona et al. (1999).

\subsubsection{Contrastes entre as médias}

A comparação do desempenho dos selecionados em relação ao controle foi feita com as informações das vacas nascidas de 1993 a 1996 (n=274), que pertencem às $3^{\mathrm{a}}$ a $4^{\mathrm{a}}$ gerações de seleção, considerando como primeira geração os animais nascidos em 1981 (Anexo F e H). Os contrastes entre as médias, para os caracteres com distribuição 
normal, foi feito no PROC MIXED (SAS, 2000), ajustando efeitos já descritos anteriormente. As exceções foram, DIAP que foi analisado com o efeito de ano de entrada na monta e não grupo contemporâneo (ano x touro), e a interação rebanho $\mathrm{x}$ ano de nascimento ou rebanho $\mathrm{x}$ ano de entrada na monta, que não foi significativa para alguns caracteres. Nesta análise, as médias contrastadas, no caso dos registros repetidos, são referentes a fêmeas com, no máximo, 4 registros.

Sucesso ao parto foi analisado como um caracter com distribuição binomial, com uma função de ligação probit em modelo linear generalizado, usando o software ASREML (Gilmour et al., 2000). A função de ligação representa um modelo biológico da média, ou seja, assume-se que as respostas binomiais (0 ou 1) sejam manifestações observáveis de processos subjacentes contínuos não observáveis. Esta idéia de uma variável subjacente normal é compatível com o modelo genético aditivo infinitesimal. Quando a variável subjacente está abaixo de um certo limiar o indivíduo tem uma forma de expressão fenotípica (por exemplo, sucesso ao parto), quando ela está acima do limiar o indivíduo tem outra expressão fenotípica (por exemplo, fracasso ao parto), e assim a probabilidade de uma resposta favorável (sucesso) pode ser estimada. A categoria observada é dependente de um valor fenotípico subjacente relativo ao limiar fixo. (Falconer \& Mackay, 1996). O modelo probit, também chamado de modelo de limiar, cuja variância residual na escala subjacente é tomada como uma unidade da medida, $\sigma^{2}=1$ (Gianola \& Foulley, 1983), assegura que as estimativas sejam no intervalo 0 e 1, isto é, que a média do sucesso ao parto estimada para cada um dos rebanhos ficará entre 0 e $100 \%$ (Littel et al., 1996).

As estimativas do efeito de rebanho na escala subjacente foram retransformadas para a escala de probabilidade tomando-se a função densidade da normal acumulada da média ajustada. Os contrastes entre as médias dos rebanhos selecionados e do controle para todas os caracteres foram testados usando um teste t. Para SP o teste foi construído com os valores na escala probit, e os erros-padrões da diferença na escala de probabilidade obtidos, como sugerido por Gilmour ${ }^{3}$, por diferença. 


\subsubsection{Componentes de variância e soluções para o efeito animal (BLUPs)}

Os componentes de variância foram estimados por máxima verossimilhança restrita (REML) usando o software MTDFREML (Boldman et al., 1995) modificado por Joerg Dodenhoff (Van Vleck ${ }^{4}$ ) para calcular o erro-padrão aproximado das estimativas dos parâmetros genéticos em análises univariadas. Para os caracteres com distribuição binomial (SP1, SP2/1 e SP) foi usado o software ASREML (Gilmour et al., 2000), cujo algoritmo de trabalho é baseado em modelos lineares generalizados e usa o método de Schall $^{5}$, citado por Gilmour et al. (2000), de solucionar equações de modelo misto. Como para as médias, as soluções para o efeito animal na escala subjacente foram também re-transformadas para a escala de probabilidade tomando-se a integral normal padrão da solução.

Para todos os caracteres foi usado modelo animal, incluindo matriz de parentesco com 5830 animais, sendo 410 sem informação dos pais (animais base). PSEL foi analisado sob um modelo com o efeitos aleatórios genético aditivo do animal e permanente do ambiente materno. Análises preliminares, testando diferentes modelos (por meio do teste da razão de verossimilhança), indicaram ser este o melhor, ao invés do "modelo completo" (efeitos genéticos aditivo direto e materno e efeito permanente de ambiente). Os demais caracteres com registro único (A550, PEM1, AEM1, CEM1, DIAP1, SP1 e SP2/1) foram analisados incluindo somente o efeito aleatório genético aditivo do animal.

Os efeitos aleatórios para os caracteres repetidos (PEM, AEM, CEM, DIAP e SP) foram genético aditivo e permanente de ambiente do animal. Análises univariadas foram feitas para obter os componentes de variância e parâmetros genéticos e/ou soluções BLUP do efeito animal para PSEL e para os de registros repetidos PEM, AEM, CEM, DIAP e SP. Para os demais caracteres de registro único (PEM1, AEM1, CEM1 e DIAP1) foram rodadas análises bivariadas com PSEL, com exceção de SP1 e SP2/1 que só foram feitas análises univariadas.

\footnotetext{
${ }^{3}$ GILMOUR, A.R. (New South Wales Agriculture, Orange, Australia). Comunicação via e-mail. 2001.

${ }^{4}$ VAN VLECK, L.D. (University of Nebraska, Lincoln, USA). Comunicação via e-mail. 2000.

5 SCHALL, R. Estimation of generalized linear models with random effects. Biometrika, v.78, p.719-727. 1991.
} 
Como citado anteriormente, o peso à seleção de machos e fêmeas foi analisado como um só caracter a fim de obter estimativas BLUP dos valores genéticos para estimar a mudança genética anual, avaliando os animais pelo seu próprio desempenho, mas também pelo de seus parentes machos e fêmeas. Em uma análise com modelo animal considerando somente um dos sexos, o valor genético obtido teria contribuição de um só parental. Além disso, este procedimento permitiu ter, nas análises bivariadas, toda a amostra populacional representada antes da seleção. Procurando diminuir as diferenças entre P378 e P550, análises foram feitas também com o caracter padronizado pelo desvio-padrão de cada sexo, como sugerido por Koch et al. (1994).

As soluções das subclasses do efeito animal (valores genéticos) foram usadas para obter a estimativa da tendência genética anual, por meio da regressão dessas soluções no ano de nascimento do animal. Para PSEL este procedimento foi feito para machos e fêmeas separadamente.

\subsection{RESULTADOS E DISCUSSÃO}

\subsubsection{Informações sobre a seleção das fêmeas}

Para maximizar o ganho genético somente indivíduos com os mais altos desvios da média dos contemporâneos deveriam ser usados como pais da próxima geração, mas para fêmeas, considerando-se as baixas taxas reprodutivas nos trópicos, a possibilidade de seleção é quase nula. De 1981 a 1996 foram selecionadas anualmente para reposição das matrizes $53 \%$ das fêmeas avaliadas no $\mathrm{NeC}$ e $50 \%$ no NeS. Esta

pequena diferença entre os dois rebanhos se deve ao fato das novilhas do $\mathrm{NeC}$ nem sempre serem registradas, devido ao seu pequeno porte, razão pela qual colocava-se em monta, proporcionalmente, um maior número delas. Do total de fêmeas selecionadas, $21,0 \%$ de $\mathrm{NeC}$ e 18,3\% de $\mathrm{NeS}$ nunca pariram (Anexo G).

A relação entre o diferencial de seleção efetivo e o diferencial de seleção esperado pode fornecer uma idéia do efeito conjunto das seleções natural e artificial, e 
verificar se a seleção natural está operando. Se as diferenças em fertilidade estiverem relacionadas aos valores fenotípicos do caracter sob seleção direta, a seleção natural poderá auxiliar ou retardar a seleção artificial (Koch et al., 1994; Falconer \& Mackay, 1996). As razões dos diferenciais de seleção efetivos e esperados para P550 das fêmeas selecionadas para reprodução foram 1,24 e 0,93, respectivamente para $\mathrm{NeC}$ e $\mathrm{NeS}$, indicando pequeno efeito da seleção natural sobre a fertilidade das vacas, mas com tendência das fêmeas de maiores diferenciais de seleção para P550 deixarem mais progênies no $\mathrm{NeC}$, e aquelas de menores diferenciais para P550 deixarem mais progênies no NeS. Ou seja, a seleção natural, no esquema de seleção realizado, interferiu pouco no processo de seleção artificial, agindo de uma forma estabilizadora. Koch et al. (1994) observaram razões maiores que a unidade (1,3 a 1,5) para as matrizes nas três linhas seleção, indicando que as fềmeas com maiores diferenciais de seleção deixaram maior número de progênies em 20 anos de experimento com Hereford nos EUA. Contrariamente, MacNeil et al. (1992) observaram na "Linha 1-Hereford" que desde a década de 60, após cerca de 30 anos de seleção para ganho de peso pós-desmama, as novilhas que vieram a ser mães tinham pesos ligeiramente inferiores à média de peso a um ano, e inferem que o ambiente no qual estes bovinos produziram bezerros colocou um limite superior no potencial de crescimento que também permite reprodução.

\subsubsection{Análise dos BLUPs - resposta direta no peso à seleção e correlacionada na altura das fêmeas ao sobreano.}

As médias observadas dos pesos à seleção da população inicial por ano e sexo, e das primeiras e das demais progênies nascidas no experimento de seleção, por ano, sexo e rebanho de nascimento, fornecem por si só uma idéia clara da mudança fenotípica ocorrida ao longo dos anos (Anexo H).

Estimativas obtidas por meio de análises de quadrados mínimos desta mesma população, incluindo os animais nascidos até 1995, além dos parâmetros populacionais, foram relatadas por Razook et al. (1998). No presente estudo, a estimativa da tendência genética no caracter sob seleção direta foi obtida somente por meio das soluções de 
modelo misto, ajustando modelo animal, e incluindo a matriz de parentesco completa até os animais base.

Pelo fato dos pesos à seleção dos machos (P378) e fêmeas (P550) terem sido obtidos em idades e sob manejos pós-desmama distintos, foi feita uma análise bivariada de P378 e P550, fixando a correlação ambiental em zero, a qual revelou o que já era esperado, uma correlação genética menor que a unidade $(0,88)$ entre os pesos à seleção nos dois sexos. Para minimizar este problema, as análises foram feitas de duas maneiras, usando os pesos sem qualquer padronização, e padronizando-os pelo respectivo desviopadrão de cada sexo $(35,78 \mathrm{~kg}$ para machos e 39,20 kg para fêmeas). As soluções obtidas por ambos procedimentos foram muito similares, provavelmente pelo fato dos desvios-padrões fenotípicos não diferirem substancialmente.

As diferenças nos valores genéticos do peso à seleção no decorrer do tempo refletem as diferentes tendências realizadas nos rebanhos (Parnell et al., 1997). A média dos valores genéticos do peso à seleção no início do experimento (1978-80) era 0,9 kg para os machos e 0,3 kg para as fêmeas. Após 16 anos (1981 a 1996) de seleção a média dos valores genéticos foi $0,8 \mathrm{~kg}$ e $-1,3 \mathrm{~kg}$ no $\mathrm{NeC}, 36,5 \mathrm{~kg}$ e $36,4 \mathrm{~kg}$ no $\mathrm{NeS}, 39,7 \mathrm{~kg}$ e $39,7 \mathrm{~kg}$ no NeT, para machos e fêmeas, respectivamente. Os valores genéticos somente das fêmeas, obtidos na análise univariada dos pesos dos machos e fêmeas como um só caracter, sem padronização, estão plotados na Figura 1, os quais são expressos como desvios da média de todos os animais da população base (anterior a 1978). Apesar das primeiras progênies nascidas nos rebanhos separados serem de 1981, em 1978 foram usados tourinhos com um certo diferencial de seleção positivo para peso ao sobreano, e assim, as progênies fêmeas nascidas em 1981 no NeS já tinham média de PSEL diferente das demais. Em 1983 os dois rebanhos selecionados já mostram valores genéticos muito semelhantes, que se manteve ao longo dos anos. Nas montas de 1988 e 1989 foram colocados no NeT dois touros nascidos e usados por dois anos no $\mathrm{NeC}$, fato que refletiu na diminuição do valor genético das progênies de 1989 e um pouco menos na de 1990. 


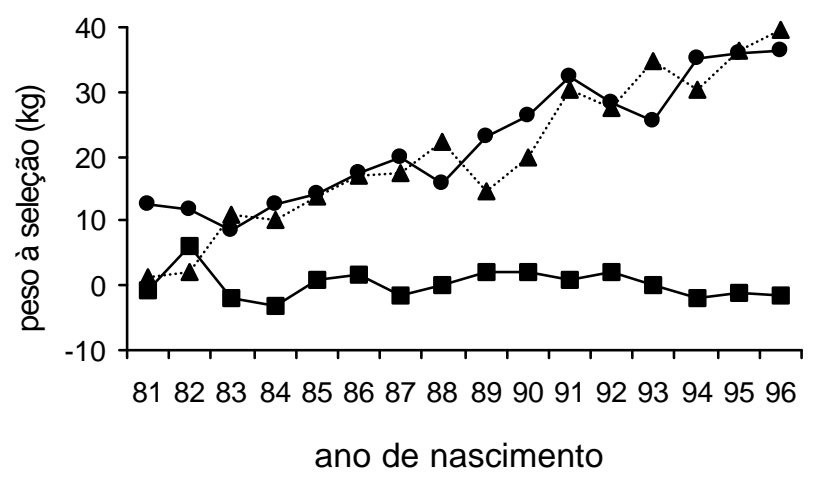

Figura 1 - Valores genéticos médios para peso à seleção das fêmeas dos três rebanhos (controle $\mathbf{\square}$, seleção • e tradicional • ).

A tendência dos valores genéticos médios anuais do PSEL para cada rebanho, obtida tanto para os pesos sem padronização, como também para os padronizados, estão na Tabela 2. Como porcentagem da média do controle (Anexo H) os valores correspondem a $0,62 \%$ e $0,85 \%$ ao ano nos machos e $0,77 \%$ e $0,98 \%$ ao ano nas fêmeas, respectivamente para $\mathrm{NeS}$ e NeT. As maiores respostas foram conseguidas nas fêmeas, fato difícil de ser explicado, e em NeT, provavelmente por ter sido um rebanho mais aberto que NeS, além do fato de que em $1981 \mathrm{NeS}$ já apresentava média diferente de NeC mas NeT não (Figura 1). Razook et al. (1998), estimaram a tendência genética anual em $\mathrm{NeS}$ como desvio de $\mathrm{NeC}$, separadamente para machos (P378) e para as fêmeas (P550), pelo método dos quadrados mínimos, e relataram resposta superior à encontrada neste trabalho (2,7 kg/ano ou 0,11 unidades de desvio-padrão/ano para machos e fêmeas). Esta diferença pode ser devido ao fato que um dos métodos usados (Dickerson ${ }^{6}$, citado por Razook et al., 1998) pressupõe que não houve mudança genética na população controle, e portanto, se houve, a resposta pode estar sub ou superestimada; além de que na análise por quadrados mínimos os efeitos maternos não foram levados em conta. As metodologias usadas por Razook et al. (1998) já foram extensamente usadas na análise de experimentos de seleção quando uma população controle é mantida 
(Irgang et al., 1985; Baker et al., 1991; Koch et al., 1994; Parnell et al., 1997, entre outros). Entretanto, a metodologia de modelos mistos, em particular a análise de máxima verossimilhança com um modelo animal, parece fornecer ferramentas que permitem um entendimento melhor dos resultados dos experimentos de seleção (Meyer \& Hill, 1991; Baker et al., 1991; Martinez et al., 2000). Sorensen \& Kennedy (1983 e 1984) demonstraram a eficácia da metodologia de modelos mistos para separar as tendências genéticas e ambientais e levar em conta a variância devido à deriva genética sob certas condições. Primeiro, as variâncias e covariâncias genéticas e fenotípicas da população antes da seleção são conhecidas, segundo, a seleção é uma função linear dos registros e, terceiro, que a matriz de parentesco completa, com todos os animais envolvidos na seleção, seja usada na análise. Destas três condições, pode-se supor que as duas últimas foram cumpridas, uma vez que, fora as raras exceções (somente em casos de doenças e defeitos) a seleção foi sempre uma função linear dos registros, e toda a matriz de parentesco, a partir da população base, foi usada na análise. Além disso, se uma linha controle é usada e esta é geneticamente relacionada à selecionada, o uso de todos os dados em uma única análise fornece estimativas dos efeitos fixos e aleatórios com menores variâncias, provavelmente resultado do maior contraste entre as linhas (Mrode et al., 1990a).

No Anexo I, estão plotadas as médias anuais ajustadas do peso aos 550 dias, como desvio da população controle, representando a mudança genética nas fêmeas em $\mathrm{NeS}$ e NeT, estimada por quadrados mínimos (Anexo I - Figura 4), e os valores genéticos médios do peso aos 550 dias, representando a mudança genética nas fêmeas dos três rebanhos, estimada por modelo misto, sem incluir os registros dos machos (Anexo I - Figura 5). Juntamente com a Figura 1, é possível observar que conforme as informações da população vão sendo incorporadas na análise (em ordem crescente, Figuras 1, e Figuras 4 e 5 do Anexo I), menores são as flutuações anuais. $\mathrm{O}$ uso da matriz de parentesco tem o efeito de comparar o registro do animal com um índice baseado nas informações de seus parentes, e os valores genéticos individuais são

${ }^{6}$ DICKERSON, G.E. Techniques for research in quantitative animal genetics. In: Techniques and procedures in animal research. New York, 1969. p.36-79. 
regredidos em direção aos valores preditos pelo índice, suavizando flutuações excessivas (Walsh, 1999b). Devido a esta propriedade, a resposta estimada por modelo misto tende a ser mais suave que a resposta verdadeira (ou aquela estimada por quadrados mínimos), pois é menos afetada pelos verdadeiros desvios de amostragem (Sorensen \& Kennedy, 1986).

Tabela 2. Estimativas da tendência genética anual para peso à seleção (PSEL), de machos e fêmeas, nos três rebanhos.

\begin{tabular}{lccc}
\hline Caracter/sexo & $\mathrm{NeC}$ & $\mathrm{NeS}$ & $\mathrm{NeT}$ \\
\hline PSEL (machos) kg/ano & $-0,060 \pm 0,113$ & $1,700 \pm 0,158$ & $2,333 \pm 0,191$ \\
PSEL (fêmeas) kg/ano & $-0,081 \pm 0,124$ & $1,887 \pm 0,169$ & $2,384 \pm 0,177$ \\
PSEL (machos) dp/ano $^{1}$ & $-0,003 \pm 0,003$ & $0,046 \pm 0,004$ & $0,063 \pm 0,005$ \\
PSEL (fêmeas) dp/ano $^{1}$ & $-0,002 \pm 0,003$ & $0,050 \pm 0,004$ & $0,064 \pm 0,005$
\end{tabular}

T, pesos padronizados pelo desvio-padrão de cada sexo.

As respostas médias anuais obtidas neste experimento para PSEL estão um pouco abaixo das obtidas nos experimentos com Bos taurus. Mrode (1988b) e Razook (1988) relatam taxa média de mudança no peso a um ano de idade similares, obtidas de 9 e 10 experimentos, igual a 2,65 kg/ano, correspondendo a $0,83 \%$ da média ao ano ou a 0,08 unidades de desvio padrão fenotípico ao ano. Resultados mais recentes das respostas anuais, nas linhas selecionadas para peso a um ano ou ganho de peso até um ano, foram de 2,49 \pm 0,24 kg/ano, 2,16 $\pm 0,31 \mathrm{~kg} / \mathrm{ano}$ e 1,20 \pm 0,12 kg/ano em três diferentes linhas de Angus e Hereford (Baker et al., 1991); de 2,64 kg/ano em Hereford (Kock et al., 1994) e de 2,19 kg/ano em Angus (Parnell et al., 1997). Além do material genético, do esquema de seleção como um todo, e do método usado para estimar as respostas médias anuais, os experimentos têm diferido quanto ao intervalo de gerações 
conseguido nestas linhas, o que pode explicar as diferenças nas respostas (Falconer \& Mackay, 1996). Enquanto que neste experimento o intervalo médio foi de 5,1 anos (Razook et al., 1998), as linhas de Baker et al. (1991) tiveram 3,2; 3,3, e 4,4 anos respectivamente, a de Koch et al. (1994) 4,2 anos e a de Parnell et al. (1997) 3,2 anos. Estas diferenças se devem essencialmente às fêmeas, desde o uso de novilhas com um ano de idade como à menor permanência das matrizes no rebanho devido a possibilidade de maiores taxas de reposição. No Brasil, esforço tem sido feito por algumas empresas de melhoramento genético, no sentido de desafiar novilhas Nelore colocando-as em monta com um ano de idade, entretanto os resultados positivos ainda são muito baixos (12\% de prenhez, Machado et al., 2001) se comparados aos obtidos em Bos taurus.

Na Figura 2 está ilustrada a resposta correlacionada na altura aos 550 dias de idade das fêmeas (A550), estimada também pelos valores genéticos em análise bivariada com PSEL. Em 1985, época em que iniciou o registro de A550, já havia diferença entre o valor genético médio de A550 do rebanho controle e dos selecionados $(-0,17 \mathrm{~cm}, 1,00$ cm e 0,90 cm respectivamente para $\mathrm{NeC}, \mathrm{NeS}$ e $\mathrm{NeT}$ ), e em 1996 os correspondentes valores foram $-0,85 \mathrm{~cm}, 3,5 \mathrm{~cm}$ e $3,6 \mathrm{~cm}$. A taxa de mudança anual foi de $-0,04 \pm 0,03$ $\mathrm{cm}$ para $\mathrm{NeC}, 0,25 \pm 0,03 \mathrm{~cm}$ para $\mathrm{NeS}$ e 0,24 $\pm 0,04$ para NeT.

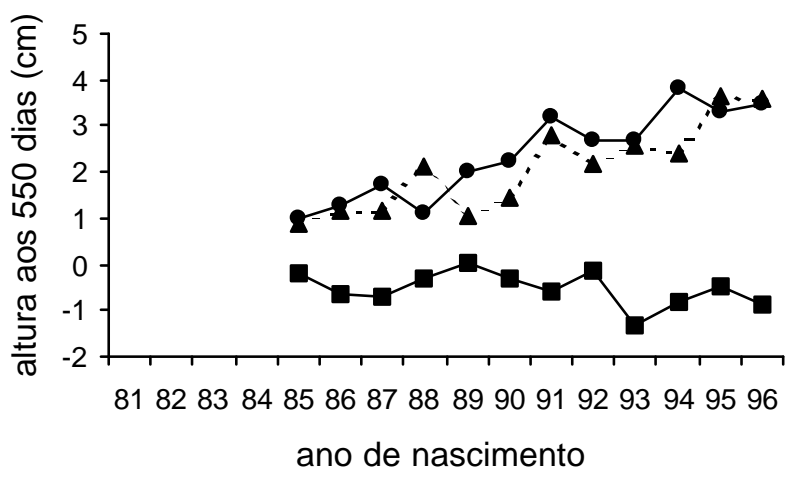

Figura 2 - Valores genéticos médios para altura à seleção das fêmeas (A550) dos três rebanhos (controle $\boldsymbol{\square}$, seleção $\bullet$ e tradicional $\bullet$ ). 
As respostas correlacionadas em A550 foram menores que as obtidas por Cyrillo et al. (2000) nos machos dos três rebanhos deste experimento. Os autores relatam resposta total de 4,5 $\mathrm{cm}$ na altura dos machos ao final da prova de ganho de peso, tanto no rebanho seleção como no tradicional, nas progênies de 1989 a 1996, correspondendo a tendências anuais iguais a $0,47 \mathrm{~cm} /$ ano para o rebanho seleção e $0,52 \mathrm{~cm} /$ ano para o tradicional, obtidas por regressão dos desvios das médias dos selecionados em relação ao controle, em função do ano de nascimento das progênies. Arthur et al. (1997) também relataram resposta superior $(0,35 \mathrm{~cm} / \mathrm{ano})$ na altura a um ano de idade de machos e fêmeas selecionados para ganho do nascimento a um ano, por 17 anos, estimada pelos valores genéticos médios anuais.

\subsubsection{Análise das médias e dos BLUPs - respostas correlacionadas no tamanho e reprodução das matrizes.}

Os contrastes entre as médias dos desempenhos das fêmeas nascidas após 1992 nos rebanhos selecionados $\mathrm{NeS}$ e $\mathrm{NeT}$ em relação ao $\mathrm{NeC}$, para os caracteres estudados nas fêmeas após a seleção, são apresentados na Tabela 3. Como esperado houve diferença significativa $(\mathrm{P}<0,01)$ para os caracteres relativos ao tamanho do animal, com exceção do escore de condição corporal, cujos resultados foram diferentes entre NeS e NeT. Em termos percentuais, as novilhas dos rebanhos NeS e NeT foram, em média, $19 \%$ mais pesadas (peso médio ajustado igual a 329 e $325 \mathrm{~kg}$ ) que as do $\mathrm{NeC}$ (peso médio ajustado igual a $275 \mathrm{~kg}$ ), e $4 \%$ mais altas na entrada da primeira estação de monta; e estas diferenças diminuíram no peso das vacas na entrada da monta (incluindo novilhas), 15\% (peso médio ajustado igual a 388 e $393 \mathrm{~kg}$ para NeS e NeT e $339 \mathrm{~kg}$ para $\mathrm{NeC})$, e se mantiveram na altura, $4 \%$.

O peso na entrada da monta das novilhas é muito próximo ao PSEL, pois foi obtido, em média, após 7,5 meses deste, e a correlação genética obtida em análise bivariada sob modelo animal de PSEL com PEM1 igual à unidade confirma este fato. A grande diferença observada entre as médias de NeS e NeT em relação a NeC para PEM1 e AEM1, bem acima da média dos BLUPs das fêmeas nascidas em 1996 em NeS e NeT, 
igual a $37 \mathrm{~kg}$ para PSEL e 2,7 cm para A550, é devido ao fato que em PSEL a média é de toda a população antes da seleção e as médias de PEM1 e AEM1 representam somente as 50\% selecionadas, com base em maiores diferenciais de seleção para P550. As médias dos BLUPs para peso na entrada da primeira monta em 1996 foram 0; 43 e 48 $\mathrm{kg}$, respectivamente para $\mathrm{NeC}, \mathrm{NeS}$, e $\mathrm{NeT}$ (Anexo K), sendo, portanto, acima daquelas obtidas para PSEL, mas abaixo das diferenças entre selecionados e controle obtidas por quadrados mínimos das fêmeas nascidas de 1993 a 1996.

Tabela 3. Estimativas do contraste e respectivo erro-padrão entre as médias dos rebanhos seleção $(\mathrm{NeS})$ e tradicional $(\mathrm{NeT})$ em relação ao rebanho controle $(\mathrm{NeC})$, herdabilidades $\left(\mathrm{h}^{2}\right)$ e repetibilidades $(\mathrm{r})$ dos caracteres estudados.

\begin{tabular}{|c|c|c|c|c|}
\hline Caracter & $\mathrm{NeS}$ & $\mathrm{NeT}$ & $\mathrm{h}^{2}$ & $\mathrm{r}$ \\
\hline \multicolumn{5}{|l|}{ Peso entrada da monta (kg) } \\
\hline $1^{\mathrm{a}}$ monta & $54 \pm 3 \quad * *$ & $50 \pm 3 \quad * *$ & $0,42 \pm 0,07^{1}$ & \\
\hline Todas montas & $49 \pm 5 * *$ & $54 \pm 4 \quad * *$ & $0,39 \pm 0,05^{2}$ & 0,58 \\
\hline \multicolumn{5}{|l|}{ Altura entrada da monta $(\mathrm{cm})$} \\
\hline $1^{\mathrm{a}}$ monta & $6,4 \pm 0,5 * *$ & $5,0 \pm 0,5 * *$ & $0,44 \pm 0,08^{1}$ & \\
\hline Todas montas & $6,0 \pm 0,6 * *$ & $5,0 \pm 0,6 * *$ & $0,55 \pm 0,06^{2}$ & 0,72 \\
\hline \multicolumn{5}{|l|}{$\begin{array}{l}\text { Condição corporal entrada da } \\
\text { monta (escore) }\end{array}$} \\
\hline $1^{\mathrm{a}}$ monta & $-0,01 \pm 0,08^{\mathrm{NS}}$ & $0,08 \pm 0,088^{\mathrm{NS}}$ & $0,09 \pm 0,07^{1}$ & \\
\hline Todas montas & $-0,42 \pm 0,14 * *$ & $0,22 \pm 0,14^{\mathrm{NS}}$ & $0,20 \pm 0,03^{2}$ & 0,30 \\
\hline \multicolumn{5}{|l|}{ Dias ao parto (dias) } \\
\hline $1^{\mathrm{a}}$ monta & $-4 \pm 6^{\mathrm{NS}}$ & $-12 \pm 6^{\mathrm{NS}}$ & $0,08 \pm 0,06^{1}$ & \\
\hline Todas montas & $3 \pm 5$ NS & $-8 \pm 4^{\mathrm{NS}}$ & $0,10 \pm 0,03^{2}$ & 0,19 \\
\hline \multicolumn{5}{|l|}{ Sucesso ao parto $(\%)$} \\
\hline $1^{\mathrm{a}}$ monta & $0,07 \pm 0,08^{\mathrm{NS} 3}$ & $0,11 \pm 0,08^{\text {NS } 3}$ & $0,04 \pm 0,06^{2}$ & \\
\hline $2^{\mathrm{a}}$ monta/pariu na $1^{\mathrm{a}}$ & $-0,11 \pm 0,12$ NS 3 & $-0,02 \pm 0,12 \quad$ NS 3 & $0,10 \pm 0,07^{2}$ & \\
\hline Todas montas & $-0,02 \pm 0,04^{\mathrm{NS} 3}$ & $0,01 \pm 0,04^{\mathrm{NS} 3}$ & $0,11 \pm 0,03^{2}$ & 0,12 \\
\hline
\end{tabular}

\footnotetext{
', análise bivariada com PSEL, erro-padrão em análise univariada; ${ }^{2}$, análise univariada.

** $\mathrm{P}<0,01, * \mathrm{P}<0,05$, ${ }^{\mathrm{NS}} \mathrm{P}>0,05$, no teste $\mathrm{t}$ para a diferença entre duas médias; ${ }^{3}$, teste $\mathrm{t}$ construído com valores na escala probit, e erro-padrão aproximado, obtido por diferença.
} 
Embora existam evidências que a seleção para peso a um ano de idade leve a mudança no peso adulto das vacas, advindas de estimativas de correlação positiva e relativamente alta entre pesos à seleção e pesos adultos e de estimativas de herdabilidade alta para peso adulto obtidas, em sua maioria, com dados de campo (Koots et al, 1994a,b; Lôbo et al., 2000), há poucos trabalhos relatando resposta realizada no peso adulto a partir da seleção para peso ou ganho em idades jovens. Após 11 anos de seleção para peso a um ano, Morris et al. (1992) observaram diferenças de 5,5\% no peso de entrada na monta das vacas selecionadas, e de $8,5 \%$ no peso de saída, em relação às vacas do rebanho controle. Archer et al. (1998b) relataram que vacas de 2 e 5 anos de idade, pertencentes às $3^{\mathrm{a}}$ e $4^{\mathrm{a}}$ gerações de seleção para ganho de peso até um ano, foram respectivamente $10,5 \%$ e $12 \%$ mais pesadas e $3 \%$ e $2,5 \%$ mais altas que as da linha controle.

Para os caracteres de reprodução analisados (vacas nascidas após 1992), nenhuma diferença significativa foi detectada entre os rebanhos selecionados e o controle, tanto nos primeiros desempenhos, como nos desempenhos repetidos. Apesar dos rebanhos terem sido criados nas mesmas condições ambientais e de manejo, o tamanho dos lotes do $\mathrm{NeC}$ sempre foi menor que os dos rebanhos $\mathrm{NeS}$ e $\mathrm{NeT}$ mas a dimensão dos piquetes de monta foi sempre a mesma, fato este que poderia ter favorecido as fêmeas do $\mathrm{NeC}$ devido à maior disponibilidade de forragem durante o período de monta.

A despeito da baixa herdabilidade estimada para estes caracteres, as médias, por ano de nascimento, das soluções BLUP para o efeito animal de DIAP1 e SP1 foram plotadas nas Figuras 3 e 4. A média do valor genético para DIAP1 das novilhas nascidas em 1981 foi 3, 0 e 1 dias para $\mathrm{NeS}$, NeT e NeC, e para as nascidas em 1996 os respectivos valores foram, 3, 4 e -3 . Embora tenha havido diferença nos resultados obtidos em ambos procedimentos (contrastes entre as médias ajustadas dos últimos 4 anos e BLUP para o efeito animal, obtido com toda a amostra), eles mostram que não houve mudança correlacionada na reprodução das novilhas após 16 anos de seleção para crescimento. O mesmo pode ser observado para SP1, que neste estudo apresentou variabilidade genética igual a zero. 


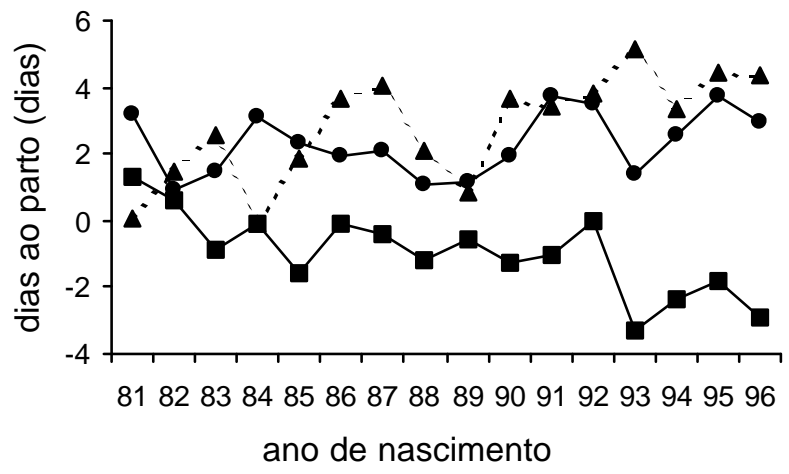

Figura 3 - Valores genéticos médios para dias ao parto da primeira monta (DIAP1), para os três rebanhos (controle $\boldsymbol{\square}$, seleção $\bullet$ e tradicional $\bullet$ ).

Os caracteres DIAP1 e SP1, como foram definidos, podem ser considerados como sendo os mesmos caracteres, uma vez que em uma monta sem sucesso (SP1 igual a 0) foi designado um valor mais alto para DIAP1, embora o primeiro caracter tenha vantagens por apresentar distribuição próxima da normal e herdabilidade um pouco superior que sucesso ao parto (Ponzoni, 1992; Ponzoni \& Gifford, 1994). Johnston \& Bunter (1996) estimaram correlação genética igual a $-0,97$ entre os primeiros desempenhos de dias ao parto, como definido neste estudo, e sucesso ao parto.

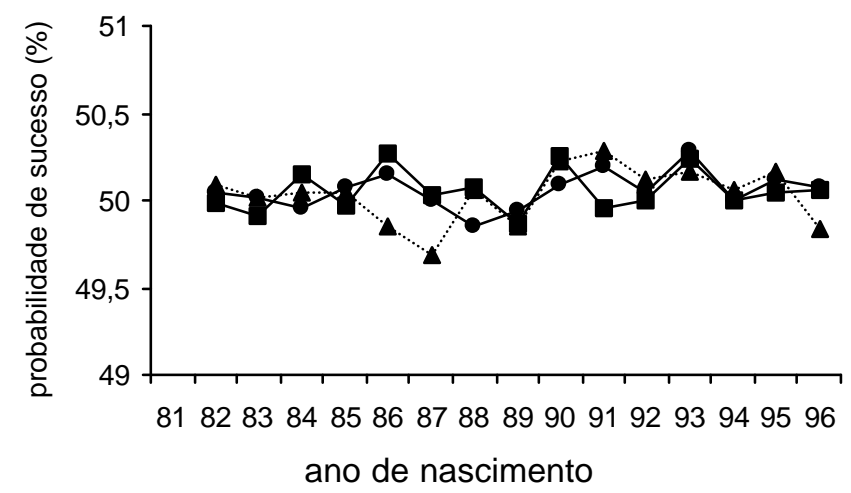

Figura 4 - Valores genéticos médios da probabilidade de sucesso ao parto na primeira monta (SP1), para os três rebanhos (controle $\boldsymbol{\square}$, seleção $\bullet$ e tradicional $\bullet$ ). 
A variabilidade fenotípica observada nos caracteres DIAP1 e SP1 foi praticamente devido só aos efeitos ambientais, dada a baixa variabilidade genética, e ilustrando isso, as soluções de ano de nascimento obtidas de análises separadas de DIAP1 e SP1, estas últimas como desvio de 50\%, são mostradas na Figura 5. Estes resultados confirmam a semelhança dos dois caracteres, já que o ambiente agiu do mesmo modo, só que em sentido contrário, pela própria definição dos caracteres. $\mathrm{O}$ comportamento semelhante das soluções foi mais acentuado após 1986, provavelmente pelo baixo número de observações nos anos anteriores, como já ressaltado anteriormente (Anexo D).

Os contrastes do caracter SP2/1 também foram não significativos, apesar de negativos. A média observada deste caracter (Tabela 1) confirma a expectativa que nos trópicos, a novilha parida e ainda em crescimento, se não manejada corretamente em termos nutricionais, tende a mostrar menores taxas reprodutivas. Resultado semelhante foi observado para os caracteres repetidos de DIAP e SP, cujos contrastes das médias entre os selecionados e o controle foram não significativos. Estes resultados estão totalmente de acordo com os poucos relatos sobre as respostas correlacionadas na reprodução das fêmeas (Mrode, 1988b) nos experimentos de seleção para crescimento.

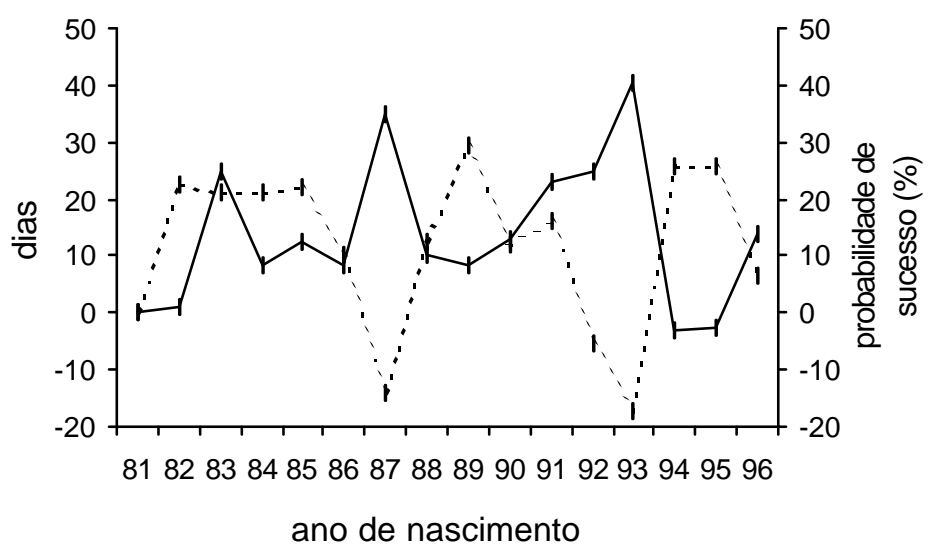

Figura 5 - Efeitos ambientais por ano de nascimento, apresentados como desvio de 1981, dos primeiros desempenhos de das ao parto, DIAP1 (linha contínua) e sucesso ao parto, SP1 (linha tracejada). 
Até meados de 1980, trabalhos e revisões sobre os efeitos da seleção para crescimento indicavam respostas correlacionadas negativas na reprodução das matrizes (Barlow, 1978; Scholtz \& Roux, 1984; Luesakul-Reodecha et al., 1986, entre outros). Em sua revisão, Barlow (1978) concluiu que o efeito detrimental poderia ser aproximadamente $1,1 \%$ de decréscimo na porcentagem de desmame para cada desvio padrão de seleção para peso ao desmame, apesar de admitir que o impacto total não estava claro e que interações poderiam ocorrer com o nível nutricional. Mas em 1984, Baker \& Morris (1984), em um sumário crítico dos resultados das respostas correlacionadas à seleção para crescimento em experimentos de seleção, alguns nem publicados, apontaram para a falta de evidências de efeitos negativos na reprodução.

Os resultados mais recentes, e portanto, com mais gerações de seleção, têm demonstrado que a seleção para peso não tem trazido respostas correlacionadas deletérias na reprodução das matrizes, qualquer que seja o caracter analisado. Num dos experimentos de seleção descritos anteriormente (Baker et al., 1991), Morris et al. (1992) não observaram diferenças significativas entre as médias, das linhas selecionadas para peso a um ano de idade e do controle, para porcentagens de vacas prenhes, de morte perinatal de bezerro, taxa de desmame e taxa reprodutiva, encontrando resposta correlacionada positiva na proporção de novilhas mostrando cio na entrada da monta. Wolfe et al. (1990), analisando puberdade nas novilhas das linhas Hereford descritas por Koch et al. (1994), também observaram que as fêmeas selecionadas foram mais jovens à puberdade que as da linha controle. No presente experimento dados de idade à puberdade não estavam disponíveis, uma vez que somente as fêmeas selecionadas aos 550 dias de idade (cerca de 50\%) foram colocadas em monta com dois anos, sendo, as restantes, descartadas.

As respostas correlacionadas no desempenho reprodutivo das fêmeas, ocorridas nas linhas selecionadas de bovinos Angus na Austrália, tem sido descritas por Parnell (1994) e Archer et al. (1998a). Utilizando método dos quadrados mínimos, nenhuma diferença foi detectada nas taxas de prenhez, dias ao parto e duração da gestação das matrizes das linhas selecionadas e controle, nascidas durante 5 anos, após 10 anos do início do experimento. 
Além dos resultados dos experimentos de seleção com uma população controle, soluções de modelos mistos para caracteres reprodutivos, ao longo dos anos de nascimento, tanto para dados experimentais como para dados de campo, em populações selecionadas para maior crescimento, tem mostrado ganho genético muito baixo $(-0,68$ dias/ano ou $-0,05 \%$ da média ao ano, Roso \& Schenkel, 1999) ou essencialmente nulo (MacNeil \& Newman, 1994; Mrode et al., 1990b), como observado aqui para as soluções do efeito animal de DIAP1 e SP1. Em populações selecionadas diretamente para maior e menor taxa reprodutiva, a despeito das baixas estimativas de herdabilidade destes caracteres, diferenças significativas foram observadas entre as duas linhas (maior e menor taxa reprodutiva) quanto a dias ao parto (308 \pm 2 e $321 \pm 3$ dias) e taxa de prenhez (76士6 e $69 \pm 7 \%$ ) das fêmeas de todas as categorias, e como resposta correlacionada o peso das fêmeas foi também significativamente diferente $(376 \pm 3$ e $387 \pm 4 \mathrm{~kg})$. A mudança genética estimada para taxa de prenhez, obtida de soluções BLUP, foi 0,145 $\pm 0,061 \%$ ao ano (Davis et al., 1993). Morris et al. (2000) relataram diferenças menores, mas significativas, na taxa de prenhez (mais $4,7 \pm 2,1 \%$ ) entre duas linhas, cujas fêmeas foram selecionadas para menor e maior idade ao primeiro cio, e os machos para maior peso a um ano em ambas linhas. Contrariamente ao descrito por Davis et al. (1993), Morris et al. (2000) observaram maior peso a um ano de idade na linha selecionada para menor idade ao primeiro cio (mais 2,4\%).

Todos estes relatos, junto aos resultados obtidos no presente estudo, confirmam resultados anteriores, revisados por Baker \& Morris (1984), e apontam para a falta de evidências de efeitos negativos na reprodução advindos da seleção para crescimento, como também, efeitos negativos no crescimento advindos da seleção para reprodução. 


\subsubsection{Herdabilidades e repetibilidades estimadas}

As herdabilidades estimadas foram 0,37 \pm 0,04 e 0,45 \pm 0,06, para PSEL e A550 respectivamente, sendo que o efeito do ambiente permanente materno respondeu por $11 \%$ da variância total de PSEL. Razook et al. (1998) estimaram herdabilidades realizadas, por meio de diferenciais de seleção acumulados, mais altas que as obtidas por modelo animal, iguais a 0,45 para P378 nos machos e de 0,42 a 0,55 para P550 nas fêmeas. Uma possível explicação para este fato é que o método usado pelos autores citados acima ignora os efeitos maternos, o que pode inflacionar a variância genética aditiva e nem sempre a variância residual (Meyer, 1992), aumentando a estimativa da herdabilidade. Entretanto, mesmo que na teoria, efeitos aleatórios adicionais tais como os maternos possam ser acomodados nas análises de modelos mistos, frequentemente a estrutura dos dados em experimentos de seleção pode não fornecer contrastes suficientes para a distinção dos diferentes efeitos (Meyer \& Hill, 1991; Baker et al., 1991). É interessante notar que apesar das análises de dados de campo mostrarem a importância do efeito genético materno no peso a um ano de idade em Nelore (9-10\% da variância total, Eler, et al.,1995; Mercadante et al., 1997; entre outros), as análises de PSEL indicaram não haver este efeito genético nos dados deste experimento, apesar da substancial variância devido ao ambiente materno.

As estimativas de herdabilidade dos caracteres estudados após a seleção das fêmeas (Tabela 3) estão de acordo com aquelas relatadas na literatura, tanto para os caracteres de crescimento como para os de reprodução, obtidos em experimentos de seleção e com dados de campo. Pesos e alturas em idades mais jovens assim como em idades tardias tem herdabilidade alta (Bullock et al., 1993; Johnston et al., 1996; Arthur et al., 1997; Meyer, 1999; Rosa et al., 2000; Silva et al., 2000); escore de condição corporal herdabilidade mais baixa, 0,14 a 0,21 (Johnston et al., 1996); enquanto que dias ao parto apresenta herdabilidade baixa, 0,07 a 0,17 (Meacham \& Notter, 1987; Meyer et al., 1991; Rege \& Famula, 1993; Johnston \& Bunter, 1996; Gressler et al., 2000; Pereira et al., 2000) e taxa de prenhez também baixa e às vezes próxima de zero, 0,02 a 0,21 (Buddenberg et al., 1989; Meyer et al., 1990; Morris \& Cullen., 1994; Evans et al., 1999; 
Doyle et al., 2000; Mwansa et al., 2000). Com exceção dos experimentos de seleção para aumento da taxa reprodutiva (Davis et al., 1993; Morris et al., 2000), os rebanhos bovinos destinados para corte continuarão sendo selecionados para aumentar a produção de carne, ou seja, para maior crescimento, e a lenta melhoria na fertilidade, considerando as baixas herdabilidades, poderá vir somente da exposição precoce das novilhas ao touro (no caso de Bos indicus, já que para Bos taurus isso é fato). Acompanhando as estimativas de herdabilidade, as repetibilidades estimadas foram altas para peso e altura, média para condição corporal e mais baixas para os caracteres de reprodução, como também observado nos estudos citados anteriormente.

Os resultados encontrados no presente estudo, comparando o desempenho reprodutivo de fêmeas selecionadas para peso ao sobreano por 3,5 gerações de seleção (Razook et al., 1998) com fêmeas selecionadas para média deste peso, juntamente com os resultados dos trabalhos publicados na última década, tanto com dados experimentais (Mrode et al., 1990b; Wolfe et al., 1990, Morris et al., 1992; MacNeil \& Newman, 1994; Parnell, 1994; Archer et al., 1998a) como com dados de campo (Meyer et al., 1991; Johnston \& Bunter, 1996; Mercadante et al., 2000; Silva et al., 2000) indicam que a seleção para peso corporal não compromete o desempenho reprodutivo das fêmeas, tanto para rebanhos criados em ambientes temperados como em tropicais.

As evidências encontradas por Herd (1995) no experimento de seleção com bovinos Angus descrito por Parnell et al. (1997), que vacas selecionadas para maior ganho de peso apresentam requerimento diário de mantença semelhante às selecionadas para menor ganho de peso, pois apesar da diferença no peso corporal (24\%), as primeiras necessitam cerca de $79 \%$ da energia metabolizável que as segundas por conter mais gordura e menos proteína por unidade de peso; aliado ao fato que nenhum desses experimentos, com uma população controle, tiveram mais que 5 gerações de seleção avaliadas, pode ser a explicação para o desempenho reprodutivo semelhante entre linhas seleção apesar da diferença nos caracteres de crescimento. 


\subsection{CONCLUSÕES}

A seleção para peso ao sobreano promoveu resposta alta e consistente no peso ao sobreano dos machos e fêmeas ( $2 \mathrm{~kg} / \mathrm{ano}$ ou 0,8 por cento da média ao ano), resposta correlacionada positiva na altura das fêmeas à seleção $(0,25 \mathrm{~cm} / \mathrm{ano})$, assim como no peso e altura das matrizes em idades mais tardias, mas não promoveu diferenças no desempenho reprodutivo das matrizes, avaliado em termos de dias ao parto e sucesso ao parto. 


\section{CONCLUSÕES GERAIS}

Antes da conclusão propriamente dita, serão feitas algumas considerações quanto às várias análises/abordagens realizadas afim de obter a resposta correlacionada à seleção para crescimento no desempenho reprodutivo das matrizes.

A primeira abordagem, usando dados das matrizes nascidas desde o início do experimento, ou seja, das gerações 1 a 4, é limitada no sentido de não estimar a resposta correlacionada decorrente somente da seleção acumulada. A segunda, usando novamente dados de todas as matrizes num modelo misto que permite o estudo longitudinal do desempenho reprodutivo, é limitada pelo pequeno número de informações em cada idade, resultando em estimativas de variâncias, herdabilidades e consequentemente valores genéticos não muito confiáveis devido aos prováveis altos erros associados a essas estimativas. Uma terceira abordagem, usando os dados das matrizes nascidas nos últimos quatro anos, estima a resposta correlacionada na reprodução advinda da seleção acumulada para peso, mas é também limitada pelo reduzido número de observações analisado, além do fato que estas fêmeas não apresentavam registro completo de sua vida reprodutiva.

Todas essas estratégias esbarram ainda no problema da amostra analisada referente aos caracteres de reprodução ser altamente selecionada, representando somente $50 \%$ das fêmeas nascidas, além do fato de não considerar o restante das informações disponíveis referente à amostra anterior à seleção numa só análise, e tampouco a matriz de parentesco que faz ligação entre as gerações, esta última incorporada somente na segunda abordagem. Adicionalmente, análises incorporando toda a informação disponível desde o início do experimento foram feitas com o primeiro desempenho reprodutivo das matrizes. Apesar das considerações quanto às análises realizadas, os 
resultados obtidos em cada uma delas foram coerentes, apontando para uma conclusão única.

A seleção para peso ao sobreano promoveu resposta alta e consistente no peso ao sobreano dos machos e fêmeas ( $2 \mathrm{~kg} / \mathrm{ano}$ ou 0,8 por cento da média ao ano), resposta correlacionada positiva na altura das fêmeas à seleção $(0,25 \mathrm{~cm} / \mathrm{ano})$, assim como no peso e altura das matrizes em idades mais tardias, mas não promoveu diferenças no desempenho reprodutivo das matrizes, avaliado em termos de dias ao parto e sucesso ao parto. 
ANEXOS 
Anexo A - Cálculo do peso ajustado aos 378 dias de idade (P378) dos machos.

$$
\mathrm{P} 378=[\mathrm{P} 210+(\mathrm{G} 112 \times 168)], \text { sendo } \mathrm{P} 210=\{[(\mathrm{PV}-\mathrm{PN}) / \mathrm{I} \times 210]+\mathrm{PN}\} \mathrm{e}
$$

G112=(PFP - PIP)/112. P210 é o peso ao desmame padronizado para 210 dias, PV é o peso na entrada da prova de desempenho após jejum e I a idade neste peso, PN é o peso ao nascimento, PIP e PFP são pesos ao início (após o período de adaptação) e ao final da prova de desempenho, ambos obtidos após jejum hídrico e alimentar durante 12 horas, e G112 é o ganho em peso diário no período de 112 dias da prova de desempenho, após período de adaptação.

Anexo B - Cálculo do peso ajustado aos 550 dias de idade (P550) das fêmeas.

$\mathrm{P} 550=\{\mathrm{P} 210+[(\mathrm{PFP}-\mathrm{PDR}) / \mathrm{N}$ x 340] $\}$, sendo $\mathrm{N}$ o número de dias no pasto após desmame e PFP o peso após este período, e PDR o peso real ao desmame.

Anexo C - Cálculo da altura ajustada para 550 dias de idade (A550) das fêmeas.

A550=altura em abril $+(550-$ idade em abril $) \times b$

Sendo: $\quad b=0,39741 \times 10^{-3}$ para $\mathrm{NeC}$, $b=0,66708 \times 10^{-3}$ para NeS, $b=0,58462 \times 10^{-3}$ para NeT. 
Anexo D - Distribuição dos registros repetidos de dias ao parto (DIAP) e sucesso ao parto (SP) nos anos de entrada na monta.

\begin{tabular}{ccc}
\hline Ano de entrada na monta & Dias ao parto (DIAP) & Sucesso ao parto (SP) \\
\hline 1983 & 70 & 30 \\
1984 & 127 & 133 \\
1985 & 154 & 154 \\
1986 & 214 & 214 \\
1987 & 248 & 248 \\
1988 & 275 & 278 \\
1989 & 310 & 325 \\
1990 & 358 & 358 \\
1991 & 385 & 385 \\
1992 & 348 & 348 \\
1993 & 343 & 343 \\
1994 & 363 & 363 \\
1995 & 345 & 345 \\
1996 & 343 & 343 \\
1997 & 353 & 354 \\
1998 & &
\end{tabular}


Anexo E - Distribuição dos registros de peso (PEM), altura (AEM) e condição corporal (CEM) na entrada da monta, dias ao parto (DIAP) e sucesso ao parto (SP) nas classes de idade da vaca na monta (CIVM).

\begin{tabular}{cccccc}
\hline CIVM (anos) & PEM & AEM & CEM & DIAP & SP \\
\hline 2 & 899 & 764 & 726 & 878 & 926 \\
3 & 762 & 682 & 636 & 758 & 769 \\
4 & 654 & 621 & 581 & 657 & 660 \\
5 & 521 & 521 & 491 & 526 & 526 \\
6 & 427 & 427 & 427 & 427 & $(>5)$ \\
7 & 327 & 327 & 327 & 326 & \\
8 & 247 & 247 & 247 & 247 & \\
$>8$ & 410 & 410 & 408 & 417 & \\
\hline
\end{tabular}




\section{Anexo F - Coeficientes de geração e de endogamia.}

Os coeficientes de geração e de endogamia foram calculados a partir das primeiras progênies nascidas, ou seja, a partir dos animais nascidos em 1981, e assim, os pais de 1981 considerados como geração e endogamia zero.

Por ocorrer sobreposição de gerações em bovinos, principalmente pelo fato das matrizes permanecerem no rebanho, até o descarte por falha reprodutiva, juntamente com as recém selecionadas e os machos apresentarem taxas de reposição bem mais altas que as fêmeas, os animais contemporâneos podem diferir quanto à geração a qual pertencem. $\mathrm{O}$ coeficiente de geração do indivíduo é um valor representativo da geração do animal, e foi calculado como (Brinks et al. ${ }^{7}$, citado por Razook et al., 1993): $\mathrm{CG}=(\mathrm{CG}$ pai + CG mãe $) / 2+1$, em que $\mathrm{CG}$ é o número médio de segregações mendelianas dos pais até os animais fundadores, e a partir do coeficiente de geração tem-se idéia do número de gerações de seleção, CG - 1 (Koch et al., 1994).

$\mathrm{O}$ coeficiente de endogamia de Wright, para um animal $\mathrm{X},\left(\mathrm{F}_{\mathrm{X}}\right)$ é calculado como: $\mathrm{F}_{\mathrm{X}}=\sum_{\mathrm{AC}=1}^{\mathrm{K}}\left(\frac{1}{2}\right)^{\mathrm{n}_{1}+\mathrm{n}_{2}\left(1+\mathrm{F}_{\mathrm{AC}}\right)}$, onde, $\mathrm{AC}$ é um ancestral comum dos pais de $\mathrm{X}$; K é o número de ancestrais comuns no pedigree de $\mathrm{X} ; \mathrm{n}_{1}$ é o número de gerações separando o ancestral comum a partir do pai de $\mathrm{X}, \mathrm{n}_{2}$ é o número de gerações separando o ancestral comum a partir da mãe de $\mathrm{X}, \mathrm{F}_{\mathrm{AC}}$ é o coeficiente de endogamia do ancestral comum (Bourdon, 2000).

Os acasalamentos sempre foram dirigidos por meio de inspeção visual das genealogias, a fim de evitar acasalamentos consanguíneos. A partir de 1994 passou-se a utilizar o programa SIREGE (Polastre et al., 1992) para o mesmo fim, contudo com maior eficiência, observado pela queda dos níveis de endogamia médios (Anexo H).

\footnotetext{
${ }^{7}$ BRINKS, J.S.; CLARK, R.T.; KIEFFER, N.M. Evaluation of response to selection and inbreeding in a closed line of Hereford cattle. Washington, Agricultural Research Service, 1965. 36p. (Technical Bulletin, 1323).
} 
Anexo G - Número de fêmeas avaliadas, selecionadas e média dos diferenciais de seleção esperados (dses) e efetivos (dsef) das fêmeas, por ano de nascimento (an).

\begin{tabular}{ccccccccccc}
\hline \multicolumn{4}{c}{ Rebanho Controle (NeC) } & \multicolumn{5}{c}{ Rebanho Seleção (NeS) } \\
\hline an & avali- & selecio- & dses & paridas & Dsef & avali- & selecio- & dses & paridas & dsef \\
& adas & nadas & $(\mathrm{kg})$ & & $(\mathrm{kg})$ & adas. & nadas & $(\mathrm{kg})$ & & $(\mathrm{kg})$ \\
\hline $\mathbf{1 9 8 1}$ & 12 & 5 & 1,18 & 5 & $-6,22$ & 48 & 21 & 13,22 & 19 & 16,67 \\
$\mathbf{1 9 8 2}$ & 15 & 10 & 7,89 & 10 & 6,83 & 42 & 23 & 15,19 & 19 & 17,21 \\
$\mathbf{1 9 8 3}$ & 18 & 11 & 12,26 & 9 & 15,25 & 42 & 21 & 16,67 & 18 & 16,15 \\
$\mathbf{1 9 8 4}$ & 17 & 11 & 5,94 & 8 & 8,79 & 32 & 14 & 14,92 & 12 & 14,51 \\
$\mathbf{1 9 8 5}$ & 22 & 9 & $-1,38$ & 7 & $-3,59$ & 44 & 18 & 18,19 & 13 & 15,30 \\
$\mathbf{1 9 8 6}$ & 16 & 10 & $-4,48$ & 7 & $-1,83$ & 39 & 20 & 15,90 & 18 & 15,89 \\
$\mathbf{1 9 8 7}$ & 12 & 10 & $-0,90$ & 7 & 6,76 & 44 & 23 & 17,10 & 21 & 17,14 \\
$\mathbf{1 9 8 8}$ & 23 & 13 & $-1,17$ & 12 & $-1,64$ & 54 & 21 & 22,51 & 20 & 21,48 \\
$\mathbf{1 9 8 9}$ & 23 & 13 & $-4,51$ & 9 & $-5,23$ & 41 & 25 & 14,99 & 22 & 18,07 \\
$\mathbf{1 9 9 0}$ & 18 & 10 & $-5,15$ & 6 & $-5,95$ & 29 & 22 & 4,34 & 17 & 0,79 \\
$\mathbf{1 9 9 1}$ & 16 & 11 & $-3,33$ & 9 & $-1,03$ & 37 & 24 & 11,15 & 16 & 15,11 \\
$\mathbf{1 9 9 2}$ & 33 & 16 & 6,01 & 14 & 6,02 & 50 & 29 & 11,39 & 23 & 11,90 \\
$\mathbf{1 9 9 3}$ & 13 & 11 & 5,72 & 8 & 4,34 & 34 & 23 & 7,37 & 14 & 1,5 \\
Total & 266 & 140 & 18,08 & 111 & 22,39 & 568 & 284 & 195,09 & 232 & 181,72 \\
Média & 20,5 & 10,8 & 1,39 & 8,5 & 1,72 & 43,7 & 21,8 & 15,01 & 17,8 & 13,98 \\
\hline
\end{tabular}


Anexo H - Número de animais $(\mathrm{N})$, média (kg) e desvio-padrão (DP) do peso à seleção, na implementação do experimento por ano e sexo, e a partir da primeira progênie nascida por ano de nascimento (AN), rebanho e sexo, com coeficientes de geração (CG) e endogamia (F) médios dos animais com registros de P378 (machos) e P550 (fêmeas).

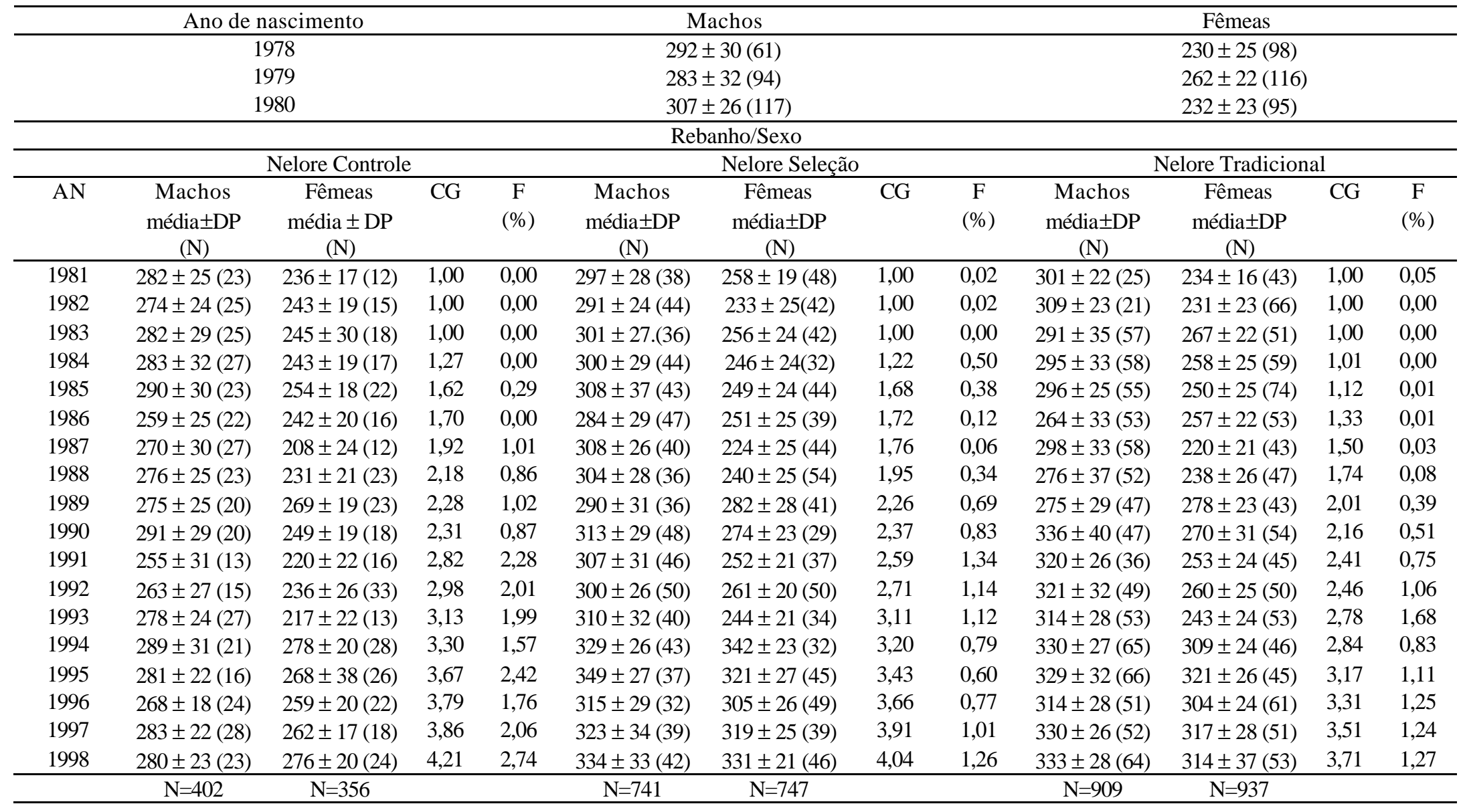




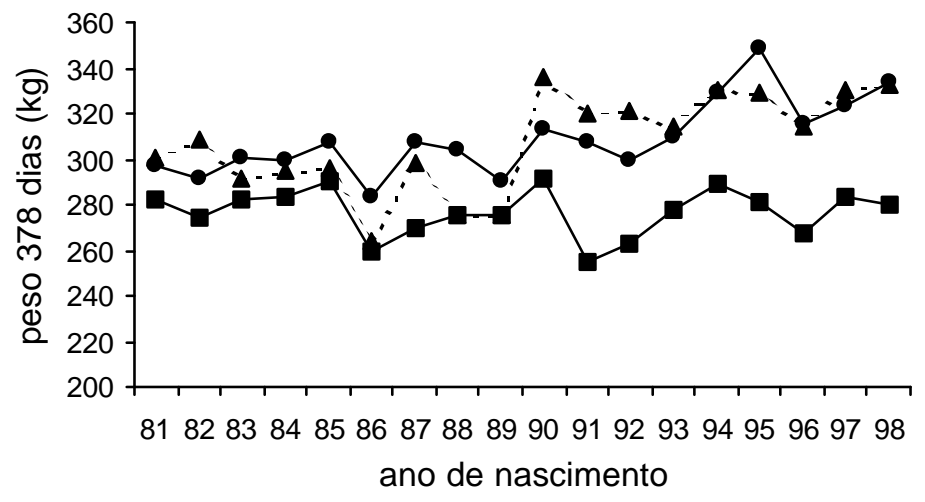

Figura 1 - Médias anuais observadas (mudança fenotípica) do peso aos 378 dias (P378) dos machos dos três rebanhos (controle घ, seleção $\bullet \mathrm{e}$ tradicional $\bullet$ ).

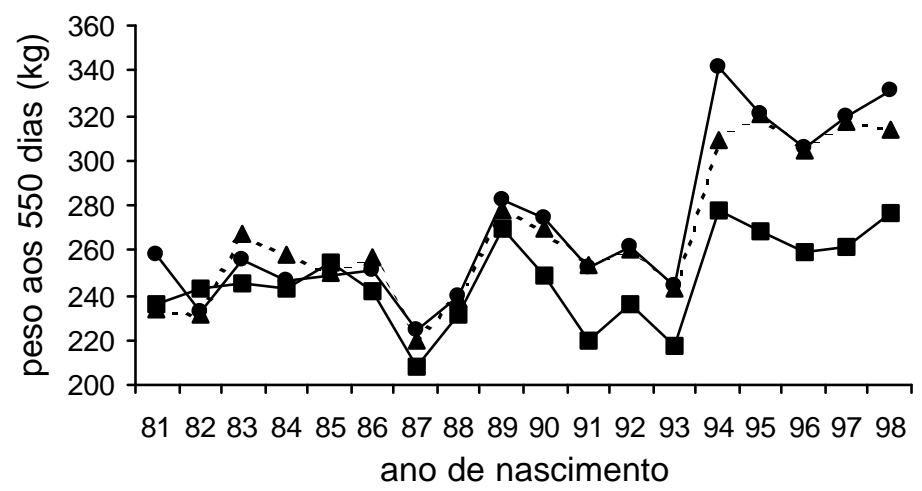

Figura 2 - Médias anuais observadas (mudança fenotípica) do peso aos 550 dias (P550) das fêmeas dos três rebanhos (controle $\mathbf{\square}$, seleção $\bullet \mathrm{e}$ tradicional $\bullet$ ). 
Anexo I - Médias ajustadas (quadrados mínimos) e valores genéticos médios (modelo animal - análise univariada), do peso aos 550 dias de idade das fêmeas.

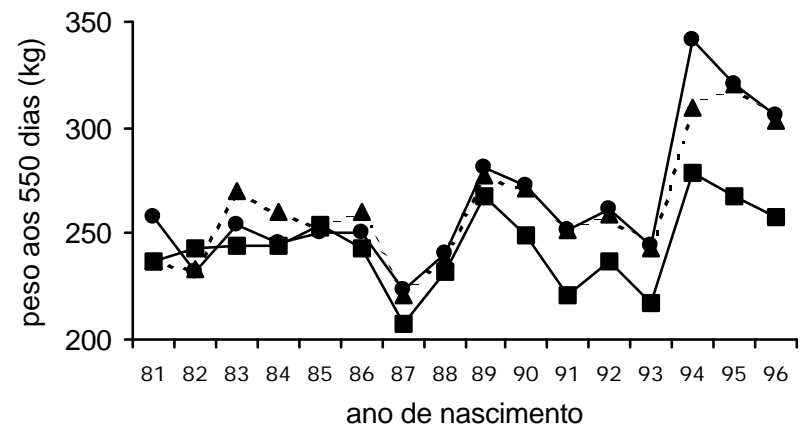

Figura 3 - Médias anuais ajustadas do peso aos 550 dias das fêmeas dos três rebanhos (controle $\mathbf{\square}$, seleção • e tradicional • ).

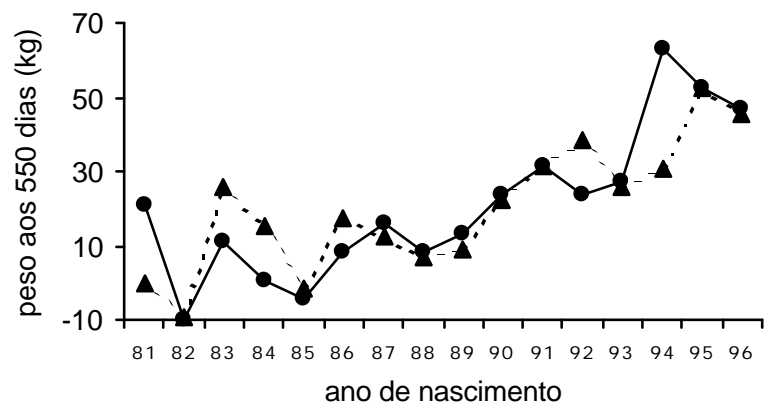

Figura 4 - Médias anuais ajustadas do peso aos 550 dias das fêmeas dos rebanhos selecionados, como desvio da população controle (seleção • e tradicional - ). Representa a mudança genética nos rebanhos selecionados obtida por quadrados mínimos (corrigida para a mudança ambiental). 


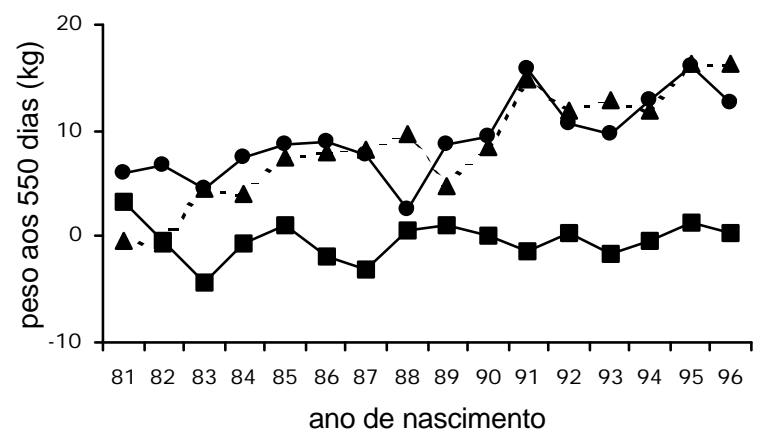

Figura 5 - Valores genéticos médios do peso aos 550 dias das fêmeas dos três rebanhos (controle $\boldsymbol{\square}$, seleção $\bullet$ e tradicional $\bullet$ ). Representa a mudança genética obtida por modelo misto nos três rebanhos, sem incluir os registros dos machos.

Anexo J - Soluções de ano de nascimento, expressos como desvio de 1981, obtidos em análise univariada do peso à seleção (machos e fêmeas), representando a mudança ambiental. Os valores genéticos correspondentes estão plotados na Figura 1 do Capítulo 5.

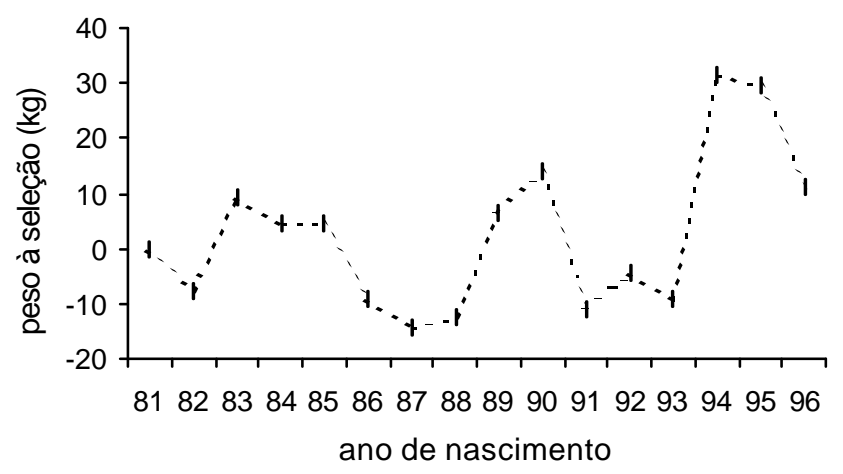

Figura 6 - Efeitos ambientais do peso à seleção por ano de nascimento, apresentados como desvio de 1981. 
Anexo K - Valores genéticos médios do peso de entrada na primeira monta, obtidos em análise bivariada com peso à seleção.

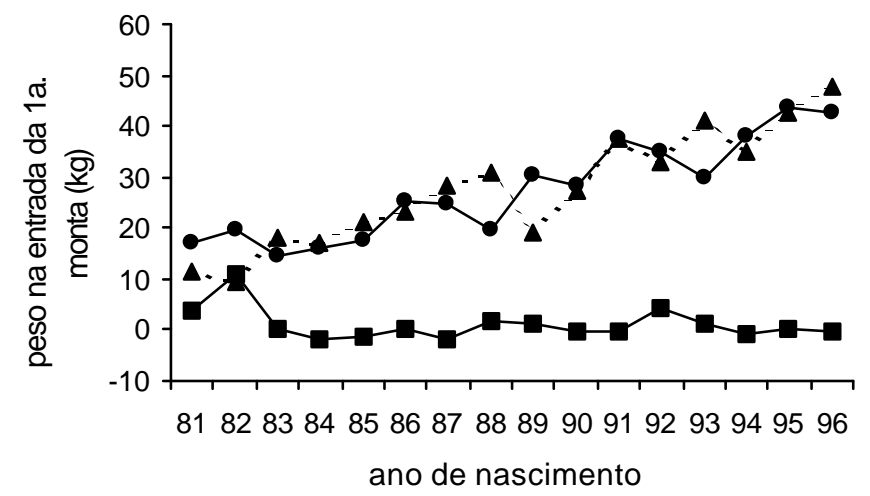

Figura 7 - Valores genéticos médios para peso na entrada da primeira monta das fêmeas dos três rebanhos (controle $\boldsymbol{\square}$, seleção $\bullet$ e tradicional $\bullet$ ).

Anexo L - Médias ajustadas dos registros repetidos de peso na entrada da monta por rebanho, altura e condição corporal, e dias ao parto e probabilidade de prenhez, por classe de idade da vaca (registros das nascidas de 1981 a 1996).

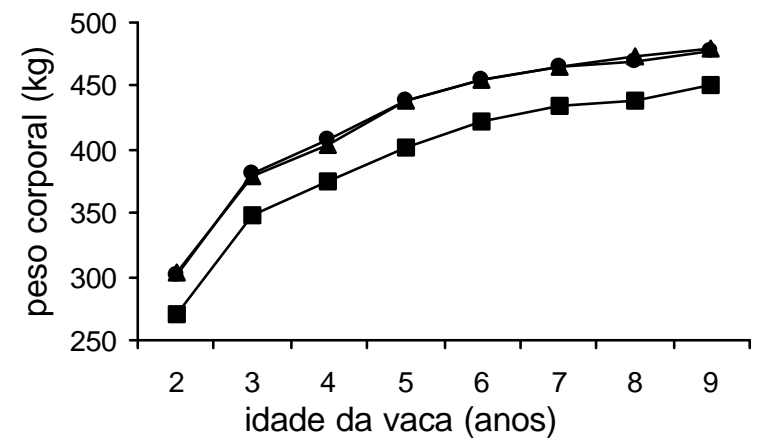

Figura 8 - Peso na entrada da monta (PEM) das vacas, por rebanho (controle $\mathbf{\square}$, seleção - e tradicional $\bullet$ ) e idade. 


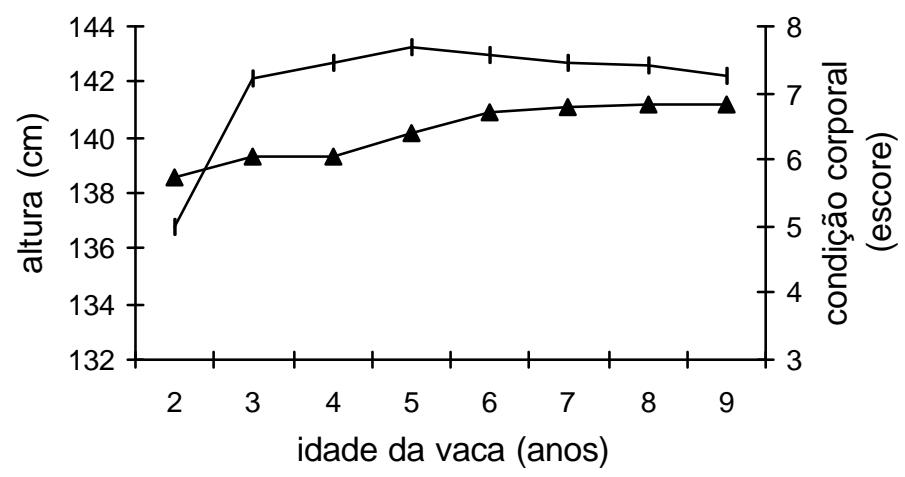

Figura 9 - Altura (AEM) e escore de condição corporal (CEM) na entrada da monta das vacas por idade (AEM ; CEM $\bullet$ ).

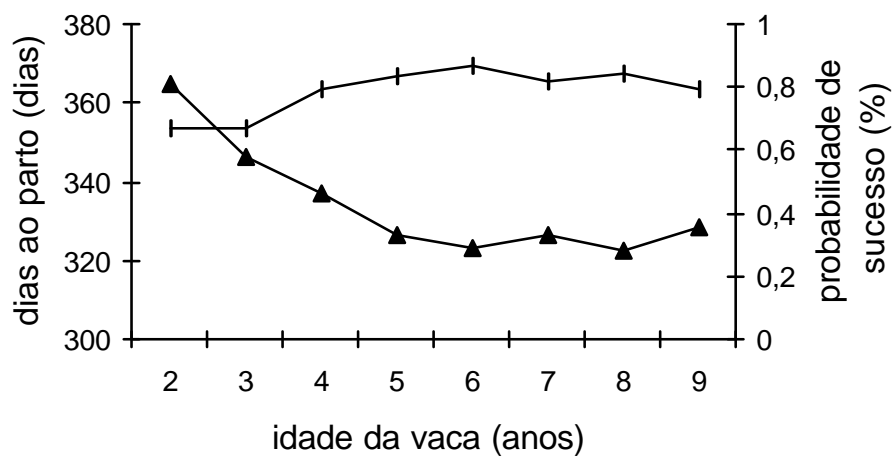

Figura 10 - Dias ao parto (DIAP) e probabilidade de sucesso ao parto das vacas por idade (DIAP ; SP $\bullet$ ). 


\section{REFERÊNCIAS BIBLIOGRÁFICAS}

ARCHER, J.A.; ARTHUR, P.F.; PARNELL, P.F.; VAN de VEN, R.J. Effect of divergent selection for yearling growth rate on female reproductive performance in Angus cattle. Livestock Production Science, v. 57, p.33-40, 1998a.

ARCHER, J.A.; HERD, R.M.; ARTHUR, P.F.; PARNELL, P.F. Correlated responses in rate of maturation and mature size of cows and steers to divergent selection for yearling growth rate in Angus cattle. Livestock Production Science, v.54, p.183192, $1998 b$.

ARTHUR, P.F.; PARNELL, P.F.; RICHARDSON, E.C. Correlated responses in calf body weight and size to divergent selection for yearling growth rate in Angus cattle. Livestock Production Science, v.49, p.305-312, 1997.

BAKER; R.L.; MORRIS, C.A. A review of correlated responses to weight selection in beef cattle under different management and climatic conditions. In: WORLD CONGRESS ON SHEEP AND BEEF CATTLE BREEDING, 2., Pretoria, 1984. Proceedings. Pretoria, 1984. p.1-16.

BAKER, R.L.; MORRIS, C.A.; JOHNSON, D.L.; HUNTER, J.C.; HICKEY, S.M. Results of selection for yearling or 18-month weight in Angus and Hereford cattle. Livestock Production Science, v.29, p.277-296, 1991.

BARLOW, R. Biological ramifications of selection for preweaning growth in cattle. A review. Animal Breeding Abstract, v.46, p.469-494, 1978.

BERGMANN, J.A.G.; GRESSLER, S.L.; PEREIRA, C.S.; PENNA, V.M.; PEREIRA, J.C.C. Avaliação de fatores genéticos e de ambiente sobre algumas características reprodutivas de fêmeas da raça Nelore em regime de estação de monta restrita. Arquivo Brasileiro de Medicina Veterinária e Zootecnia, v.50, p.633-645, 1998. 
BLAIR, H.T.; POLLACK, E.J. Estimation of genetic trend in a selected population with and without the use of a control population. Journal of Animal Science, v.58, p.878-886, 1984.

BLASCO, A. The bayesian controversy in animal breeding. Journal of Animal Science, v.79, p.2023-2046, 2001.

BLASCO, A.; SORENSEN; D.; BIDANEL, J.P. Bayesian inference of genetic parameters and selection response for litter size components in pigs. Genetics, v.149, p.301-306, 1998.

BOLDMAN, K.G.; KRIESE, L.A.; VAN VLECK, L.D.; VAN TASSEL, C.P.; KACHMAN, S.D. A manual for use for MTDFREML. A set of programs to obtain estimates of variances and covariances. Lincoln: Department of Agricultural; Agricultural Research Service, 1995. 120p.

BOURDON, R.M. Understanding animal breeding. Upper Saddle River: PrendiceHall, 2000. 538p.

BUDDENBERG, B.J.; BROWN, C.J.; JOHNSON, Z.B. Heritability estimates of pregnancy rate in beef cows under natural mating. Journal of Animal Science, v.67, p.2589-2594, 1989.

BULLOCK, K.D.; BERTRAND, J.K.; BENYSHEK, L.L. Genetic and environmental parameters for mature weight and other growth measures in polled Hereford cattle. Journal of Animal Science, v.71, p.1737-1741, 1993.

BULMER, M.G. The effect of selection on genetic variability. The American Naturalist, v.105, p.210-211, 1971.

CFM AGROPECUÁRIA. Sumário de touros nelore 1999. São José do Rio Preto, 1999. 54p.

CYRILLO, J.N.S.G.; RAZOOK, A.G.; FIGUEIREDO, L.A.; BONILHA-NETO, L.M.; RUGGIERI, A.C.; TONHATI, H. Efeitos da seleção para peso pós-desmame sobre medidas corporais e perímetro escrotal de machos Nelore de Sertãozinho (SP). Revista Brasileira de Zootecnia, v.29, p.403-412, 2000. 
DAVIS, G.P.; CORBET, N.J.; MACKINNON, M.J.; HETZEL, D.J.S.; ENTWISTLE, K.W.; DIXON, R. Response in female fertility and calf growth to selection for pregnancy rate in tropical beef cattle. Australian Journal of Agricultural Research, p.44, v.1509-1521, 1993.

DOYLE, S.P.; GOLDEN, B.L.; GREEN, R.D.; BRINKS, J.S. Additive genetic parameter estimates for heifer pregnancy and subsequent reproduction in Angus females. Journal of Animal Science, v.78, p.2091-2098, 2000.

EISEN, E.J. Selection theory and experiments. (compact disc). In: WORLD CONGRESS ON GENETICS APPLIED TO LIVESTOCK PRODUCTION, 6. Armindale, 1998. Proceedings. Armindale, 1998.

ELER, J.P.; VAN VLECK, L.D.; FERRAZ, J.B.S.; LÔBO, R.B. Estimation of variances due to direct and maternal effects for growth traits of Nelore cattle. Journal of Animal Science, v.73, p.3253-3258, 1995.

EVANS, J.L.; GOLDEN, B.L.; BOURDON, R.M.; LONG, K.L. Additive genetic relationship between heifer pregnancy and scrotal circumference in Hereford cattle. Journal of Animal Science, v.77, p.2621-2628, 1999.

FALCONER, D.S.; MACKAY, T.F.C. Introduction to quantitative genetics. Essex: Longman, 1996. 464p.

FITZHUGH, H.A. Animal size and efficiency, with special reference to the breeding female. Animal Production, v.27, p.393-401, 1978.

GIANOLA, D.; FOULLEY, J.L. Sire evaluation for ordered categorical data with a threshold model. Genetic, Selection, Evolution, v.15, p.201-224, 1983.

GILMOUR, A.R.; CULLIS, B.R.; WELHAM, S.J.; THOMPSON, R. ASREML reference manual. $\mathrm{ftp}: / / \mathrm{ftp} . \mathrm{res}$. bbsrc.ac.uk/pub/aar/. 2000.

GRESSLER, S.L.; BERGMANN, J.A.G.; PEREIRA, C.S.; PENNA, V.M.; PEREIRA, J.C.C.; GRESSLER, M.G.M. Estudo das associações entre perímetro escrotal e características reprodutivas de fêmeas Nelore. Revista Brasileira de Zootecnia, v.29, p.427-437, 2000. 
HERD, R.M. Effect of divergent selection for yearling growth rate on the maintenance feed requirements of mature Angus cows. Livestock Production Science, v.41, p.39-49, 1995.

HILL, W.G. Estimation of genetic change. I. General theory and design of control populations. Animal Breeding Abstracts, v.40, p.1-15, 1972a.

HILL, W.G. Estimation of realised heritabilities from selection experiments. I. Divergent selection. Biometrics, v.28, p.747-765, 1972 b.

HILL, W.G. Design of quantitative genetic selection experiments. In: ROBERTSON,

A. (Ed.) Selection experiments in laboratory and domestic animals. Slough: CAB, 1980. p.1-13.

IRGANG, R.; DILLARD, E.U.; TESS, M.W.; ROBISON, O.W. Selection for weaning weight and postweaning gain in Hereford cattle. Journal of Animal Science, v.60, p.1142-1155, 1985.

JAMROZIK, J.; SCHAFFER, L.L. Estimates of genetic parameters for a test day model with random regressions for yield traits of first lactation Holstein. Journal of Dairy Science, v.80, p.762-770, 1997a.

JAMROZIK, J.; SCHAFFER, L.L. Genetic evaluation of dairy cattle using test day yields and random regression model. Journal of Dairy Science, v.80, p.1217-1226, $1997 b$.

JOHNSTON, D.J.; BUNTER, K.L. Days to calving in Angus cattle: genetic and environmental effects, and covariances with other traits. Livestock Production Science, v.45, p.13-22, 1996.

JOHNSTON, D.J.; CHANDLER, H.; GRASER, H-U. Genetic parameters for cow weight and condition score in Angus, Hereford, and Poll Hereford cattle. Australian Journal of Agricultural Research, v.47, p.1251-1260, 1996.

KENNEDY, B.W. Use of mixed model methodology in analysis of designed experiments. In: GIANOLA, D.; HAMMOND, K. (Ed.) Statistical methods for genetic improvement of livestock. Berlin: Spring Verlag, 1990. p.77-97.

KENNEDY, B.W.; SCHAEFFER, L.R.; SORENSEN, D.A. Genetic properties of animal models. Journal of Dairy Science, v.71, p.17-26, 1988. Supplement. 
KIRKPATRICK, M.; LOFSVOLD, D.; BULMER, M. Analysis of the inheritance, selection and evolution of growth trajectories. Genetics, v.124, p.979-993, 1990.

KOCH, R.M.; CUNDIFF, L.V.; GREGORY, K.E. Cumulative selection and genetic change for weaning or yearling weight or for yearling weight plus muscle score in Hereford cattle. Journal of Animal Science, v.72, p.864-885, 1994.

KOOTS, K.R.; GIBSON, J.P.; SMITH, C.; WILTON, J.W. Analyses of published genetic parameters estimates for beef production traits. 1. Heritability. Animal Breeding Abstracts, v.62, p.309-338, 1994a.

KOOTS, K.R.; GIBSON, J.P.; WILTON, J.W. Analyses of published genetic parameters estimates for beef production traits. 2. Phenotypic and genetic correlations. Animal Breeding Abstracts, v.62, p.825-853, $1994 \mathrm{~b}$.

LITTEL, R.C.; MILLIKEN, G.A.; STROUP, W.W.; WOLFINGER, R.D. SAS system for mixed models. Cary: SAS Institute, 1996. 433p.

LÔBO, R.N.B.; MADALENA, F.E.; VIEIRA, A.R. Average estimates of genetic parameters for beef and dairy cattle in tropical regions. Animal Breeding Abstracts, v.68, p.433-462, 2000.

LUESAKUL-REODECHA, C.; MARTIN, T.G.; NELSON, L.A. Effects of long-term selection for 365-day weight on maternal performance of beef cows. In: WORLD CONGRESS ON GENETICS APPLIED TO LIVESTOCK PRODUCTION, 3., Lincoln, 1986. Proceedings. Lincoln, 1986. p.205-209.

MACGREGOR, R.G.; CASEY, N.H. Evaluation of calving interval and calving date $\mathbf{s}$ measures of reproductive performance in a beef herd. Livestock Production Science, v.57, p.181-191, 1999.

MACHADO, P.F.A.; BERGMANN, J.A.G.; PEREIRA, J.C.C.; SILVA, M.A. Predição da taxa de gestação de novilhas da raça Nelore acasaladas com um ano de dade. Arquivo Brasileiro de Medicina Veterinária e Zootecnia, v.53, p.237-245, 2001. MACNEIL, M.D.; NEWMAN, S. Genetic analysis of calving date in Miles City Line 1 Hereford cattle. Journal of Animal Science, v.72, p.3073-3079, 1994. 
MACNEIL, M.D.; URICK, J.J.; NEWMAN, S.; KNAPP, B.W. Selection for postweaning growth in inbred Hereford cattle: the Fort Keogh, Montana Line 1 example. Journal of Animal Science, v.70, p.723-733, 1992.

MAKI-TANILA, A.; KENNEDY, B.W. Mixed model methodology under genetic models with a small number of additive and non-additive loci. In: WORLD CONGRESS ON GENETICS APPLIED TO LIVESTOCK PRODUCTION, 3., Lincoln, 1986. Proceedings. Lincoln, 1986. p.443-448.

MARTINEZ, V.; BUNGER, L.; HILL, W.G. Analysis of response to 20 generations of selection for body composition in mice: fit to infinitesimal model assumptions. Genetic, Selection, Evolution, v.32, p.3-21, 2000.

MEACHAM, N.S.; NOTTER, D.R. Heritability estimates for calving date in Simmental cattle. Journal of Animal Science, v.64, p.701-705, 1987.

MERCADANTE; M.E.Z.; LÔBO, R.B. Estimativa de (co)variâncias e parâmetros genéticos dos efeitos direto e materno de características de crescimento de fêmeas de um rebanho Nelore. Revista Brasileira de Zootecnia, v.26, p.1124-1133, 1997.

MERCADANTE, M.E.Z.; LÔBO, R.B.; OLIVEIRA, H.N. Estimativas de (co)variâncias entre características de reprodução e de crescimento em fêmeas de um rebanho Nelore. Revista Brasileira de Zootecnia, v.29, p.997-1004, 2000.

MEYER, K. Variance components due to direct and maternal effects for growth traits of Australian beef cattle. Livestock Production Science, v.31, p.179-204, 1992.

MEYER, K. "DxMRR" - a program to estimate covariance functions for longitudinal data by restricted maximum likelihood (compact disc). In: WORLD CONGRESS ON GENETICS APPLIED TO LIVESTOCK PRODUCTION, 6., Armindale, 1998. Proceedings. Armindale, 1998.

MEYER, K. Estimates of genetic and phenotypic covariance functions for postweaning growth and mature weight of beef cows. Journal of Animal Breeding and Genetic, v.116, p.181-205, 1999.

MEYER, K. Random regressions to model phenotypic variation in monthly weights of Australian beef cows. Livestock Production Science, v.65, p.19-38, 2000. 
MEYER, K.; HILL, W.G. Mixed model analysis of a selection experiment for food intake in mice. Genetic Research, v.57, p.71-81, 1991.

MEYER, K.; HILL, W.G. Estimation of genetic and phenotypic covariance functions for longitudinal or 'repeated' records by restricted maximum likelihood. Livestock Production Science, v.47, p.185-200, 1997.

MEYER, K.; HAMMOND, K.; MACKINNON, M.J.; PARNELL, P.F. Estimates of covariances between reproduction and growth in Australian beef cattle. Journal of Animal Science, v.69, p.3533-3543, 1991.

MEYER, K.; HAMMOND, K.; PARNELL, P.F.; MACKINNON, M.J.; SIVARAJASINGAM, S. Estimates of heritability and repeatability for reproductive trait in Australian Beef Cattle. Livestock Production Science, v.25, p.15-30, 1990.

MORRIS, C.A.; CULLEN, N.G. A note on genetic correlations between pubertal traits of males or females and lifetime pregnancy rate in beef cattle. Livestock Production Science, v.39, p.291-291, 1994.

MORRIS, C.A.; BAKER, R.L.; HUNTER, J.C. Correlated responses to selection for yearling or 18-month weight in Angus and Hereford cattle. Livestock Production Science, v.30, p.33-52, 1992.

MORRIS, C.A.; WILSON, J.A.; BENNET, G.L.; CULLEN, N.G.; HICKEY, S.M.; HUNTER, J.C. Genetic parameters for growth, puberty, and beef cow reproductive traits in a puberty selection experiment. New Zealand Journal of Agricultural Research, v.43, p.83-91, 2000.

MRODE, R.A. Selection experiments in beef cattle. Part 1. A review of design and analysis. Animal Breeding Abstracts, v.56, p.67-73, 1988a.

MRODE, R.A. Selection experiments in beef cattle. Part 2. A review of responses and correlated responses. Animal Breeding Abstracts, v.56, p.155-167, 1988b.

MRODE, R.A.; SMITH, C.; THOMPSON, R. Selection for rate and efficiency of lean gain in Hereford cattle. 1. Selection pressure applied and direct responses. Animal Production, v.51, p.23-34, 1990a. 
MRODE, R.A.; SMITH, C.; THOMPSON, R. Selection for rate and efficiency of lean gain in Hereford cattle. 2. Evaluation of correlated responses. Animal Production, v.51, p.35-46, $1990 \mathrm{~b}$.

MWANSA, P.B.; KEMP, R.A.; CREWS, D.H.; KASTELIC, J.P.; BAILEY, D.R.C.; COULTER, G.H. Selection for cow lifetime pregnancy rate using bull and heifer growth and reproductive traits in composite cattle. Canadian Journal of Animal Science, v.80, p.507-510, 2000.

NEWMAN, J.A.; RAHNEFELD, G.H.; FREDEEN, H.T. Selection intensity and response to selection for yearling weight in beef cattle. Canadian Journal of Animal Science, v.53, p.1-12, 1973.

NORTHCUTT, S.L.; WILSON, D.E.; WILLHAM, R.L. Adjusting weight for body condition in Angus cows. Journal of Animal Science, v.70, p.1342-1345, 1992.

NOTTER, D.R. Evaluating and reporting reproductive traits. In: BEEF IMPROVEMENT FEDERATION, 20., Albuquerque, 1988. Proceedings. Albuquerque, 1988. p.21-42.

OLORI, V.; HILL, W.; BROTHERSTONE, S. Estimating variance components for test day milk records by restricted maximum likelihood with a random regression animal model. Livestock Production Science, v.61, p.53-63, 1999.

PACKER, I.U.; RAZOOK, A.G.; TROVO, J.B.F.; BONILHA-NETO; L.M.; FIGUEIREDO, L.A.; NASCIMENTO, J.; PACOLA， L.J.; CANDIDO, J.G.; CAMPOS, B.E.S.; MACHADO, W.B. Selection for yearly weight in Nelore and Guzera breeds. Selection applied and response. In: WORLD CONGRESS ON GENETICS APPLIED TO LIVESTOCK PRODUCTION, 3., Lincoln, 1986. Proceedings. Lincoln, 1986. p.419-423.

PARNELL, P.F. The consequences of selection for growth rate in beef cattle. Proceedings of Australia Society of Animal Production, v.20, p.17-26, 1994.

PARNELL, P.F.; ARTHUR, P.F.; BARLOW, R. Direct response to divergent selection for yearling growth rate in Angus cattle. Livestock Production Science, v.49, p.297-304, 1997. 
PEREIRA, E.; ELER, J.P.; FERRAZ, J.B.S. Correlação genética entre perímetro escrotal e algumas características reprodutivas na raça Nelore. Revista Brasileira de Zootecnia, v.29, p.1676-1683, 2000.

POLASTRE, R.; TAMBURO, F.J.Z.; LAPERUTA FILHO, J. Manual para utilização do Sistema para Relacionamento Genético Animal (SIREGE). Botucatu: UNESP, Faculdade de Medicina Veterinária e Zootecnia, 1992. 8p.

PONZONI, R.W. Which trait for genetic improvement of beef cattle reproduction: calving rate or calving day? Journal of Animal Breeding and Genetic, v.109, p.119-128, 1992.

PONZONI, R.W.; GIFFORD, D.R. Reproductive and some peri-natal variables in a mixed breed beef cattle herd. Journal of Animal Breeding and Genetic, v.111, p.52-64, 1994.

RAUW, W.M.; KANIS, E.; NOORDHUIZEN-STASSEN, E.N.; GROMMERS, F.J. Insiderable side effects of selection for high production efficiency in farm animals: a review. Livestock Production Science, v.56, p.15-33, 1998.

RAZOOK, A.G. Seleção em bovinos de corte: II. Resultados experimentais. Zootecnia, v.26, p.27-50, 1988.

RAZOOK, A.G.; FIGUEIREDO, L.A.; BONILHA NETO, L.M.; TROVO, J.B.F.; PACKER, I.U.; PACOLA, L.J.; CÂNDIDO, J.G. Intensidades de seleção e respostas direta e correlacionadas em 10 anos de progênies de bovinos das raças Nelore e Guzerá selecionadas para peso pós-desmame. Boletim de Indústria Animal, v.50, p.147-163, 1993.

RAZOOK, A.G.; FIGUEIREDO, L.A.; BONILHA NETO, L.M.; TROVO, J.B.F.; PACKER, I.U.; PACOLA, L.J.; CYRILLO, J.N.S.G.; RUGGIERI, A.C.; MERCADANTE, M.E.Z. Selection for yearling weight in Nelore and Guzera zebu breeds: selection applied and response in 15 years of progeny. (compact disc). In: WORLD CONGRESS ON GENETICS APPLIED TO LIVESTOCK PRODUCTION, 6., Armindale, 1998. Proceedings. Armindale, 1998. 
RAZOOK, A.G.; FIGUEIREDO, L.A.; CYRILLO, J.N.S.G.; PACOLA, L.J.; BONILHA-NETO, L.M.; TROVO, J.B.; RUGGIERI, A.C.; MERCADANTE, M.E.Z. Prova de ganho de peso. Normas adotadas pela Estação Experimental de Zootecnia de Sertãozinho. Nova Odessa: Instituto de Zootecnia. 1997. 33p. (IZ. Boletim Técnico, 40).

REGE, J.E.O.; FAMULA, T.R. Factors affecting calving date and its relationship with production traits of Hereford dams. Animal Production, v.57, p.385-395, 1993.

REKAYA, R.; CARABAÑO, M.; TORO, M. Use of test-day yields for the genetic evaluation of production traits in Holstein-Friesian cattle. Livestock Production Science, v.34, p.23-34, 1999.

ROSA, A.N.; LÔBO, R.B.; OLIVEIRA, H.N.; BEZERRA, L.A.F.; REYES, A. Variabilidade genética do peso adulto de matrizes em um rebanho Nelore do Estado de São Paulo. Revista Brasileira de Zootecnia, v.29, p.1706-1711, 2000.

ROSA, A.N.; LÔBO, R.B.; OLIVEIRA, H.N.; BEZERRA, L.A.F.; REYES, A. Peso adulto de matrizes em rebanhos de seleção da raça Nelore no Brasil. Revista Brasileira de Zootecnia, v.30, p.1027-1036. 2001.

ROSO, V.M.; SCHENKEL, F.S. Tendência genética da idade ao primeiro parto de vacas Nelore. (compact disc). In: REUNIÃO ANUAL DA SOCIEDADE BRASILEIRA DE ZOOTECNIA, 36., Porto Alegre, 1999. Anais. Porto Alegre: SBZ, 1999.

SAS INSTITUTE. SAS/STAT 2000: version 8. Cary, 2000.

SCHOLTZ, M.M.; ROUX, C.Z.; DAY, M.L.; KOCH, R.M.; KINDER, J.E. Correlated responses to selection for growth, size and efficiency. In: WORLD CONGRESS ON SHEEP AND BEEF CATTLE BREEDING, 2., Pretoria, 1984. Proceedings. Pretoria, 1984. p.433-443.

SILVA, A.M.; ALENCAR, M.M.; FREITAS, A.R.; BARBOSA, R.T.; BARBOSA, P.F.; OLIVEIRA, M.C.S.; CORRÊA, L.A.C.; NOVAES, A.P.; TULLIO, R.R. Herdabilidades e correlações genéticas para peso e perímetro escrotal de machos e características reprodutivas e de crescimento de fêmeas, na raça Canchim. Revista Brasileira de Zootecnia, v.29, p.2223-2230, 2000. 
SMITH, G.M.; FITZHUGH, H.A.; CUNDIFF, T.C.; CARTWRIGHT, T.C.; GREGORY, K.E. Genetic analysis of maturing patterns in straightbred and crossbred Hereford, Angus and Shorthorn cattle. Journal of Animal Science, v.43, p.389-395, 1976.

SORENSEN, D.A.; KENNEDY, B.W. The use of the relationship matrix to account for genetic drift variance in the analysis of genetic experiments. Theoretical and Applied Genetic, v.66, p.217-220, 1983.

SORENSEN, D.A.; KENNEDY, B.W. Estimation of response to selection using leastsquares and mixed model methodology. Journal of Animal Science, v, 58, p.10971106, 1984.

SORENSEN, D.A.; KENNEDY, B.W. Analysis of selection experiments using mixed model methodology. Journal of Animal Science, v.63, p.245-258, 1986.

SORENSEN, D.A.; WANG, C.S.; JENSEN, J.; GIANOLA, D. Bayesian analysis of genetic change due to selection using Gibbs sampling. Genetic, Selection, Evolution, v.26, p.333-360, 1994.

VARGAS, C.A.; OLSON, T.A.; CHASE-Jr., C.C.; HAMMOND, A.C.; ELZO, M.A. Influence of frame size and body condition score on performance of Brahman cattle. Journal of Animal Science, v.77, p.3140-3149, 1999.

VARONA, L.; MIZTAL, I.; BERTRAND, J.K. Threshold-linear versus linear-linear analysis of birth weight and calving ease using an animal model: I. Variance component estimation. Journal of Animal Science, v.77, p.1994-2002, 1999.

VERBEKE, G.; MOLENBERGHS, G. Linear mixed models for longitudinal data. New York: Springer Verlag, 2000. 568p.

WALSH, J.B. Predicting short-term changes in the mean of a selected character. http://biosci.arizona.edu/zbook/volume 2/chapters/vl2 05.html. 1998.

WALSH, J.B. Least-squares analysis of short-term selection experiments. http://biosci.arizona.edu/zbook/volume 2/chapters/vol2 06.html. 1999a.

WALSH, J.B. Mixed-model and bayesian analysis of short-term selection experiments. http://biosci.arizona.edu/zbook/volume 2/chapters/vol2 07.html. 1999b. 
WEI, M.; CABALlERO, A.; HILL, W.G. Selection response in finite populations. Gene tics, v.144, p.1961-1974, 1996.

WOLFE, M.W.; STUMPF, T.T.; WOLFE, P.L.; DAY, M.L.; KOCH, R.M.; KINDER, J.E. Effect of selection for growth traits on age and weight at puberty in bovine females. Journal of Animal Science, v.68, p.1595-1602, 1990. 